4-28-2021

\title{
More Than Brides Alliance: Endline evaluation report
}

\author{
Andrea J. Melnikas \\ Population Council \\ Grace Saul \\ Population Council \\ Michelle Chau \\ Neelanjana Pandey \\ Population Council \\ James Mkandawire
}

See next page for additional authors

Follow this and additional works at: https://knowledgecommons.popcouncil.org/departments_sbsr-pgy How does access to this work benefit you? Let us know!

\section{Recommended Citation}

Melnikas, Andrea J., Grace Saul, Michelle Chau, Neelanjana Pandey, James Mkandawire, Mouhamadou Gueye, Aissa Diarra, and Sajeda Amin. 2021. "More Than Brides Alliance: Endline evaluation report." New York: Population Council. 


\section{Authors}

Andrea J. Melnikas, Grace Saul, Michelle Chau, Neelanjana Pandey, James Mkandawire, Mouhamadou Gueye, Aissa Diarra, and Sajeda Amin 


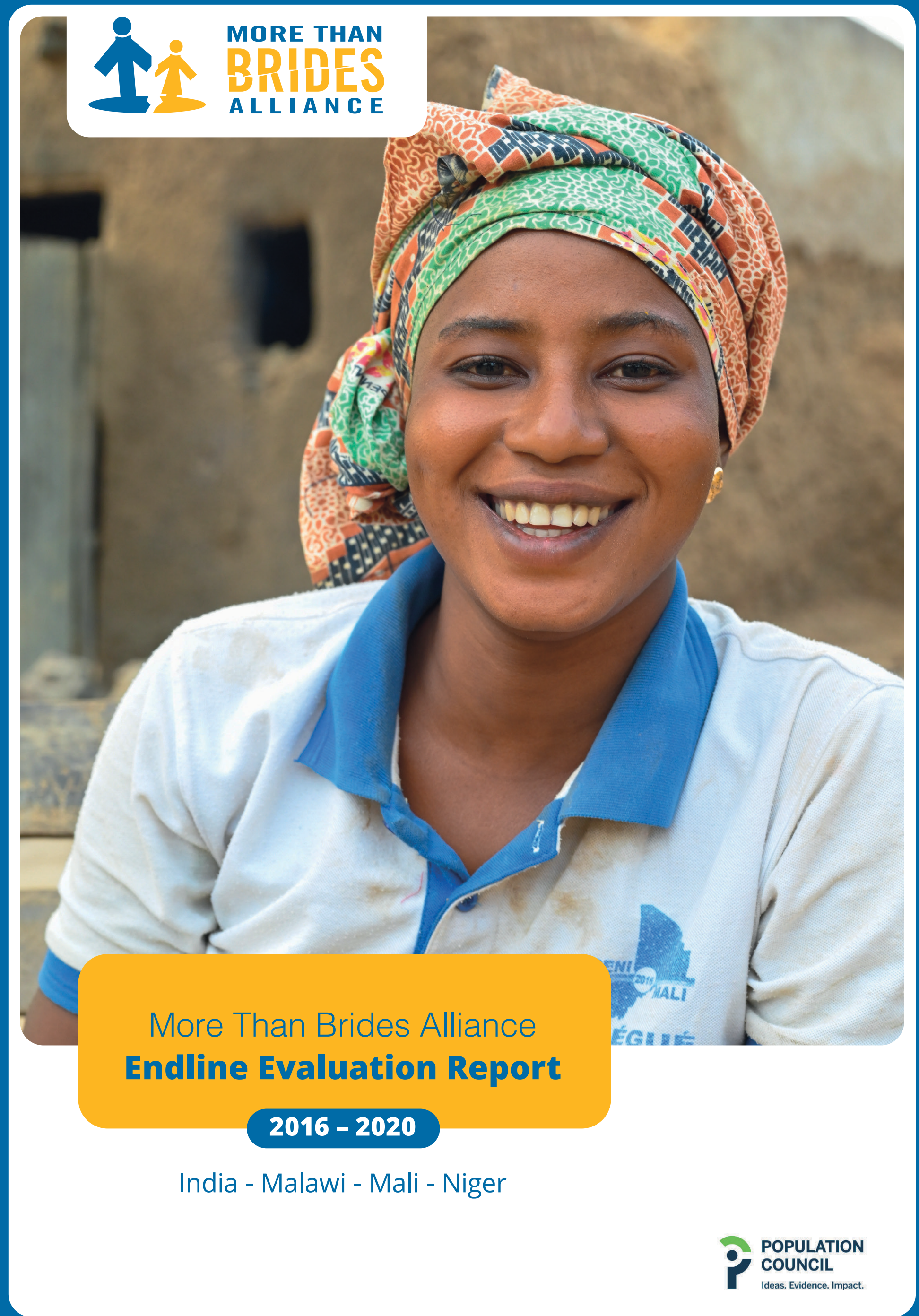


The Population Council confronts critical health and development issues-from stopping the spread of HIV to improving reproductive health and ensuring that young people lead full and productive lives. Through biomedical, social science, and public health research in 50 countries, we work with our partners to deliver solutions that lead to more effective policies, programs, and technologies that improve lives around the world. Established in 1952 and headquartered in New York, the Council is a nongovernmental, nonprofit organization governed by an international board of trustees.

\section{Population Council}

One Dag Hammarskjold Plaza

New York, NY 10017

United States

popcouncil.org

Suggested citation: Melnikas, A.J., G. Saul, M. Chau, N. Pandey, J. Mkandawire, M. Gueye, A. Diarra, and S. Amin. 2021. "More Than Brides Alliance: Endline Evaluation Report." New York: Population Council.

Photo credit: Ousmane Samassekou/Oxfam Novib

Graphics credit: Mike Vosika

(C) 2021 The Population Council, Inc. 


\section{Contents}

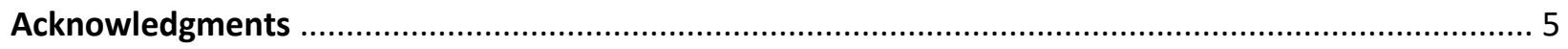

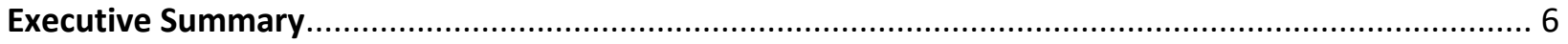

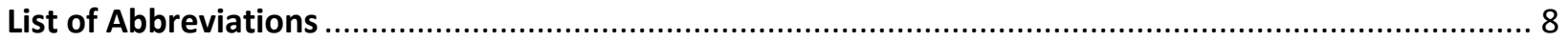

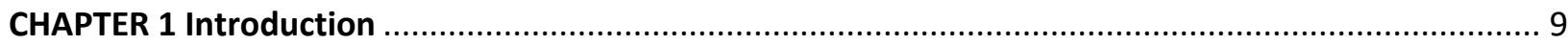

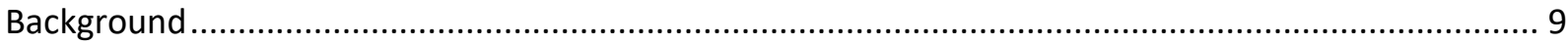

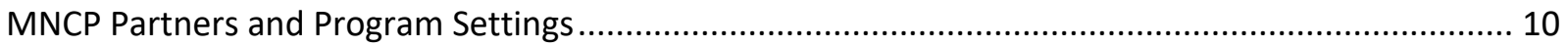

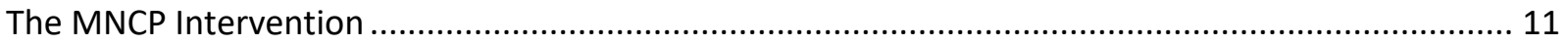

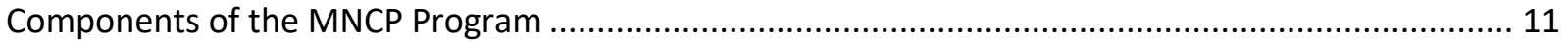

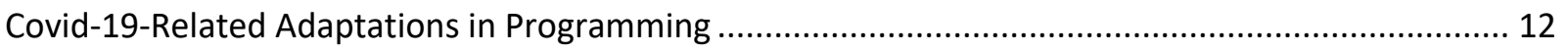

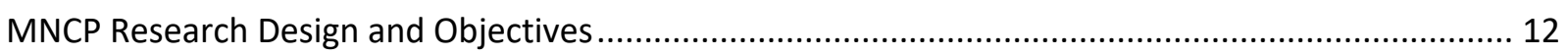

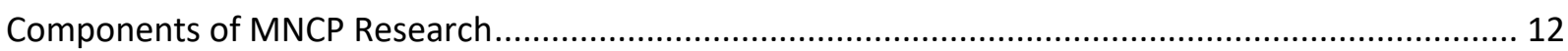

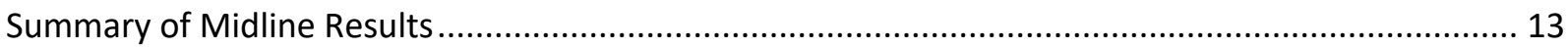

Objectives of the Endline Evaluation and Covid-19-Related Adaptations ......................................... 13

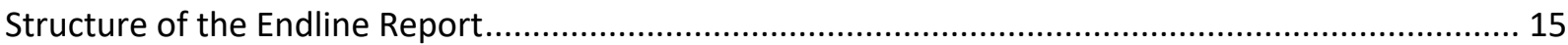

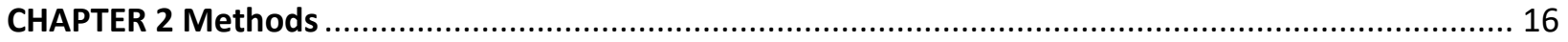

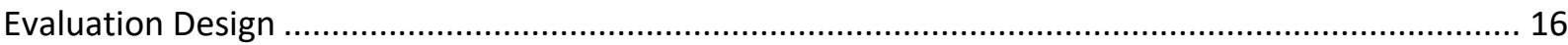

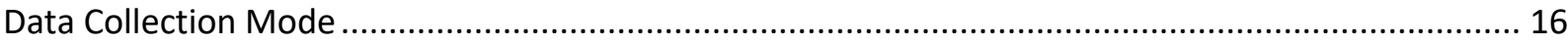

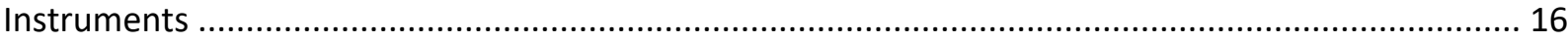

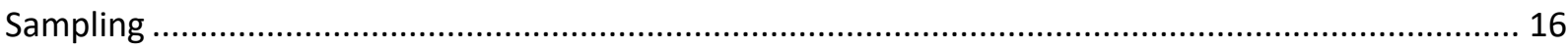

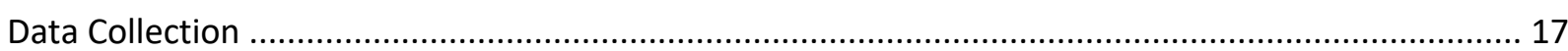

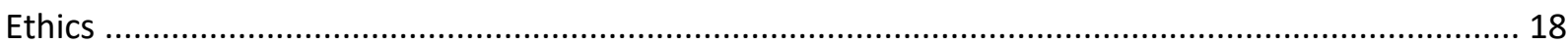

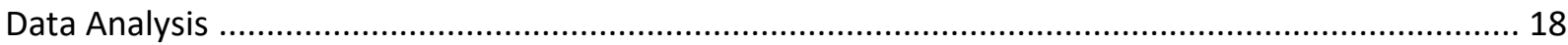

CHAPTER 3 Impact of the Covid-19 Pandemic on Adolescent Girls................................................. 19

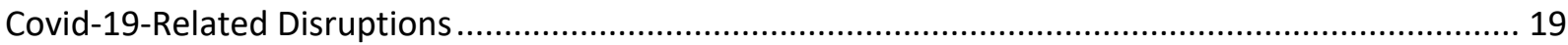

Impact of Covid-19 on Child Marriage ............................................................................................ 19

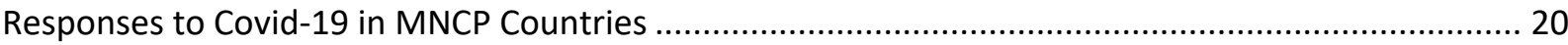

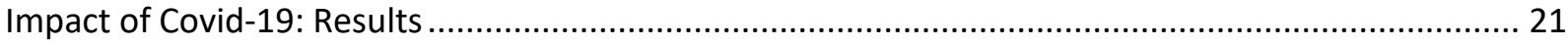

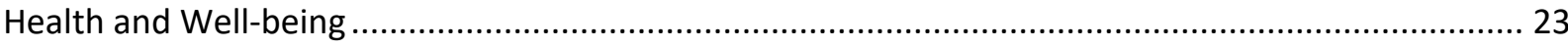

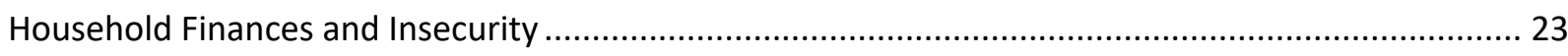

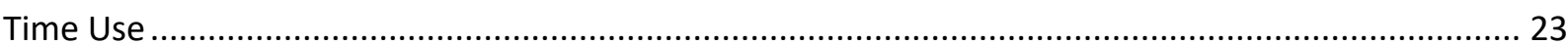

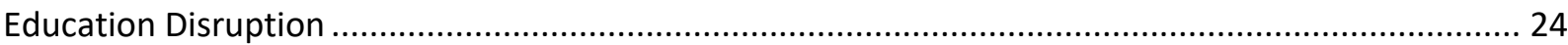

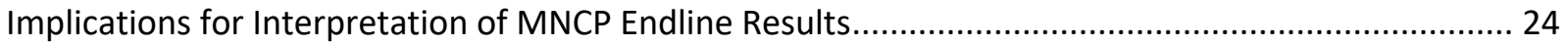




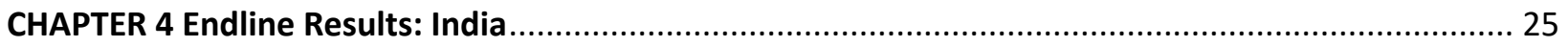

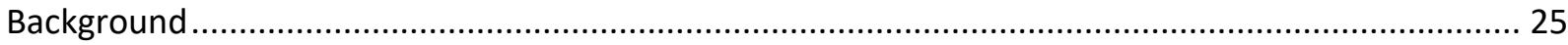

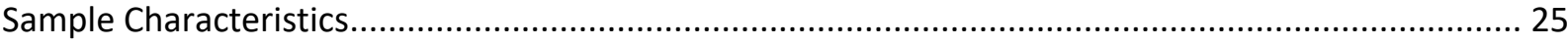

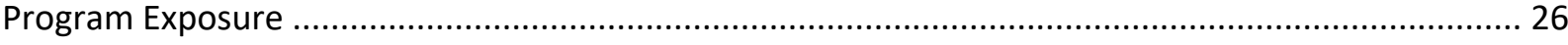

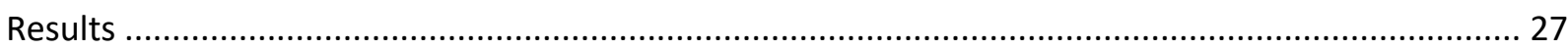

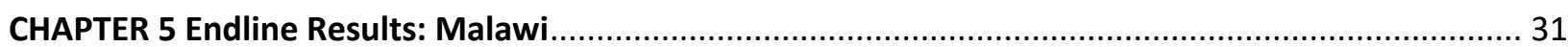

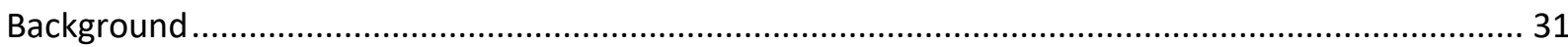

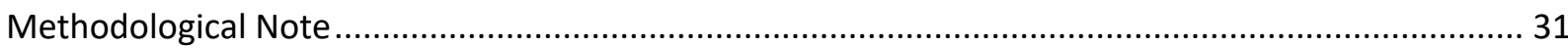

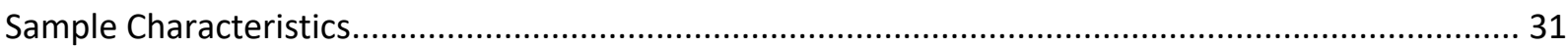

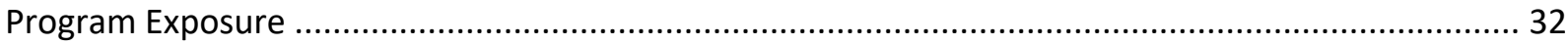

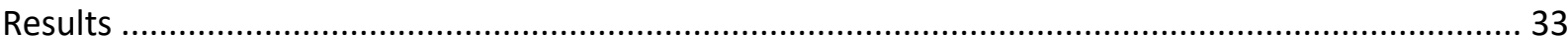

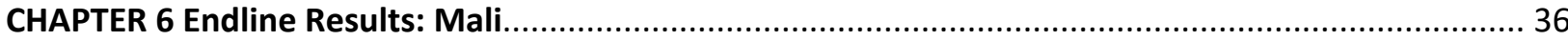

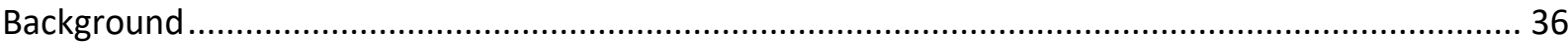

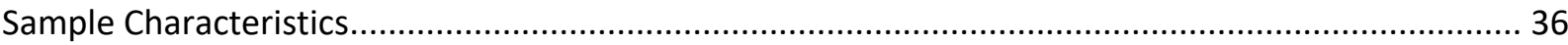

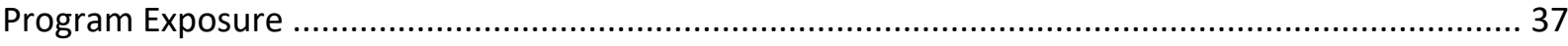

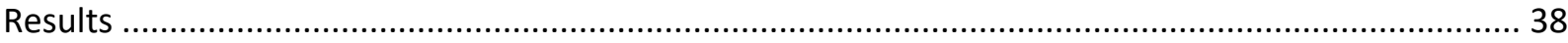

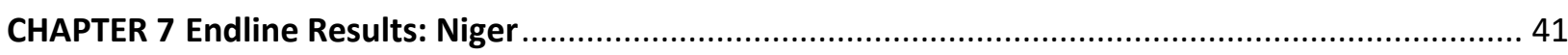

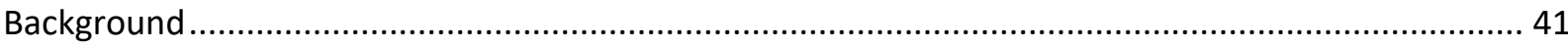

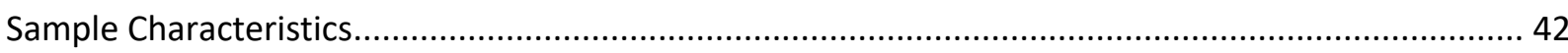

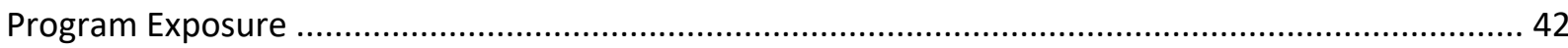

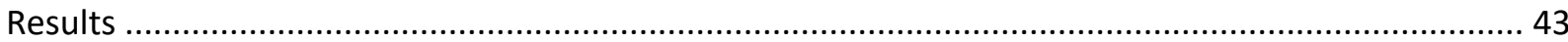

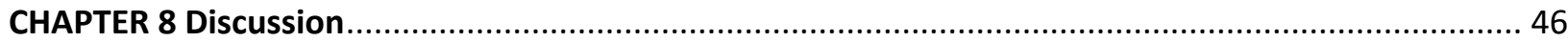

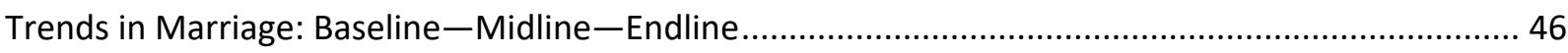

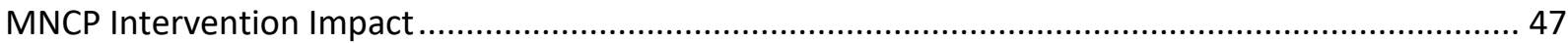

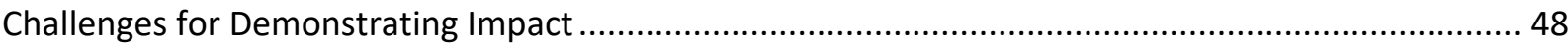

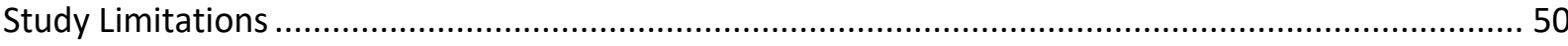

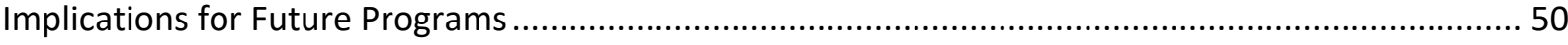

Annex 1: Implementing Partners by Country and State/Region............................................................ 52

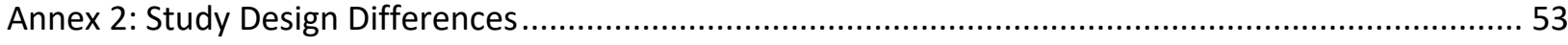

Annex 3: Trends in Key Indicators: Baseline-Midline-Endline ........................................................ 55

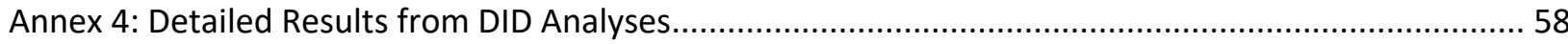

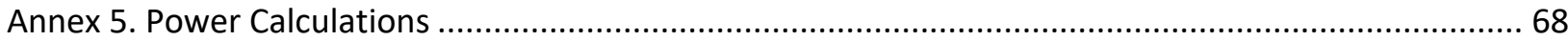

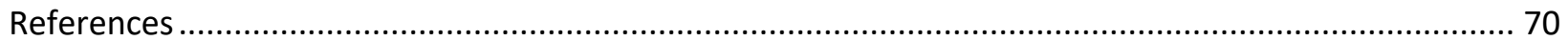




\section{Acknowledgments}

A number of individuals have contributed to the endline evaluation and report for the More Than Brides Alliance and we appreciate their efforts.

We thank the members of the More Than Brides Alliance, including Save the Children Netherlands, Oxfam Novib, and Simavi for their input and their collaboration on this project.

We also thank the Ministry of Foreign Affairs of The Netherlands for their support of the More Than Brides Alliance and, specifically, of the research and evaluation component.

We thank Mike Vosika for his graphics and formatting support for the endline report. We thank Joyce Altman for her editorial support.

We have been fortunate to work with talented research teams who were instrumental in conducting household listings and surveys with adolescent girls and young women, and endline household surveys with parents. At the Invest in Knowledge Initiative (IKI) in Malawi, we would like to thank our colleagues, including Hamza Daud, Sydney Rodney Lungu, and Nancy Mulauzi, who oversaw data collection in the field. At CERIPS in Mali, we thank Sékou Omar Fofana, Timbaleck Traoré, and Ismalia Konaté, and at LASDEL in Niger, we thank Chaibou Saadou, Ali Bako, and Siddou Moumouni.

Finally, we are grateful for the research participants, in particular the adolescent girls and young women who shared their experiences with the research team during a trying time in 2020 . We thank them for their participation, without which this study would not be possible. 


\section{Executive Summary}

This endline report covers the More Than Brides Alliance's (MTBA) project "Marriage: No Child's Play" (MNCP) in four countries: India, Malawi, Mali, and Niger. The MNCP project sought to empower girls, to raise awareness about the risks of child marriage, to improve girls' access to sexual and reproductive health (SRH) services, and to support social norms favorable to girls' education, economic engagement, and agency in marital decision-making. The MTBA consists of partners Save the Children Netherlands, Simavi, Oxfam-Novib, and the Population Council, along with 25 local implementing partners.

In this report, we present results from the MNCP evaluation, including over the final year, which was characterized by significant adaptations in both programming and research due to Covid-19. The overall MNCP evaluation was designed to provide estimates of program impact and trends in a comparable manner across settings that differ with respect to child marriage prevalence and drivers. This report explores behavioral outcomes related to child marriage, schooling, work, and pregnancy, as well as indicators related to knowledge and attitudes, based on cross-sectional surveys in intervention and comparison villages conducted with adolescent girls ages 12-19 at three time points $(2016 / 7,2018,2020)$ and with parents of adolescent girls or other adults living in households with adolescent girls at endline (2020).

In this report, we present impact-as measured by results from difference-in-differences analysis (DID)_- using baseline and endline surveys, comparing change in intervention areas to change in comparison areas. Analyses were conducted in Stata SE 14.2 and included adjustments based on evaluation design and fidelity to randomization.

We find that in India, the MNCP program demonstrated significant impact across several key indicators. The proportion of girls married declined more in intervention areas than in comparison areas in the combined sample of all four states in India, as well as in three of four states individually. Although child marriage also declined in comparison areas over the same time period, declines in intervention areas were larger and statistically significant $(p<.01)$. Child marriage prevalence in intervention areas declined from $14.5 \%$ to $4.5 \%$-a $69 \%$ decline overallwhile in comparison areas, child marriage prevalence declined $22 \%(p<.05)$. In Malawi, Mali, and Niger, we did not find program impact on the proportion of girls currently married; in each of these countries, child marriage declined, but it declined similarly in both intervention and comparison areas and thus impact cannot be attributed to the MNCP program.

Knowledge of child marriage, including knowledge of legal age at marriage and ability to name the negative effects of child marriage improved among adolescent girls in most MNCP countries. Significant impact was found in India, Malawi, and Niger on knowledge of legal age at marriage. In India and Niger, significant impact was found on knowledge of negative effects of child marriage.

The MNCP intervention showed some success in influencing indicators related to alternate pathways to child marriage, such as in increasing education and livelihood opportunities for girls. We see some significant effects on school enrollment, grade attainment, and whether girls had ever worked, but no clear pattern emerged across countries. The MNCP program demonstrated impact in increasing the proportion of girls currently working for income from baseline to endline in Niger. In Malawi, the 
program was able to achieve demonstrable impact on several indicators related to education, namely increasing the proportion of girls who had ever attended school, increasing the mean number of years of education completed, and decreasing illiteracy rates among 12-19-year-old girls.

We also examined how Covid-19 and associated infection-control restrictions have influenced girls' lives since the beginning of the pandemic. We found that a significant proportion of respondents reported that their households had experienced food shortages since March 2020: (62.7 to 81.0\% of household respondents reported food shortages across the four countries). Additionally, 78.0 to $85.5 \%$ of adult respondents across the four countries reported that Covid-19 had negatively affected their households' finances. Girls also reported feeling more depressed since the pandemic began (47.2 to $86.4 \%$ ) and having more caretaking duties at home (37.5 to $58.6 \%$ ).

There are a number of limitations to consider with regard to the MNCP impact evaluation. Due to Covid-19-related restrictions on movement and face-to-face activities, we switched from in-person interviews to phone surveys for the endline data collection. This required shorter surveys with girls ages 12-19 split over two separate phone calls. Using phone surveys likely introduced bias toward inclusion of more privileged girls and families with greater access to a phone. There were also methodological challenges related to randomization and program implementation, as noted in the midline evaluation report (Melnikas et al. 2019). As a result of this, we present adjusted results in Malawi, Mali, and Niger. In India, the sample was balanced at baseline and thus we present unadjusted results at endline.

The implementation of multisectoral programs in widely varied settings where child marriage is either highly prevalent or presents a large burden for girls and their families, allows the MNCP program to make an important contribution by capturing results of a similar program model implemented across diverse contexts. The four countries included in the MNCP evaluation varied widely in terms of past investments and achievements in child marriage prevention. The evaluation includes India, where child marriage prevalence has been declining over the last decade, and Niger where it remains stubbornly high. These contexts also differ by specific drivers of child marriage that may not be drivers in other contexts: e.g., premarital sex and pregnancy in Malawi and Mali. The results of this evaluation also challenge the assumption that it is easier for programs to demonstrate effectiveness on reducing child marriage in areas where child marriage is highest: even in lower prevalence areas in India MNCP still showed impact. Overall, our data suggest that programs such as MNCP can make an important contribution to ending the practice of child marriage even in areas where child marriage already appears to be declining. These results are promising and should encourage continued investments to bring about positive change in the lives of adolescent girls living in these challenging environments. 


\section{List of Abbreviations}

$\begin{array}{ll}\text { DHS } & \text { Demographic and Health Survey } \\ \text { DID } & \text { Difference-in-Differences } \\ \text { EA } & \text { Enumeration Area } \\ \text { GHV } & \text { Group Head Village } \\ \text { GNB } & \text { Girls Not Brides } \\ \text { GP } & \text { Gram Panchayats } \\ \text { MNCP } & \text { Marriage: No Child's Play } \\ \text { MTBA } & \text { More Than Brides Alliance } \\ \text { NFHS } & \text { National Family Health Survey } \\ \text { PSU } & \text { Primary Sampling Unit } \\ \text { SRHR } & \text { Sexual and Reproductive Health and Rights } \\ \text { UNFPA } & \text { United Nations Population Fund } \\ \text { UNICEF } & \text { United Nations International Children's Emergency Fund }\end{array}$




\section{CHAPTER 1 \\ Introduction}

\section{Background}

Globally, child marriage remains a significant health and human rights issue. Despite recent declines in child marriage worldwide-from $25 \%$ of girls married by age 18 to $21 \%$ from 2008 to 2018 (UNICEF 2018)—an estimated 12 million girls are still married each year (GNB 2021). The consequences of child marriage for girls include curtailed education, health risks associated with early childbirth, higher incidence of intimate partner violence, and mental health issues (Mensch et al. 1998; Hindin et al. 2008; Gage 2013). At the societal level, addressing child marriage is both a social good-child marriage is a human rights issue (Nour 2009)—but also an economic imperative: estimates suggest that in Niger alone, by eradicating child marriage, annual welfare gains could approach $\$ 1.7$ billion by 2030 (Wodon et al. 2017).

While the causes of child marriage are context-specific, we know that poverty and gender inequality are drivers across contexts (GNB 2021). Poverty and economic uncertainty are frequently cited as reasons for early marriage through pathways involving food insecurity, education costs, or dowry costs associated with later age at marriage (Hoogeveen et al. 2011; Alston et al. 2014; Amin et al. 2018). Evidence also suggests that premarital pregnancy and concerns about sexual security (Greene et al. 2018), economic and social shocks like climate change and displacement (Hoogeveen et al 2011; Alston et al. 2014; Andriano and Behrman 2020), natural disasters (Felton-Biermann 2006), and pandemics (Bandiera et al. 2018) including the Covid-19 pandemic (UNFPA 2020) also threaten to exacerbate child marriage and to stall progress made in recent years.

Poverty and economic uncertainty are

frequently cited as reasons for early marriage through pathways involving food insecurity, education costs, or dowry costs associated with later age at marriage.
Within the past 20 years, interventions aimed at delaying marriage for girls have attracted increased attention. A series of systematic reviews (Lee-Rife et al. 2012; Kalamar et al. 2016; Chae and Ngo 2017; Malhotra and Elnakib 2021) have examined what programmatic approaches work to reduce child marriage. These reviews have demonstrated that few programs have been rigorously evaluated-often fewer than 20 . Among those programs that do meet the criteria to be included in these reviews, empowerment programs and livelihoods approaches appear to be most promising.

The most recent systematic review of child marriage interventions (Malhotra and Elnakib 2021) incorporated 13 additional studies published since the previous reviews described above and examined sustainability in addition to program impact on child marriage. The authors conclude that cash transfers to support girls' education are the most 
successful intervention to reduce child marriage to date. They posit that this is due to the pathway of "enhancement of girls' own human capital." The success of programs that increase visible economic opportunities for girls and women is also noted.

There are some limitations of the available evidence that still leave important questions for those designing programs seeking to reduce child marriage. Many of the successful interventions to date have tested specific interventions in one country and sometimes in one sector (e.g., education, health, livelihoods) to understand the effect of that component. Multicomponent programs have not generally been as effective as single-component programs, as demonstrated in the body of evidence on child marriage programs (Malhotra and Elnakib 2021), yet the drivers of child marriage are multisectoral. Additionally, some countries (e.g., India, Bangladesh) are heavily represented in systematic reviews while other settings (e.g., West Africa) have few rigorous evaluations meeting inclusion criteria. The extent to which findings may be translated from one context to another remains unclear.

\section{MNCP Partners and Program Settings}

From 2016 to 2020, the More Than Brides Alliance (MTBA) - a consortium composed of Save the Children Netherlands, Simavi, and Oxfam Novib as international implementing partners, 25 different local implementing partners, and the Population Council as research partner-implemented and evaluated the Marriage: No Child's Play (MNCP) program in select regions of India, Malawi, Mali, Niger, and Pakistan. The Population Council led the impact evaluation in India, Malawi, Mali, and Niger, with Oxfam Novib conducting a separate evaluation in Pakistan. Across countries, the MNCP program varied widely in number of local implementing partner organizations (ranging from 2 in Malawi to 12 in India) and in number of intervention villages (ranging from 42 in Mali and Niger to 609 in India). Table 1 provides details about the localities where the intervention took place in each country included in this impact evaluation. See Annex 1 for a complete list of MTBA partner organizations involved in implementation of the MNCP program in each locality.

The MNCP project and evaluation contribute to the body of literature on what works to delay marriage by implementing and evaluating this intervention across diverse settings, from the country with the highest child marriage prevalence globally (Niger) to the country with the highest absolute number of child marriages (India), as well as in settings where premarital sex is common and often a driver of child marriage (Malawi) and in settings where sexual initiation occurs almost exclusively within marriage (India and Niger). The countries included in this evaluation have different burdens of child marriage (Table 2) and in some cases different child marriage drivers. Although a deep dive into the political economy of each country is beyond the scope of this project, 
we highlight some key indicators that may influence child marriage and programs to address the practice in each setting (Table 3).

Table 2. Key Child Marriage Indicators, MNCP Countries

\begin{tabular}{lrrrr}
\hline Country & $\begin{array}{r}\text { Proportion of women } \\
20-24 \text { married by age 15 }\end{array}$ & $\begin{array}{r}\text { Proportion of women } \\
20-24 \text { married by age 18 }\end{array}$ & $\begin{array}{r}\text { Ranking: Child marriage } \\
\text { prevalence }\end{array}$ & $\begin{array}{r}\text { Legal minimum age of } \\
\text { marriage for girls }\end{array}$ \\
\hline India & $7 \%$ & $27 \%$ & $12 \%$ & 18 \\
\hline Malawi & $9 \%$ & $42 \%$ & 5 & 16 \\
\hline Mali & $16 \%$ & $54 \%$ & 1 & 15 \\
\hline Niger & $28 \%$ & $76 \%$ & 120 top 20] & 12 \\
\hline
\end{tabular}

Marriage statistics from DHS surveys; Ranking, burden, and law information from Girls Not Brides.

Table 3. Other Key Contextual Indicators, MNCP Countries

\begin{tabular}{|c|c|c|c|c|c|c|}
\hline Country & $\begin{array}{r}\% \text { women } \\
20-24 \text { first sex } \\
\text { by age } 18\end{array}$ & $\begin{array}{r}\% \text { households } \\
\text { with a mobile } \\
\text { phone \# }\end{array}$ & $\begin{array}{r}\% \text { women } 15-49 \text { who } \\
\text { did not work for income in } \\
\text { past } 12 \text { months }\end{array}$ & $\begin{array}{r}\% \text { women } \\
15-49 \text { with no } \\
\text { education }\end{array}$ & $\begin{array}{r}2019 \text { GNI } \\
\text { per capita, } \\
\text { USD }\end{array}$ & $\begin{array}{r}2020 \mathrm{HDI} \\
\text { ranking } \\
\text { (of 189) }\end{array}$ \\
\hline India & $22 \%$ & $90 \%$ & $70 \%$ & $27 \%$ & 2,120 & 131 \\
\hline Malawi & $57 \%$ & $50 \%$ & $33 \%$ & $12 \%$ & 380 & 174 \\
\hline Mali & $67 \%$ & $89 \%$ & $42 \%$ & $65 \%$ & 870 & 184 \\
\hline Niger & $73 \%$ & $50 \% *$ & $71 \%$ & $80 \%$ & 600 & 189 \\
\hline
\end{tabular}

\section{The MNCP Intervention}

\section{Components of the MNCP Program}

The MNCP program approach includes a community package of interventions implemented at multiple levels and across sectors. Across contexts, the program sought to empower girls, to raise awareness about the risks of child marriage, to improve girls' access to SRH services, and to support social norms favorable to girls' education, economic engagement, and agency in marital decision-making. The MNCP program focused on treating the community and included activities related to seven key outcome areas, namely:

- Empowering at-risk and already married adolescent girls with life-skills education, sexual and reproductive health and rights (SRHR) information, and peer support groups,

- Enhancing access to education opportunities and improving retention in school for girls,

- Enhancing access to economic and income-generating opportunities for girls and their families,

- Enhancing access to improved child-protection systems,

- Increasing access to quality, youth-friendly SRHR services, 
- Contributing to changing social norms that perpetuate the practice of child marriage, and

- Influencing legal and policy frameworks.

The MNCP program aims to be holistic and to target pathways to child marriage on multiple levels simultaneously, treating communities as either having the full MNCP package or no intervention. The intervention was tailored to the specific challenges and drivers of child marriage in each implementation context, leading to significant variation in the program across countries and states/regions. Figure 1 illustrates key components of the MNCP intervention across settings.

Figure 1. Program Components at Different Levels

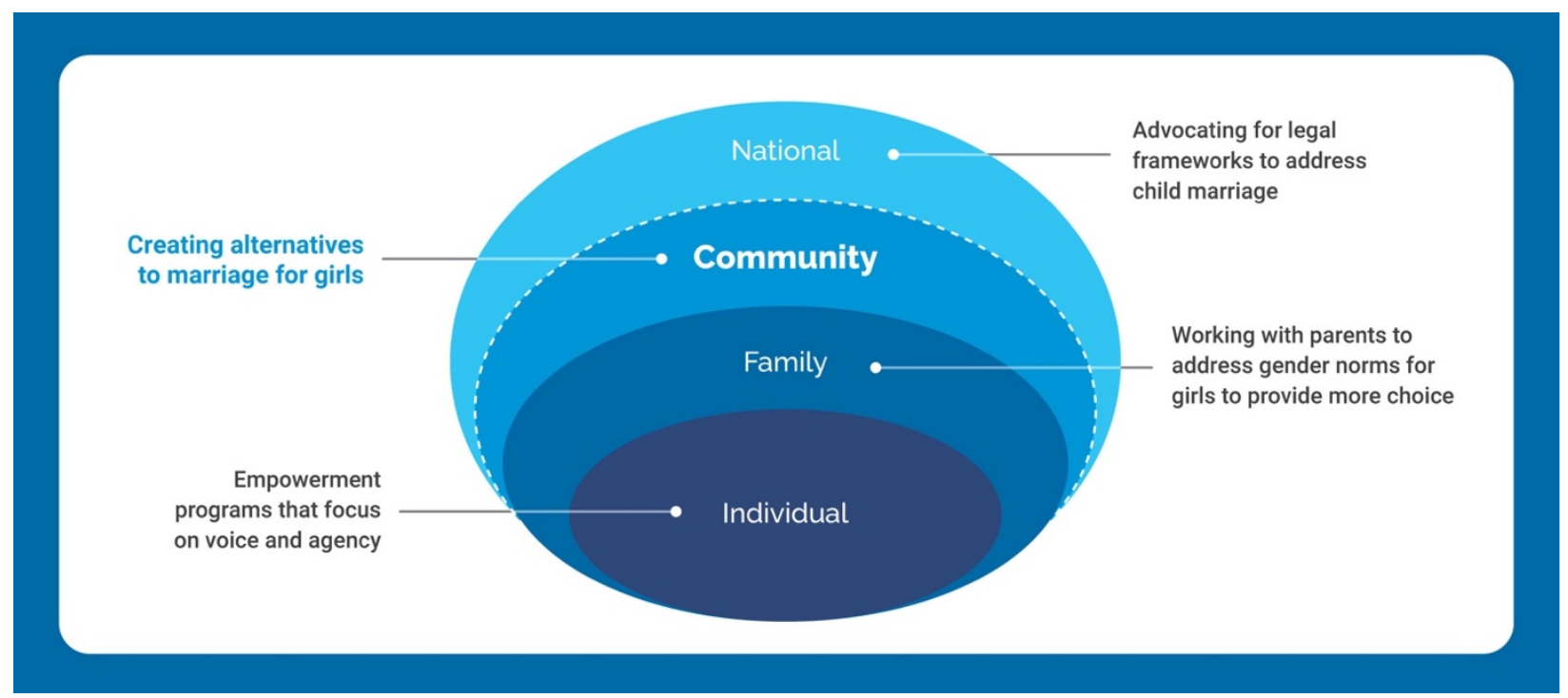

Covid-19-Related Adaptations in Programming

In its final year of programming, MNCP was forced to adapt its strategies due to the Covid-19 pandemic and associated restrictions on movement and in-person gatherings. During this period, certain planned activities-including those involving large groups, in particular-were suspended or were significantly modified to limit the number of participants. In some countries, activities planned with or for government officials were suspended or abridged, due to competing priorities among government personnel during the ongoing crisis. Other MNCP activities were able to adapt, however. For example, implementing partners maintained communication with mentors, youth groups, community child-protection committees, and other program stakeholders via telephone calls, SMS, WhatsApp, Facebook, and/or radio broadcasts in order to keep networks active, to share information on programmatic themes as well as on COVID-19, and to coordinate direct material support efforts in some settings, including the provision of sanitary napkins, hand sanitizer, and masks. While most of these remote communication methods had already been used within the MNCP intervention, the use of and reliance on technology increased substantially during the pandemic.

\section{MNCP Research Design and Objectives}

\section{Components of MNCP Research}

The MNCP research included quantitative and qualitative data collection to inform program implementation and to evaluate program impact. As shown in Figure 2, a baseline survey was conducted in each setting prior to the start of programs, a midline survey was conducted in 2018 
after approximately two years of program implementation, and an endline survey was conducted at the end of the program implementation period. At each round of the study, data were collected via community-level cross-sectional surveys with adolescent girls 12-19 in areas where program activities took place and in matched comparison areas, where there was no direct MNCP engagement. This report presents key results of these surveys. More detailed information on the design of the evaluation is available in the MTBA midline evaluation report (Melnikas et al. 2019). Qualitative research may be found at both the Population Council and More Than Brides project websites (Population Council 2016; More than Brides 2020).

Figure 2: MNCP Research and Evaluation Timeline

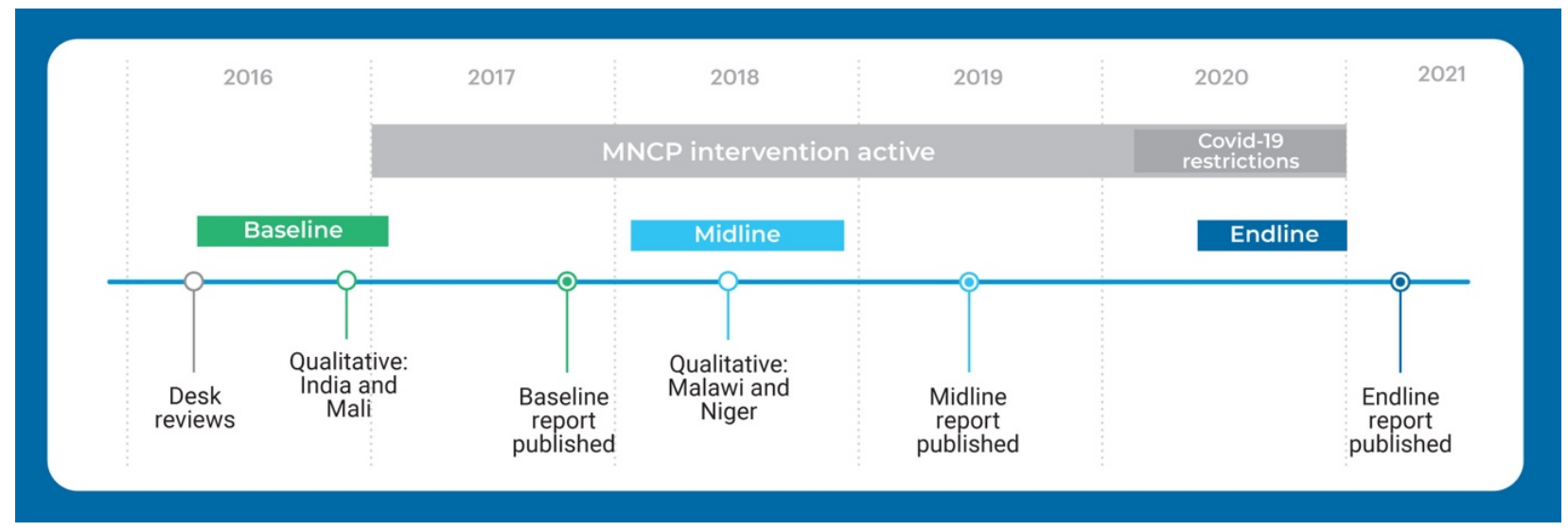

Summary of Midline Results

The MNCP midline evaluation, conducted in 2018, found child marriage to have declined across all samples since baseline. We observed declines ranging from $29 \%$ to $47 \%$ across countries (representing declines of 3-11 percentage points overall); however, we were not able to conclude that declines in child marriage were directly related to the program. Rather, we saw these trends occur across intervention and comparison communities, reflecting larger trends in the decline of child marriage globally (UNICEF 2018). The midline results did detect some program-attributable improvements in knowledge related to child marriage and SRHR in intervention areas between baseline (2016) and midline (2018) (Melnikas et al. 2019). Niger and Malawi saw large increases in modern contraceptive knowledge in intervention areas (by 33\% in Niger and by $29 \%$ in Malawi) while in comparison areas, contraceptive knowledge increased only slightly (by $3 \%$ in Malawi) or even declined (by $3 \%$ in Niger). The midline results also showed that knowledge of legal age at marriage improved in both intervention and comparison areas in Malawi and in three Indian states (Bihar, Jharkhand, and Rajasthan), but was only attributable to the program in one state in India (Odisha). We did not find that the MNCP intervention directly resulted in improved education or livelihood indicators, however those indicators were trending in a positive direction at midline.

\section{Objectives of the Endline Evaluation and Covid-19-Related Adaptations}

In this endline report, we examine results from the MNCP program after more than four years of implementation, including over the final year, which was characterized by significant adaptations due to Covid-19 in both programming and research. In March 2020, we halted endline data collection as Covid-19 spread internationally. To minimize travel and face-to-face contact, endline data were collected using phone surveys (with significantly shorter instruments). Anticipating that Covid-19 restrictions likely disrupted positive trends on SRHR, education, and 
marriage indicators we saw at the midline evaluation in 2018, we added an additional module to the instruments to understand how Covid-19 and the associated lockdowns and school closures influenced household finances, girls' education, plans for marriage, and mental and physical health.

The endline surveys were designed to produce comparable data across contexts. Program impact was assessed relative to comparison groups. Comparisons between baseline, midline, and endline surveys serve to describe trends in intervention and comparison areas. The evaluation is thus able to provide estimates of program impact and trends in a comparable manner in settings that differ considerably in terms of burden and prevalence of child marriage, as well as drivers of child marriage such as premarital sex, marriage arrangements, and poverty. The report explores behavioral outcomes such as child marriage, schooling, work, and pregnancy as well as indicators of knowledge and attitudes. 


\section{Structure of the Endline Report}

Chapter 1 provides a broad overview of the problem of child marriage, evidence to date, and a description of program objectives. In Chapter 2, we provide an overview of the methods, including how the research adapted post-midline due to limits on in-person data collection. In Chapter 3 , we examine findings from the endline survey on the impact of the Covid-19 pandemic and associated lockdowns on the well-being of adolescent girls and their households and propose pathways through which the Covid-19 pandemic and associated lockdowns may influence child marriage. In Chapters 4-7, we examine findings by country with a focus on program impact on key indicators including child marriage, education, SRHR knowledge and access, livelihood activities, and gender-equitable attitudes. Finally, in Chapter 8 we discuss endline findings across all four contexts, acknowledge study limitations and challenges for demonstrating impact, and consider implications for future child marriage programs and research. 


\section{Methods}

\section{Evaluation Design}

The original MTBA design intended to measure change at the community level at three points in time (baseline in 2017; midline in 2018; and endline in 2020) by comparing aggregate levels of marriage, education, livelihood activities, and knowledge and behaviors related to SRHR across intervention and comparison areas. Specific information on baseline methodology, including site selection and cluster randomization is available in a series of baseline reports (Population Council 2016). After collection of the midline data in 2018, we assessed program impact using differencein-differences (DID), comparing changes in the intervention areas from baseline to midline to changes in comparison areas over the same time period. At endline we also use DID, but compare baseline to endline changes in the intervention areas to changes in comparison areas.

\section{Data Collection Mode}

Due to the Covid-19 pandemic and suspension of in-person data-collection activities, planned faceto-face endline interviews with adolescent girls were not feasible in 2020 and we sought an alternative to that approach that would still allow for understanding program impact and evaluating the influence of Covid-19 on key outcome indicators. After starting endline data collection in India and Mali in February 2020, we recalled field teams in early March due to potential health risks related to Covid-19. As the pandemic continued to accelerate globally, in mid-2020 we decided to switch to remote data-collection activities with the aim of still conducting surveys with adolescent girls in sampled communities in order to understand key program outcomes. We added interviews with parents of adolescent girls or other adult members of adolescent girls' households to measure the impact of the Covid-19 pandemic at the household level.

\section{Instruments}

The methodological change in data-collection mode required moving from a longer adolescent survey instrument that collected household-level socioeconomic indicators as well as indicators across multiple domains to a series of shorter instruments due in part to the difficulty of implementing long surveys with adolescent girls in low-resource settings by phone. We split the adolescent girl survey into two instruments and added an adult survey to collect information about the household. In addition, both surveys included Covid-19-specific information to understand how the pandemic and resulting lockdowns and school closures influenced adolescents and their families.

\section{Sampling}

Because at baseline and midline we conducted household listings and resampled girls 12-19 in selected communities in order to assess community-level impact of the intervention (rather than following girls prospectively) we needed to change our sampling methodology at endline as faceto-face listing of thousands of households was deemed unsafe. We first attempted to sample girls by selecting a central point of contact in a community (in this case, a health worker) and asking 
for her assistance locating eligible girls. While this approach worked in some communities in India, we were unable to list a sufficient number of girls in each area and thus sampled from the endline listing from February 2020 (India), and the midline listings from 2018 (Malawi, Mali, and Niger), selecting eligible girls that would be 12-19 at the time of the endline survey. Girls who were projected to be 12-19 at endline were randomly selected from the midline listing data to create original and replacement samples for each area. For each girl sampled, we obtained the contact of her parent or guardian to invite their participation in the adult survey as well. We aimed to interview girls' parents or other adult members of girls' households for at least half of the girls in the sample.

Replacement: Because we sampled girls for participation in the endline survey from a midline household listing from 2018, we also sampled replacements to ensure that enumerators could find an adequate number of girls to participate in the survey. In most settings we sampled a random list of replacements to be used as needed, starting from the top of the list and moving downward. We anticipated in the two years since midline data collection girls may have left the village. In Mali, because of the timing of the survey and significant movement of adolescent girls since midline, we oversampled replacements for each village and in some cases needed to go through the sampled list completely to collect enough responses. In villages where the team was unable to list more than 20 girls (8 villages in Segou, Mali), girls were oversampled in villages matched by intervention/comparison status proximity to the nearest larger town/city.

Sampling Issues: In Niger, security issues resulted in 8 villages being excluded from data collection. To compensate for those areas, areas that were deemed most similar based on intervention assignment and ethnic composition were oversampled. In Malawi, 3 enumeration areas (EAs) were excluded because they did not have enough eligible girls 12-19 based on their midline data. Similar to Niger, we oversampled girls in areas that were the same assignment and ethnic group in other EAs to try to maintain balance between intervention and comparison areas.

\section{Data Collection}

Data were collected by experienced research teams (CERIPS ${ }^{1}$ in Mali, LASDEL ${ }^{2}$ in Niger, IKI ${ }^{3}$ in Malawi, and Population Council India) that had also collected data for the baseline (2016/7) and midline (2018) surveys. Individual eligible respondents were sampled from the listing data and visited by interviewers in person to request contact phone numbers for the adolescent respondent and an associated adult (parent, guardian, or other adult household member). Initial consent and permission were also obtained at that time. In some cases, and depending on local ethics committee guidance, incentives in the form of reusable masks were provided to the household at the time of the listing. Once the phone listing exercise was complete, interviewers conducted surveys with adolescent girls (part 1 and part 2 surveys) and with adults remotely from private locations. Incentives in the form of airtime were provided to participants or households (depending on local ethics committee guidance) after completion of surveys. Data were collected using tablets or phone and the mobile data-collection tool on a SurveyCTO-aided, cloud-based platform.

\footnotetext{
${ }^{1}$ Centre d'Etudes et de Recherche sur l'Information en Population et Santé

${ }^{2}$ Laboratoire d'Etudes et de Recherche sur les Dynamiques Sociales et le Développement Local

${ }^{3}$ Invest In Knowledge
} 
Households were assigned unique IDs and each survey was linked using this ID. Table 4 shows sample sizes per survey.

Table 4. Baseline, Midline, Endline Samples, MNCP Countries

\begin{tabular}{|c|c|c|c|c|c|c|}
\hline Country & State/Region & $\begin{array}{r}\text { Baseline } \\
\text { Adolescent Girl } \\
\text { Survey } \\
\end{array}$ & $\begin{array}{r}\text { Midline Adolescent } \\
\text { Girl Survey }\end{array}$ & $\begin{array}{r}\text { Endline } \\
\text { Adolescent Girl } \\
\text { Survey } 1 \\
\end{array}$ & $\begin{array}{r}\text { Endline } \\
\text { Adolescent Girl } \\
\text { Survey } 2 \\
\end{array}$ & $\begin{array}{r}\text { Endline } \\
\text { Adult Survey }\end{array}$ \\
\hline & & $2016-17$ & 2018 & & & 2020 \\
\hline India & $\begin{array}{l}\text { Bihar, Jharkhand, } \\
\text { Rajasthan, Odisha }\end{array}$ & 2,982 & 2,801 & 1,479 & 1,479 & 1,479 \\
\hline Malawi & $\begin{array}{l}\text { Mangochi, } \\
\text { Nkhata Bay }\end{array}$ & 1,020 & 1,029 & 764 & 764 & 786 \\
\hline Mali & Sikasso, Ségou & 855 & 829 & 819 & 816 & 479 \\
\hline Niger & Maradi, Tillabéri & 600 & 599 & 620 & 620 & 329 \\
\hline
\end{tabular}

\section{Ethics}

Ethical and research clearance for this study was issued by the Institutional Review Board of the Population Council and by the National Committee on Research in the Social Sciences and Humanities (NCRSH) in Lilongwe (Malawi), the Institut National de Recherche en Santé Publique (INRSP) (Mali), and Comité d'Éthique pour la Recherche en Santé (Niger).

\section{Data Analysis}

We conducted DID analysis using Stata SE 14.2 adjusted for the cluster design. In India and Malawi where the intervention sites were randomized and balanced at baseline we did not adjust for covariates. For India we therefore present unadjusted results from the DID. In Malawi, we do not adjust for covariates but we do acknowledge that the program implementation deviated from the randomization slightly, with some intervention areas not receiving the intervention and some comparison areas being treated. We therefore present the "as implemented" results in Malawi, which more closely reflects the impact of the program. In Mali and Niger, the DID analysis included covariates as the research design was quasi-experimental (matched comparison areas) and intervention and comparison areas differed at baseline. The DID analysis for Mali and Niger is adjusted for age, education level, wealth, and ethnicity. Age and education level were included at the individual level based on the adolescent girl survey responses. Household wealth and girls' ethnicities were not collected in endline surveys. For this reason, wealth and ethnicity were calculated at the community level based on responses from adult and previous surveys. Ethnicity was calculated as proportion of the community who were members of the dominant ethnic group. Wealth was calculated as the average wealth score within the community. For the baseline and midline, wealth calculations were from these respective survey years. For endline, wealth was calculated as an average of the baseline and midline responses within the community. 


\section{Impact of the Covid-19 Pandemic on Adolescent Girls}

\section{Covid-19-Related Disruptions}

Beyond its direct costs in terms of human lives, health, and the excessive burden placed on health-care systems, the Covid-19 pandemic has caused wide-reaching disruptions. Various ways in which the pandemic has impacted the lives of adolescent girls are described in Figure 3.

Figure 3. Multidimensional Consequences of Covid-19

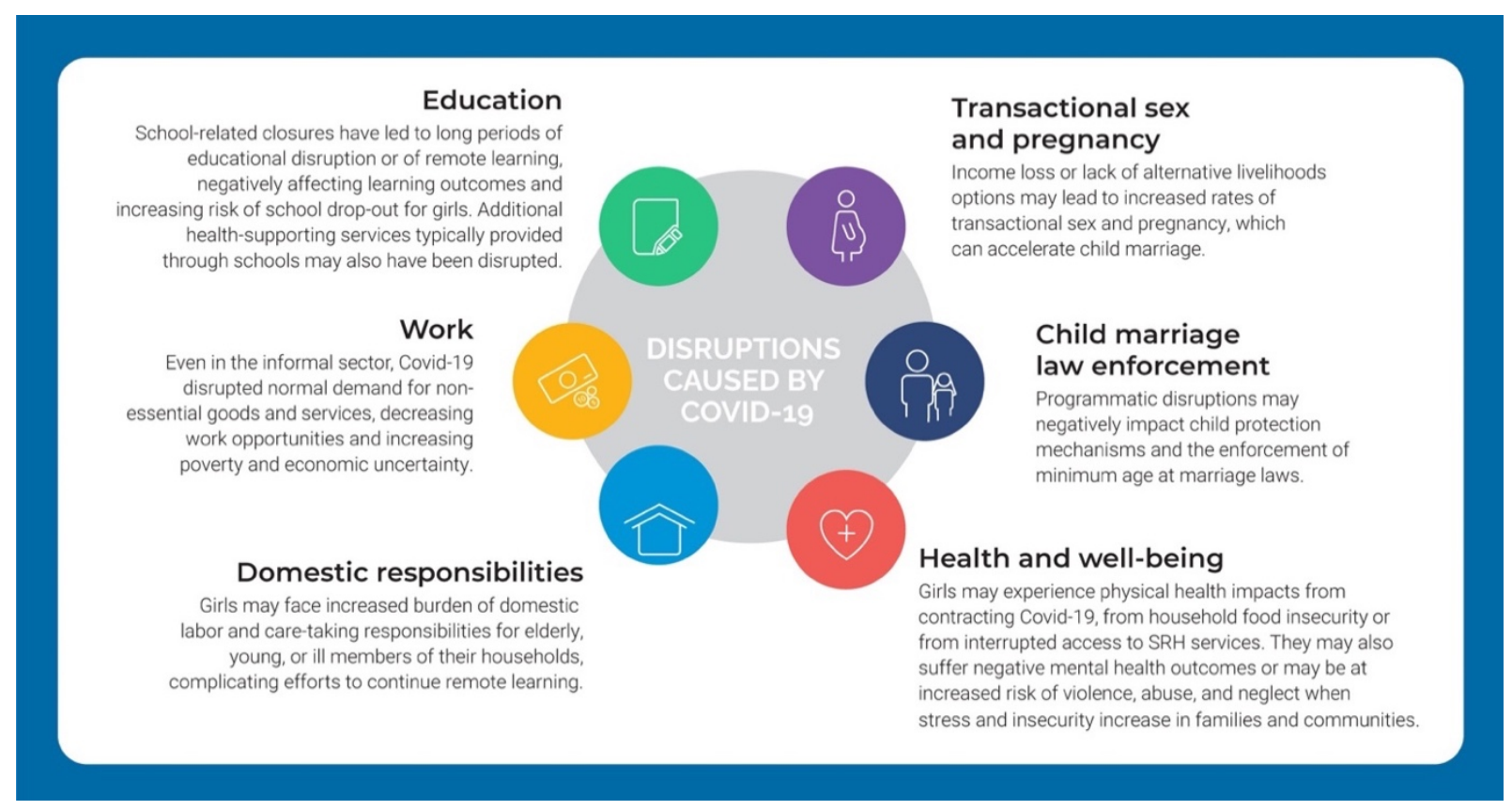

In the endline evaluation, we examine the influence of Covid-19 on adolescent girls' lives with respect to household finances and financial insecurity, educational disruption, physical and mental health outcomes, and gender inequities including gender-based violence.

\section{Impact of Covid-19 on Child Marriage}

We know from previous research on displacement (Mourtada et al. 2017; Melnikas et al. 2020), climate change (Alston et al. 2014), and infectious diseases like Ebola (Bandiera et al. 2018) that political, environmental, and health crises exacerbate known drivers of child marriage-including poverty and gender inequity - and may lead to increases in early pregnancy and child marriage. The Covid-19 pandemic is expected to stall global progress made on reducing child marriage and improving gender equity: estimates from UNFPA suggest that an additional 13 million child marriages will result from disruptions caused by Covid-19 (UNFPA 2020). 
As much of the true impact of the Covid-19 pandemic on child marriage will not be detectable in national data over the short-term, it is important to monitor intermediary drivers of child marriage to better understand how this complex crisis exacerbates girls' risks. Figure 4 proposes some of the pathways through which the Covid-19 pandemic is expected to exacerbate child marriage. As poverty and insecurity increase at the household and community levels as a result of sickness or deaths within families, lost income, and volatile economic markets, parents may feel pressured to have their daughters married earlier to alleviate financial strain on households or as a means of securing their daughters' financial futures. Disruptions of programs and services that help support families economically and enable adolescent girls to stay in school may exacerbate financial strain on families and increase girls' vulnerability to child marriage. Increased demand for domestic and care-taking labor within households may serve to keep girls out of school beyond the immediate period of school closures or may motivate households to seek out young brides to join their households to fulfill those domestic roles. School closures and difficulties in continuing education remotely may negatively impact learning outcomes, increase the incidence of school drop-out, and reduce educational attainment for girls, ultimately leading to child marriage as a means of securing girls' livelihoods.

Concerns related to girls' sexuality are also key. In contexts where virginity before marriage is closely linked to family honor and marriageability, increased financial insecurity, anxiety, and uncertainty about the future may lead families to have their daughters married early to prevent them from engaging in sexual relationships or from being the victims of sexual violence. Limited economic opportunities and increased financial insecurity may lead girls to engage in transactional sex in some settings, with resulting premarital pregnancies driving child marriage. Increased risk of sexual violence may also lead to pregnancies that subsequently drive child marriage.

Figure 4. How Does Covid-19 Influence Child Marriage?

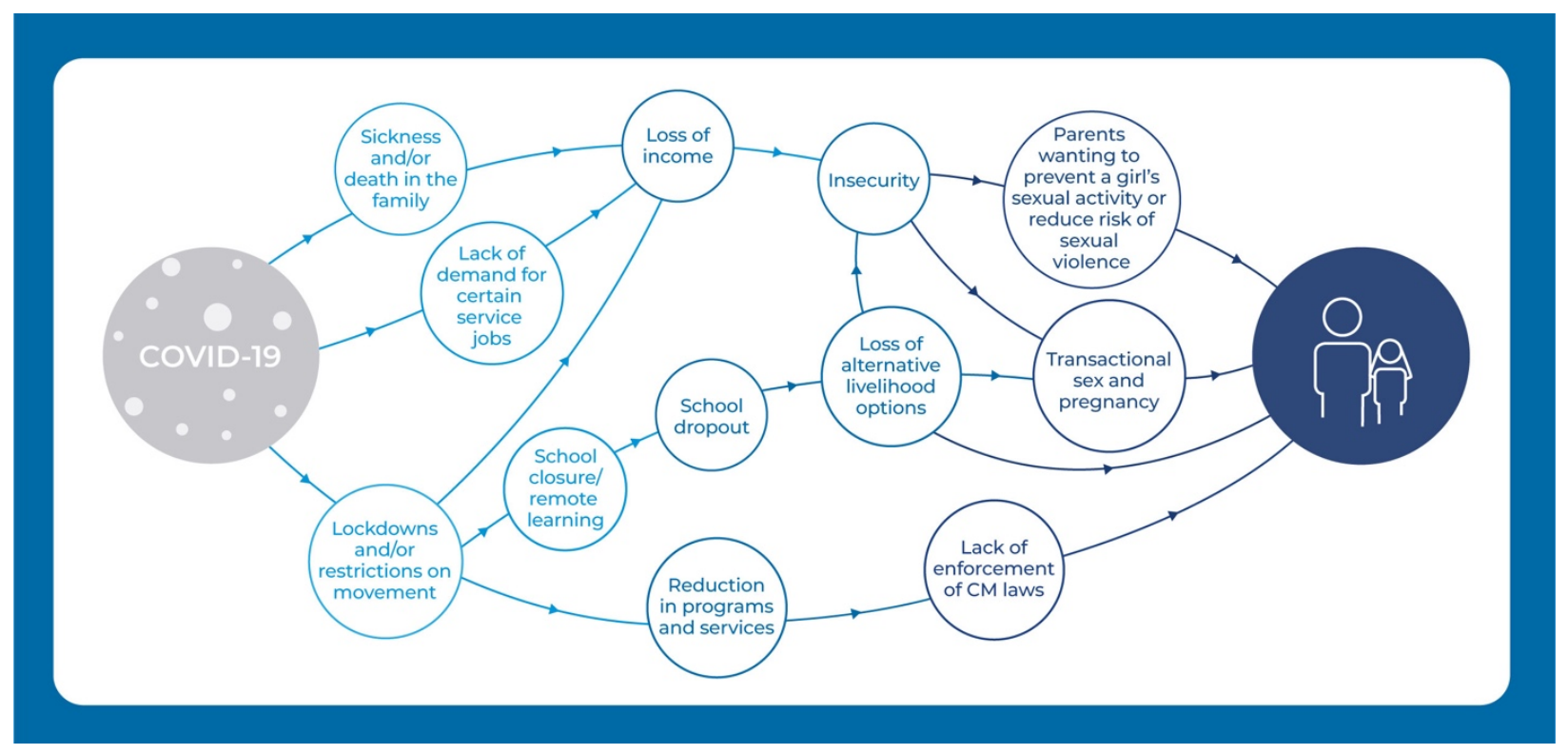

\section{Responses to Covid-19 in MNCP Countries}

As shown in Table 5, each of the countries where the MNCP project took place took precautions to stop the spread of Covid-19, including school closures and in some cases, extreme lockdowns. 
We note that Covid-19-related lockdowns and subsequent programming adaptations varied depending on the national and local restrictions in each setting.

Table 5. Covid-19-Related Restrictions, by Country

\begin{tabular}{|c|c|c|c|c|}
\hline \multirow[b]{2}{*}{ Country } & \multicolumn{4}{|l|}{ First documented } \\
\hline & Covid-19 case & Lockdown or stay-at-home orders & Travel restrictions & School closures \\
\hline \multirow[t]{5}{*}{ India } & \multirow[t]{5}{*}{30 Jan 2020} & Yes, national lockdown: & \multirow{5}{*}{$\begin{array}{l}\text { Yes, tourist visas } \\
\text { suspended in March } \\
\text { 2020; internal } \\
\text { movement restricted }\end{array}$} & Yes, March- \\
\hline & & Phase 1 (25 March - 14 April) & & September 2020 \\
\hline & & Phase 2 (15 April - 3 May) & & After this period, states \\
\hline & & Phase 3 (4-17 May) & & could decide. In \\
\hline & & Phase 4 (18-31 May) & & $\begin{array}{l}\text { November/ December } \\
\text { few schools partially } \\
\text { opened to take exams }\end{array}$ \\
\hline Mali & 25 Mar 2020 & $\begin{array}{l}\text { Yes, lockdown in March } 2020 \text {, } \\
\text { including a curfew until early May }\end{array}$ & $\begin{array}{l}\text { Yes, flights } \\
\text { suspended }\end{array}$ & $\begin{array}{l}\text { Yes, March-June } 2020 \\
\text { (exam classes; } \\
\text { September for others) }\end{array}$ \\
\hline Malawi & 2 Apr 2020 & $\begin{array}{l}\text { Yes, national lockdown ordered but } \\
\text { blocked by injunction; local } \\
\text { jurisdictions could issue their own }\end{array}$ & $\begin{array}{l}\text { Yes, borders were } \\
\text { closed }\end{array}$ & $\begin{array}{l}\text { Yes, March-August } \\
2020\end{array}$ \\
\hline Niger & 19 Mar 2020 & $\begin{array}{l}\text { Yes, restrictions implemented } \\
\text { March-May; strictest measures in } \\
\text { Niamey }\end{array}$ & $\begin{array}{l}\text { Yes, all land and air } \\
\text { borders closed } \\
\text { March 2020; Niamey } \\
\text { isolated from rest of } \\
\text { country until May } 15\end{array}$ & Yes, March-June 2020 \\
\hline
\end{tabular}

\section{Impact of Covid-19: Results}

Endline evaluation results suggest that the Covid-19 pandemic is exacerbating key indicators along hypothesized pathways to child marriage. Girls appear to be suffering as a result of Covid19 and to be at increased risk of child marriage. Figure 5 presents key findings on the impact of the pandemic on girls' lives at endline using data from adolescent and parent/adult in the household surveys. 


\section{Figure 5. Impacts of the Covid-19 Pandemic}

\section{Impacts of the Covid-19 Pandemic}

HEALTH \& WELL-BEINC

Reported feeling more depressed

Reported tensions in the house increased

Worries about getting sick with Coronavirus

Worries about money

Reported that access to SRHR services is more difficult during pandemic

TIME USE

Spends more time doing chores

Spends more time caring for children/elderly

Spends more time with friends

Spends more time in the house

HOUSEHOLD FINANCES \& INSECURITY

Participated in activity to earn money since Covid started

Earned less money than before Covid

Feels that violence in her neighborhood increased

EDUCATION DISRUPTION

Attended school just before Covid closures

Reported having returned to school since reopening

\section{PARENTS OR OTHER ADULT HOUSEHOLD MEMBERS}

INCOME \& FOOD INSECURITY

Feels that Covid-19 has negatively affected finances

Reported that household has experienced

food shortages since Covid started

Reported that household has a girl who left the home since Covid started

GIRLS' EDUCATION

Reported that at least one girl in home was able to continue studies during lockdown

Reported that at least one boy in home was able to continue studies during lockdown

GIRLS' TIME USE

Girls spend more time doing chores

Girls spend more time caring for children/elderly
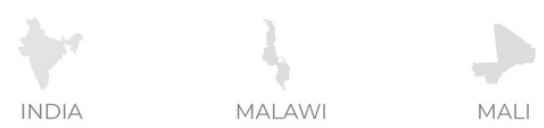

NIGER
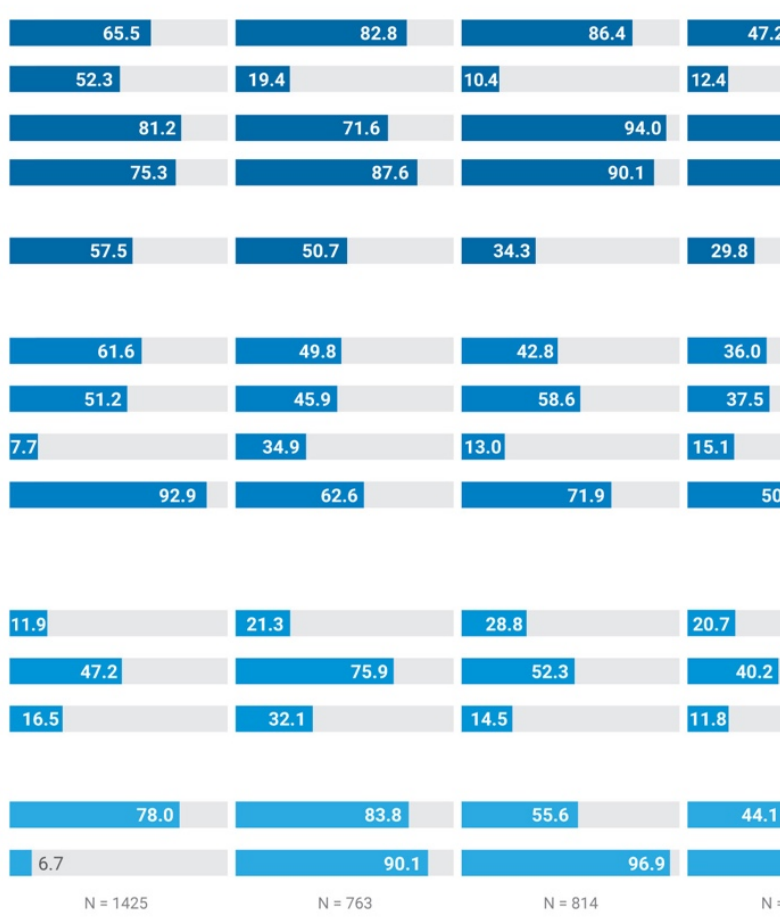

$N=1425$

28.8

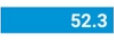

14.5
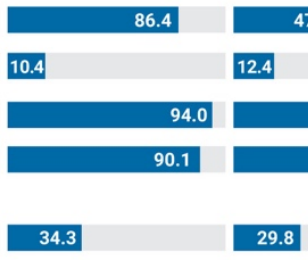

36.0

37.5

15.1

50.3

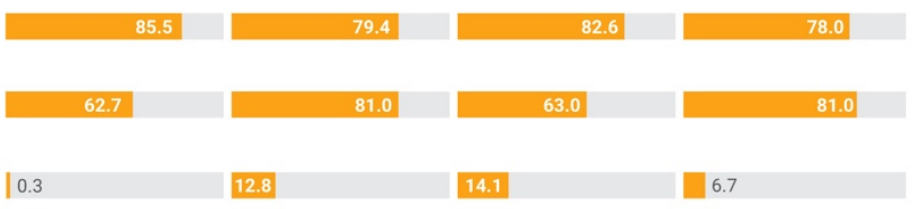

\begin{tabular}{|l|l|l|l|l}
\hline 0.3 & 12.8 & 14.1 & 6.7
\end{tabular}
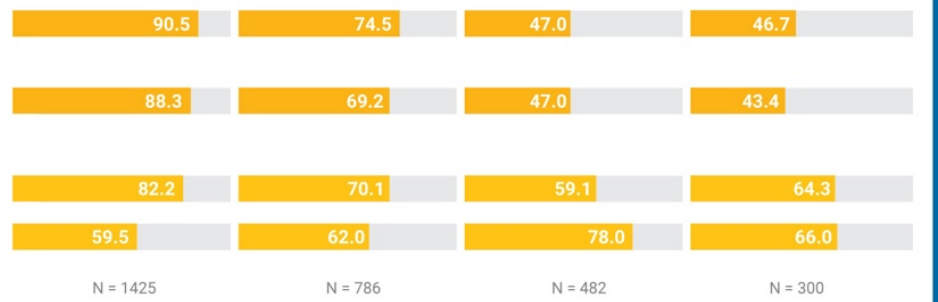


\section{Health and Well-being}

Results show that the Covid-19 pandemic and associated lockdowns and school closures had an effect on girls' mental health and reported access to health services. We find that a majority of girls-ranging from $71.6 \%$ in Malawi to $94.0 \%$ in Mali-reported worrying about getting sick from Covid-19. More than half of girls in India and Malawi also reported having more difficulty accessing SRHR services since the pandemic began. Many girls reported feeling more depressed during the pandemic, ranging from $47.2 \%$ in Niger to $86.4 \%$ in Mali.

\section{Household Finances and Insecurity}

We find that increasing financial strain on households since the pandemic began is commonly reported across countries, with important effects on household health and well-being. The majority of adult respondents in all countries reported that Covid-19 has negatively affected their households' finances and that more than half_-and in some cases 4 of 5 (Niger and Malawi)_ households report experiencing food shortages since the pandemic began. High proportions of girls—ranging from $75.3 \%$ in India to $90.1 \%$ in Mali-report worrying about money during the pandemic. In India, where lockdown measures imposed by the government have been most severe, we find that $52.3 \%$ of girls report increased tensions within their households. Some girls reported that violence in their neighborhoods has increased (ranging from a high of $32.0 \%$ of girls in Malawi to a low of $11.8 \%$ in Niger).

In Mali and Malawi, $14.1 \%$ and $13.2 \%$ of parents interviewed, respectively, reported that a $12-$ 19 -year-old girl in their household had left their village since the beginning of the pandemic. We note that these figures come from a sample of parents (or other adult member of the household) whose adolescent daughter was present in the home at the time of the phone number listing exercise and was invited to participate in the adolescent survey. In Mali, researchers found a high proportion of girls to be absent at the time of the phone number listing exercise, and their households were subsequently replaced in the sample with other randomly selected households where the sampled girl was present. Data from the adult survey regarding adolescent girls' movements during the pandemic thus represent an underestimate of the true level of girls' migration in Mali. Responses on girls' reasons for leaving (Figure 6) suggest that alleviating economic strain on the household may be a key driver of girls' movement outside of their villages, increasing concerns about vulnerability for child marriage.

\section{Time Use}

We sought to understand how the Covid-19 pandemic and associated lockdowns and school closures has influenced how girls spend their time and whether girls are facing larger burdens of domestic work within their households. In India, $61.6 \%$ of girls report spending

Figure 6: Reasons for Leaving Village during the Covid-19 Pandemic (Malawi n=101, Mali $\mathrm{n}=68$ )

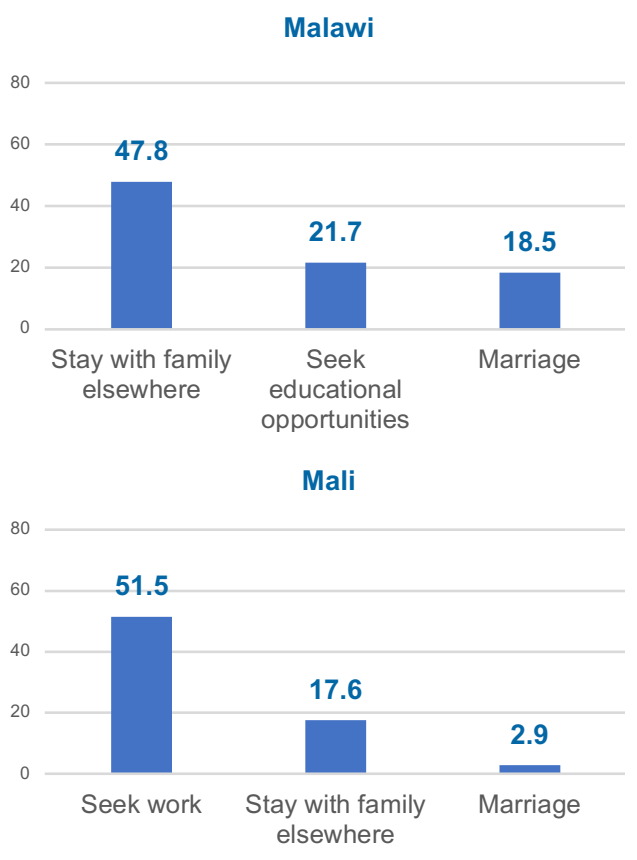


more time doing chores since the pandemic began. The majority of girls reported increased time spent caring for children or the elderly in Mali (58.6\%) and India (51.2\%).

\section{Education Disruption}

We asked both adolescent and adult respondents about how Covid-19 lockdowns have disrupted education for the children in their households. We found that in places where schools had been reopened at the time of the survey, a majority of girls who had been enrolled in school prior to closures had returned to school. While this is encouraging, fewer than half of households in Mali $(47 \%)$ and Niger $(46.7 \%)$ reported at least one girl in the household being able to continue her studies during school closures, whereas in India, $90.5 \%$ of adults interviewed reported that at least one girl in their household had been able to continue her studies remotely. We did not find large gender differences, suggesting that in these contexts both girls and boys have struggled to continue their studies during the pandemic. As others have noted, falling behind in school is strongly associated with school drop-out (Sunny et al. 2017) and may lead to early pregnancy and child marriage (Glynn et al. 2018).

\section{Implications for Interpretation of MNCP Endline Results}

The MNCP endline results were collected after approximately 7-9 months of Covid-19-related restrictions, including school closures and restrictions on movement. Endline findings have likely been influenced by the experience of these restrictions. While we expect that both intervention and comparison areas experienced similar restrictions and closures, we also assume some areas had more continuity of program services and perhaps differential experiences of remote schooling. 


\section{Endline Results: India}

\section{Background}

Despite declines in recent years, child marriage remains a significant issue in India: an estimated $25.3 \%$ of women $20-24$ report being married by age 18 , with some noted geographic variation (IIPS and ICF 2017). In year 2015/16, the regions with the highest percentage of women 20-24 reporting married by age 18 included Bihar (39.0\%) and Jharkhand (37.0\%) (IIPS and ICF 2017). We have seen declines in child marriage in data from the National Family Health Surveys (NFHS) from 2005-06 and 2015-16: for example, Bihar saw a decline in marriage by age 18 among those aged $20-24$ from $69.0 \%$ to $42.5 \%$. While child marriage has declined significantly in some areas, it has remained relatively high in others suggesting that child marriage is more stubborn in "hot spots" characterized by geographic, ethnic, religious, or other factors that may influence the practice.

In the body of research on child marriage and its drivers in India it is generally agreed that the main drivers are poverty, gendered norms, limited and inequitable educational and livelihood investments and opportunities for girls, and concerns about sexual security and girls' safety. Poverty is generally acknowledged as a key driver in India; while successful livelihood and lifeskills programs support this notion, more causal evidence is needed. In the last three decades there have been a number of interventions to address child marriage in India that have demonstrated mixed success. Systematic reviews including a 2021 review by Malhotra and Elnakib found a number of programs in India had demonstrated success in reducing child marriage or delaying marriage, with most focused on a livelihoods or life-skills approach (Pande et al. 2006; Jensen 2012) and one focused on SRHR information (Daniel and Nanda 2012).

As noted in national surveys, child marriage has been declining in India in recent years. We find this in this project's midline report as well: at midline child marriage was declining in India in most areas. We also found that school enrollment was generally high for girls, especially in younger cohorts and the program was showing modest success in improving knowledge about SRHR and legal age at marriage.

\section{Sample Characteristics}

Table 6 shows sample characteristics comparing baseline, midline, and endline samples by intervention area. These tables suggest that, generally speaking, our samples were comparable across intervention status at baseline. 
Table 6. Sample Characteristics for India, by State

\begin{tabular}{|c|c|c|c|c|c|c|}
\hline \multirow[b]{2}{*}{ Country } & \multicolumn{2}{|l|}{ Baseline } & \multirow{2}{*}{$\begin{array}{r}\text { Midline } \\
\text { Intervention }\end{array}$} & \multicolumn{3}{|c|}{ Endline } \\
\hline & Intervention & Comparison & & Comparison & Intervention & Comparison \\
\hline \multicolumn{7}{|l|}{ Bihar } \\
\hline Currently married & 16.0 & $11.0^{* *}$ & $6.2^{+++}$ & $4.5^{+++}$ & $7.6^{+++}$ & $10.3^{++}$ \\
\hline Not enrolled in school & 35.7 & $24.4^{* * \star}$ & $27.0^{++}$ & $24.7^{*}$ & $20.0^{+++}$ & $20.2^{+}$ \\
\hline $\begin{array}{l}\text { Ever pregnant (ever } \\
\text { married 15-19) }\end{array}$ & 58.8 & 47.2 & 38.5 & $(10.0)^{* *}$ & $(66.7)$ & $(66.7)^{++}$ \\
\hline \multicolumn{7}{|l|}{ Jharkhand } \\
\hline Currently married & 26.9 & 25.9 & $18.6^{++}$ & $19.8^{+}$ & $9.3^{+++}$ & $19.3^{* \star}$ \\
\hline Not enrolled in school & 45.2 & $40.9^{*}$ & $38.4^{++}$ & 37.4 & $19.3^{+++}$ & 25.0 \\
\hline $\begin{array}{l}\text { Ever pregnant (ever } \\
\text { married 15-19) }\end{array}$ & 57.7 & 56.1 & 57.6 & 54.4 & $(64.0)$ & 72.7 \\
\hline \multicolumn{7}{|l|}{ Odisha } \\
\hline Currently married & 8.9 & 6.0 & 7.8 & 7.1 & $0.0^{+++}$ & $2.2^{\star \star}$ \\
\hline Not enrolled in school & 36.3 & 45.3 & 40.4 & 43.3 & $15.0^{+++}$ & $26.7^{+++^{* *}}$ \\
\hline $\begin{array}{l}\text { Ever pregnant (ever } \\
\text { married 15-19) }\end{array}$ & 52.9 & $(57.1)$ & 28.6 & 48 & -- & $(20.0)$ \\
\hline \multicolumn{7}{|l|}{ Rajasthan } \\
\hline Currently married & 8.4 & 6.5 & 7.2 & $4.2^{*}$ & $2.1^{++}$ & $9.1^{* *}$ \\
\hline Not enrolled in school & 35.7 & 33.3 & $26.5^{+++}$ & $22.8^{+++}$ & $16.8^{+++}$ & $15.7^{+++}$ \\
\hline $\begin{array}{l}\text { Ever pregnant (ever } \\
\text { married 15-19) }\end{array}$ & 14.7 & 15.3 & 5.8 & 4.7 & (33.3) & $(40.0)^{+++}$ \\
\hline
\end{tabular}

\section{Program Exposure}

In Figure 7, we look at whether respondents report being aware of the MNCP program in intervention areas from midline to endline. We see increases in awareness of the MNCP program in each state except Odisha, with a pronounced increase in Jharkhand. We also see a $20 \%$ increase overall (10 percentage points) from midline to endline with nearly $2 / 3$ of girls surveyed in intervention areas reporting awareness of the program.
Figure 7. Proportion Who Report Being Aware of the MTBA Program in Intervention Areas, Midline to Endline, India

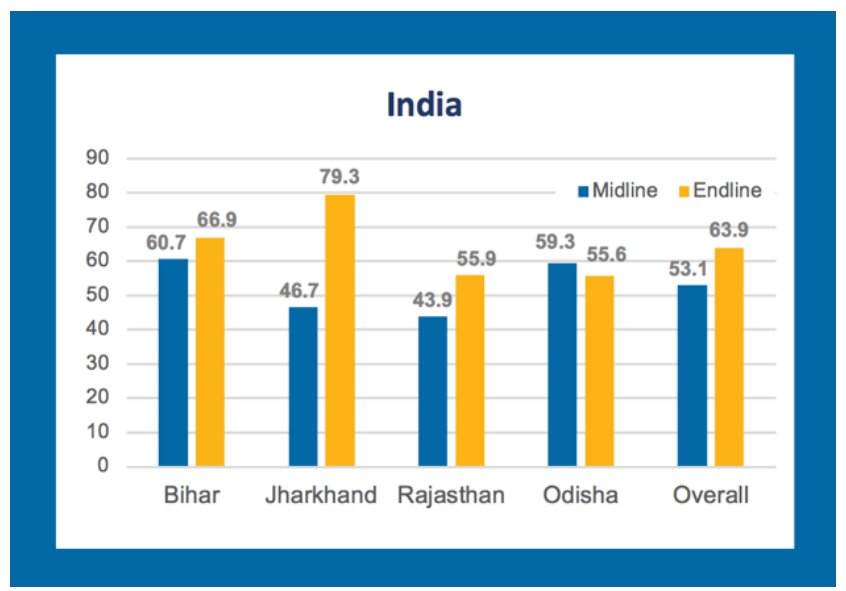




\section{Results}

Figure 8. Summary Results, India

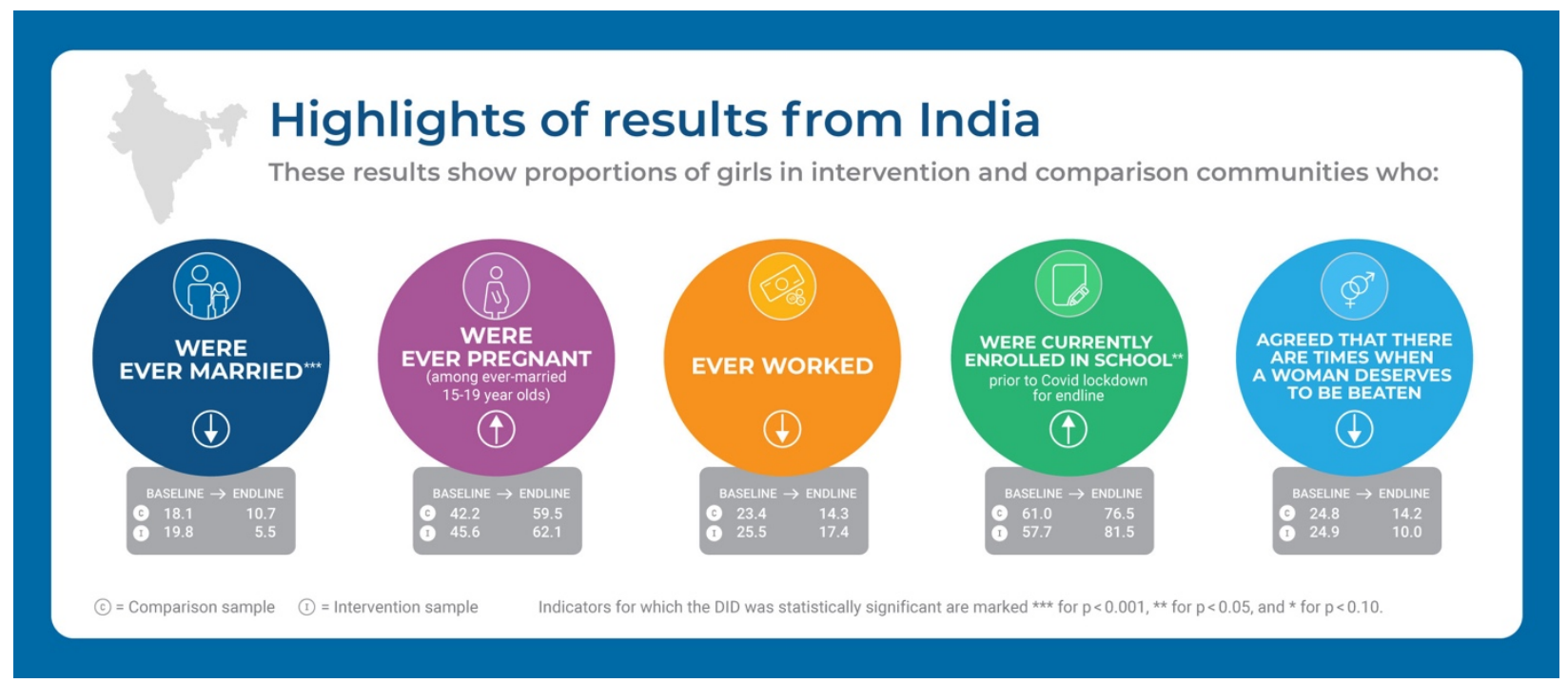

In Table 7 we present the main findings from the DID analysis on key indicators of interest. The arrows shown next to INT and COM indicate the direction of change from baseline to endline for each indicator in intervention and comparison areas, respectively. Results highlighted in blue show indicators for which the DID was significant and intervention communities performed better than comparison communities from baseline to endline.

Table 7. Endline Results, India

\begin{tabular}{|c|c|c|c|}
\hline & & & $\begin{array}{l}\text { Direction of } \\
\text { change from }\end{array}$ \\
\hline Impact area & Indicator & State & baseline to endline \\
\hline \multirow{15}{*}{ Marriage } & \multirow[t]{5}{*}{ Can correctly identify legal age at marriage } & All states & INT $\uparrow \mathrm{COM} \uparrow$ \\
\hline & & Bihar & INT $\uparrow \mathrm{COM} \uparrow$ \\
\hline & & Jharkhand & INT $\uparrow \mathrm{COM} \uparrow$ \\
\hline & & Odisha & INT $\uparrow \mathrm{COM} \uparrow$ \\
\hline & & Rajasthan & INT $\uparrow \mathrm{COM} \uparrow$ \\
\hline & \multirow[t]{5}{*}{ Ever married } & All states & INT $\downarrow$ COM $\downarrow$ \\
\hline & & Bihar & INT $\downarrow$ COM $\downarrow$ \\
\hline & & Jharkhand & INT $\downarrow$ COM $\downarrow$ \\
\hline & & Odisha & INT $\downarrow$ COM $\downarrow$ \\
\hline & & Rajasthan & INT $\downarrow \mathrm{COM} \uparrow$ \\
\hline & \multirow{5}{*}{$\begin{array}{l}\text { Can name at least three adverse effects } \\
\text { of child marriage }\end{array}$} & All states & INT $\uparrow \mathrm{COM} \uparrow$ \\
\hline & & Bihar & INT $\uparrow \mathrm{COM} \uparrow$ \\
\hline & & Jharkhand & INT $\uparrow \mathrm{COM} \uparrow$ \\
\hline & & Odisha & INT $\uparrow \mathrm{COM} \uparrow$ \\
\hline & & Rajasthan & INT $\uparrow \mathrm{COM} \uparrow$ \\
\hline
\end{tabular}


Ever pregnant (among ever-married girls 1519)

Knows about HIV

\section{Health}

Livelihoods

\begin{tabular}{|c|c|}
\hline All states & INT $\uparrow \mathrm{COM} \uparrow$ \\
\hline Bihar & $\mathrm{INT} \uparrow \mathrm{COM} \uparrow$ \\
\hline Jharkhand & $\mathrm{INT} \uparrow \mathrm{COM} \uparrow$ \\
\hline Odisha & INT - COM $\downarrow$ \\
\hline Rajasthan & INT $\uparrow \mathrm{COM} \uparrow$ \\
\hline All states & INT $\uparrow \mathrm{COM} \uparrow$ \\
\hline Bihar & INT $\uparrow \mathrm{COM} \uparrow$ \\
\hline Jharkhand & INT $\uparrow \mathrm{COM} \uparrow$ \\
\hline Odisha & INT $\uparrow \mathrm{COM} \uparrow$ \\
\hline Rajasthan & INT $\uparrow \mathrm{COM} \uparrow$ \\
\hline All states & INT $\uparrow \mathrm{COM} \uparrow$ \\
\hline Bihar & INT - COM - \\
\hline Jharkhand & INT - COM - \\
\hline Odisha & INT $\uparrow \mathrm{COM} \uparrow$ \\
\hline Rajasthan & INT $\uparrow \mathrm{COM} \uparrow$ \\
\hline All states & INT $\downarrow$ COM $\downarrow$ \\
\hline Bihar & INT - COM $\uparrow$ \\
\hline Jharkhand & $\mathrm{INT} \downarrow \mathrm{COM} \downarrow$ \\
\hline Odisha & INT $\downarrow$ COM $\downarrow$ \\
\hline Rajasthan & INT $\downarrow$ COM $\downarrow$ \\
\hline All states & INT $\uparrow \mathrm{COM} \uparrow$ \\
\hline Bihar & INT $\uparrow \mathrm{COM} \uparrow$ \\
\hline Jharkhand & INT $\downarrow$ COM $\uparrow$ \\
\hline Odisha & INT $\uparrow \mathrm{COM}-$ \\
\hline Rajasthan & INT $\uparrow \mathrm{COM} \uparrow$ \\
\hline All states & INT $\uparrow \mathrm{COM}-$ \\
\hline Bihar & INT $\uparrow \mathrm{COM} \uparrow$ \\
\hline Jharkhand & INT $\uparrow \mathrm{COM}-$ \\
\hline Rajasthan & $\mathrm{INT} \uparrow \mathrm{COM} \uparrow$ \\
\hline Odisha & $\mathrm{INT} \uparrow \mathrm{COM} \uparrow$ \\
\hline All states & INT $\uparrow \mathrm{COM} \uparrow$ \\
\hline Bihar & $\mathrm{INT} \uparrow \mathrm{COM} \uparrow$ \\
\hline Jharkhand & INT $\uparrow$ COM - \\
\hline Rajasthan & $\mathrm{INT} \uparrow \mathrm{COM} \uparrow$ \\
\hline Odisha & $\mathrm{INT} \uparrow \mathrm{COM} \uparrow$ \\
\hline All states & $\mathrm{INT} \uparrow \mathrm{COM} \uparrow$ \\
\hline Bihar & INT $\uparrow \mathrm{COM} \uparrow$ \\
\hline Jharkhand & INT $\uparrow \mathrm{COM} \uparrow$ \\
\hline Rajasthan & INT - COM $\uparrow$ \\
\hline Odisha & $\mathrm{INT} \uparrow \mathrm{COM} \uparrow$ \\
\hline All states & INT $\uparrow \mathrm{COM} \uparrow$ \\
\hline Bihar & $\mathrm{INT} \uparrow \mathrm{COM} \uparrow$ \\
\hline Jharkhand & INT $\uparrow \mathrm{COM} \uparrow$ \\
\hline Rajasthan & INT $\uparrow \mathrm{COM} \uparrow$ \\
\hline Odisha & INT $\uparrow \mathrm{COM} \uparrow$ \\
\hline
\end{tabular}

Is currently working for income

Reports that their community has a youth-friendly health center

Has ever worked for income

Ever attended school

Highest grade level completed

Can read or write enrolled)

tended school

\section{Education}

Currently enrolled in school (among ever

\begin{tabular}{lll}
\cline { 2 - 2 } & Bihar & INT $\uparrow \operatorname{COM} \uparrow$ \\
& Jharkhand & INT $\uparrow \operatorname{COM} \uparrow$ \\
Can read or write & Odishasthan & INT $-\operatorname{COM} \uparrow$ \\
\cline { 2 - 3 } & All states & INT $\uparrow \operatorname{COM} \uparrow$ \\
\cline { 2 - 3 } & Bihar & INT $\uparrow \operatorname{COM} \uparrow$ \\
\hline & Jharkhand & INT COM $\uparrow$ \\
& INT $\uparrow$ COM $\uparrow$ \\
& Rajasthan & INT $\uparrow \operatorname{COM} \uparrow$ \\
& Odisha & INT $\uparrow \operatorname{COM} \uparrow$ \\
\hline
\end{tabular}




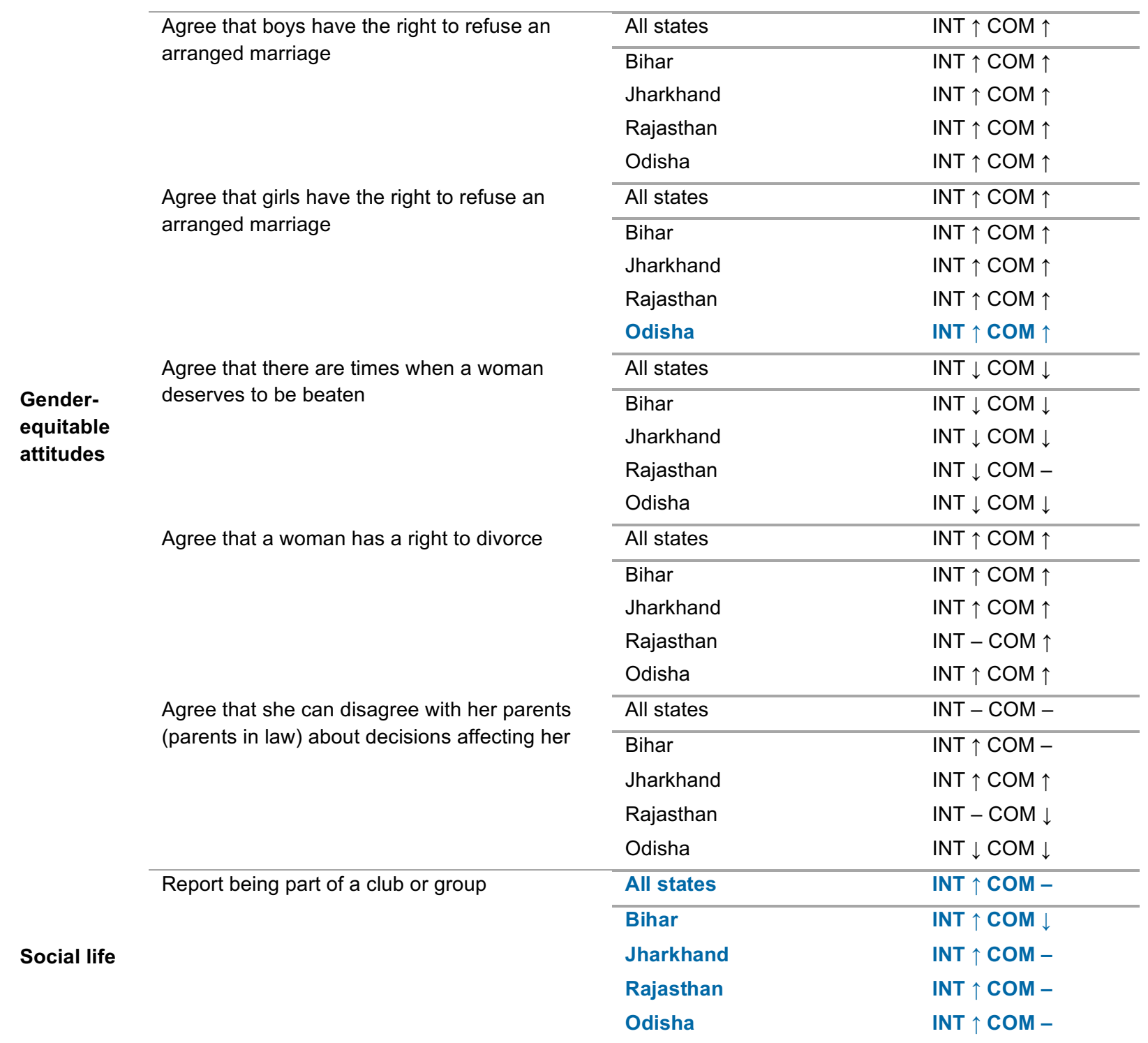

Note: Results highlighted in blue show indicators for which the DID was significant and intervention communities performed better than comparison communities.

We find that the MNCP program in India was successful in increasing knowledge of legal age at marriage and decreasing the proportion of girls who were currently married. Girls living in intervention areas were less likely to be married at endline than girls in comparison areas, though both areas showed decline in child marriage over the evaluation period.

We also see improvements in some health indicators in India. Knowledge of HIV more than doubled in intervention communities in India overall (from $22.4 \%$ to $50.2 \%$ ), with more modest increases in comparison communities. In intervention communities in Jharkhand, knowledge of HIV increased from just $6.2 \%$ at baseline to $37.3 \%$ at endline.

The MNCP program was successful in increasing school enrollment with MNCP intervention areas showing an increase in school enrollment while comparison areas experienced no change. 
The intervention additionally demonstrated positive impact with respect to the proportion of girls ever having attended school in Jharkhand and in the overall India sample. The MNCP program was less successful in increasing the proportion of girls who have ever worked (no change) and improving gender-equitable attitudes (some changes significant, but only in some states).

However, we do see significant positive effect of the MNCP program on participation in a clubwe see that across all states and overall girls in intervention areas report being part of a club or group compared to girls in comparison areas. In MNCP intervention areas participation in a club increased while it decreased in comparison areas.

These findings are encouraging and suggest that the MNCP program is successful at delaying marriage, possibly through the pathway of building social assets including participating in a club or group and through increasing education and keeping girls in school. We see impact on reducing child marriage across states (except Bihar) despite those states starting with varied levels of child marriage: Rajasthan at $8.4 \%$ and Odisha at $8.9 \%$ had relatively low child marriage at baseline compared to Jharkhand at $26.9 \%$. Child marriage in intervention areas declined from $14.5 \%$ to $4.5 \%$ - $69 \%$ decline overall (comparison areas declined $22 \%$ ). The proportion of girls who report being part of a club or group also improved dramatically from baseline (2.7\% in intervention areas) to endline $(49.8 \%)$, a nearly $20 x$ increase on that indicator. 


\section{Endline Results: Malawi}

\section{Background}

Child marriage in Malawi has declined from more than half in 1992 (54.9 of women 20-24 report being married by age 18 according to 1992 DHS) to 42.1\% (NSO [Malawi] and ICF 2017), but still remains among the highest proportion in sub-Saharan Africa. Qualitative research (Ansell et al. 2018; Steinhaus et al. 2019) suggests that pregnancy is an important factor in understanding why child marriage remains high in Malawi. Previous research has shown that premarital sexual activity is common and sexual debut occurs early in Malawi. Biddlecom and colleagues (2008) found that among girls ages 18-19 who completed primary school, 48.1\% reported ever having sex and $27.0 \%$ reported having premarital sex while still in school.

There is a growing body of research on interventions to delay marriage in Malawi, much of which is included in systematic reviews of what works to address child marriage. Interventions in Malawi included in these reviews have mostly focused on economic incentives to delay marriage, including direct cash transfers that suggests that providing economic incentives directly to girls and families can work to delay marriage, at least until the payments cease (Baird et al. 2016). In qualitative research for this project, we found that marriage is a livelihood strategy and that securing a partner who can provide may be the best economic option for girls (Population Council 2019). Despite high rates of primary schooling for girls, few girls report attending tertiary education and the gender earnings gap for women remains significant (Kim 2020).

\section{Methodological Note}

As we noted in the midline report (Melnikas et al. 2019) we included additional analyses beyond the intent-to-treat analysis to account for contamination and fidelity to intervention issues that came to light in early 2018. Due to the program unit of implementation being group head villages (GHV), a unit that can change over time, and the research unit of analysis as enumeration area (EA), we had some issues in EAs receiving the intervention. That analysis, which we called "as implemented," was presented alongside the intent-to-treat analysis. In this analysis, we present "as implemented" findings to account for how communities received MNCP, but do not otherwise adjust for additional covariates. We note that in 2020, one additional cluster (EA) was determined to be contaminated and categorized as intervention in this analysis (it was previously categorized as comparison at midline). We also had to drop three clusters due to lack of eligible girls drawn from the midline listing data available at endline.

\section{Sample Characteristics}

In Table 8 we show some key demographics by intervention status for the three surveys. Overall, we see that the samples are generally comparable across intervention and comparison areas. 
From baseline to endline we see declines in key outcomes including pregnancy and marriage, but these declines occurred in both intervention and comparison areas.

Table 8: Sample Characteristics, Malawi

\begin{tabular}{|c|c|c|c|c|c|c|}
\hline & \multicolumn{2}{|c|}{ Baseline } & \multicolumn{2}{|c|}{ Midline } & \multicolumn{2}{|c|}{ Endline } \\
\hline & Intervention & Comparison & Intervention & Comparison & Intervention & Comparison \\
\hline Age (mean) & 14.8 & 15.0 & 15.0 & 14.9 & $14.4^{+++}$ & $14.6^{+}$ \\
\hline Ever married & 16.2 & 15.1 & 11 & 8.1 & $6.3^{+++}$ & $5.2^{+++}$ \\
\hline Never attended school & 4.1 & 0.9 & 4.0 & 4.4 & 2.2 & $1.9^{++}$ \\
\hline Not enrolled in school & 35.0 & 31.4 & 33.4 & 28.7 & $17.8^{+++}$ & $12.8^{+++^{*}}$ \\
\hline Cannot read or write & 32.3 & 21.4 & 23.7 & 18.1 & $14.4^{+++}$ & $13.2^{++}$ \\
\hline Ever pregnant (ages 15-19) & 22.8 & 24.7 & 25.6 & 25.8 & $17.0+^{+}$ & $14.8^{++}$ \\
\hline
\end{tabular}

\section{Program Exposure}

As shown in Figure 9, awareness of the MNCP program in "as implemented" areas increased significantly from midline to endline- $6.5 \%$ of villages where the MTBA program was implemented reported being aware of the program at midline and this increased to $64.5 \%$ at endline. However, program exposure data also shows high knowledge of the MNCP program in nonintervention areas-63.4\% of comparison community respondents report awareness of MNCP at endline. Among those in intervention areas who knew about MTBA at endline, $45.1 \%$ reported that they had participated in an MTBA activity.
Figure 9. Proportion Who Report Being Aware of the MTBA Program in Intervention Areas, Midline to Endline, Malawi

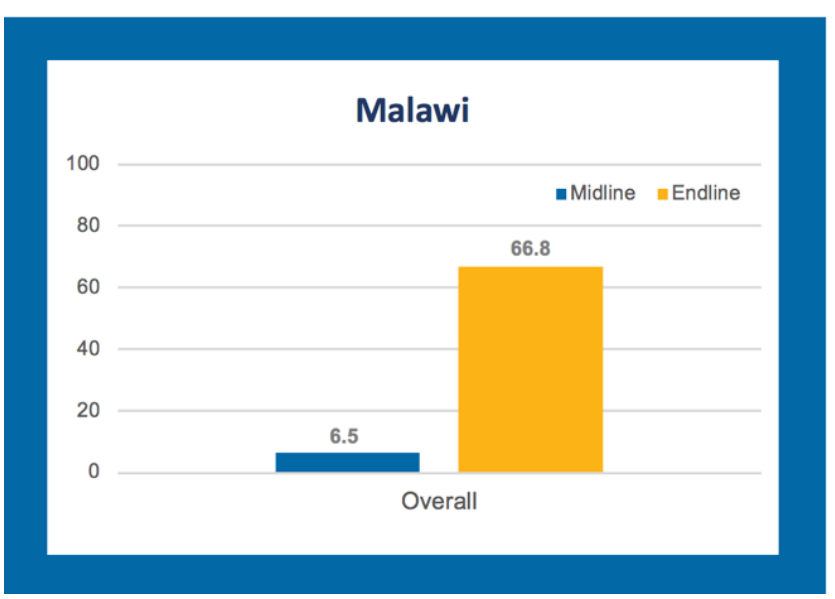




\section{Results}

Figure 10. Summary Results, Malawi

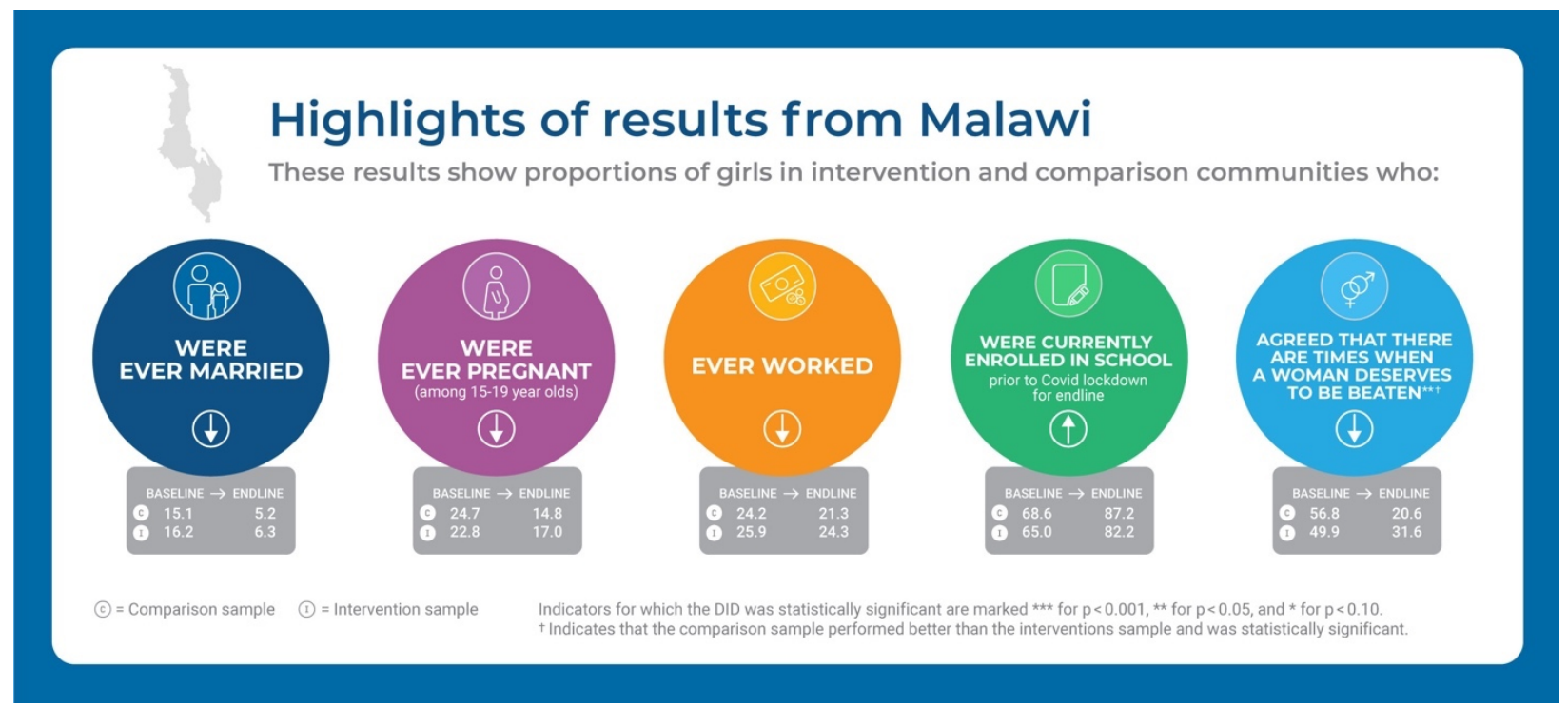

Table 9 presents impact evaluation results for Malawi. The arrows following INT and COM show the direction of change per indicator from baseline to endline in intervention and comparison areas, respectively. Indicators highlighted in blue show results for which the DID was significant and intervention areas performed better than comparison areas. Indicators highlighted in gold show results for which the DID was significant, but greater improvements were observed in comparison areas, relative to intervention areas.

Table 9. Endline Results, Malawi

\begin{tabular}{lll}
\hline \multirow{2}{*}{ Impact Area } & Indicator & $\begin{array}{l}\text { Direction of change from } \\
\text { baseline to endline }\end{array}$ \\
\hline \multirow{2}{*}{ Marriage } & Ever married & INT $\downarrow$ COM $\downarrow$ \\
& Can correctly identify legal age at marriage & INT $\uparrow$ COM - \\
Can name at least three adverse effects of child marriage & INT $\uparrow$ COM $\uparrow$ \\
Health & Mean age at marriage & INT $\uparrow$ COM - \\
\cline { 2 - 3 } & Ever pregnant (among girls 15-19) & INT $\downarrow$ COM $\downarrow$ \\
& Knows about HIV & INT $\uparrow$ COM $\uparrow$ \\
Livelihoods & Reports that their community has a youth-friendly health center & INT $\uparrow$ COM $\uparrow$ \\
\cline { 2 - 3 } & Contraceptive knowledge scale (modern methods) & INT $\uparrow$ COM $\uparrow$ \\
\cline { 2 - 3 } Education & Has ever worked for income & INT - COM - \\
\cline { 2 - 3 } & Is currently working for income & INT $\uparrow$ COM $\uparrow$ \\
\cline { 2 - 3 } & Currently enrolled in school (among ever enrolled) & INT $\uparrow$ COM $\uparrow$ \\
& Ever attended school & INT $\uparrow$ COM $\uparrow$ \\
& Mean number of years of education completed & INT $\uparrow$ COM - \\
& Cannot read or write & INT $\downarrow$ COM $\downarrow$ \\
\cline { 2 - 3 } & Agree that boys have the right to refuse an arranged marriage & INT $\uparrow$ COM - \\
\hline
\end{tabular}


Agree that girls have the right to refuse an arranged marriage

Gender- $\quad$ Agree that there are times when a woman deserves to be beaten

equitable

attitudes

Agree that a woman has a right to divorce

INT $\uparrow \mathrm{COM} \mathrm{-}$

INT $\downarrow$ COM $\downarrow$

Agree that she can disagree with her parents (parents in law)

INT $\uparrow \mathrm{COM}-$ about decisions affecting her

INT $\uparrow \mathrm{COM} \uparrow$

Social life

Report being part of a club or group

INT $\downarrow$ COM $\downarrow$

Note: Results highlighted in blue show indicators for which the DID was significant and intervention communities performed better than comparison communities. Results highlighted in gold show indicators for which the DID was significant and comparison communities performed better than intervention communities.

On the main indicator related to marriage, we see declines in both intervention and comparison areas. While this is encouraging, we do not see a significant difference in intervention areas suggesting that the decline in child marriage in Malawi over the project period may be due to larger factors beyond the project. In addition to declines in child marriage, knowledge of the adverse effects of marriage increased across both intervention and comparison areas. Knowledge of the legal age at marriage in Malawi increased significantly in intervention areas, showing program impact $(44.5 \%$ to $59.5 \%$ in intervention areas, compared to $45.6 \%$ to $51.1 \%$ in comparison areas).

We see similar trends on health outcomes: girls reporting ever being pregnant declined in both intervention and comparison areas from baseline to endline, but there was no significant difference. We also see steep increases in the proportion of girls reporting that their community has a youth-friendly health center (from $4.3 \%$ to $59.3 \%$ in intervention areas and from $3.8 \%$ to $52.7 \%$ in comparison areas). However, because these steep increases happened across intervention and comparison areas, we do not see significant differences that are attributable to the MNCP program.

In livelihoods and education, significant improvements occurred across both intervention and comparison areas. For example, the proportion of girls who reported currently working for income (among ever worked) increased by about 26 percentage points (a threefold increase) in intervention areas from baseline to endline $(13.1 \%$ to $39.0 \%)$ but also increased in comparison areas by a similar proportion (15.6\% to $47.3 \%)$. Girls also gained ground in current school enrollment increasing from $65 \%$ to $83.2 \%$ (intervention) and $68.6 \%$ to $87.9 \%$ (comparison). The MNCP program was successful in demonstrating impact on increasing the proportion of girls who ever attended school, with girls in intervention areas gaining more than girls in comparison areas $(p<.10)$. The MNCP was also successful in increasing mean years of education with girls in intervention areas gaining more than .5 years (3.9 to 4.5 mean years of education) while girls in comparison areas lost ground (4.7 to 4.6 mean years of education). The MNCP also showed significant effects on literacy: the proportion of girls who could not read or write dropped from 32.3 to $14.4 \%$ in intervention areas and from 21.4 to $13.2 \%(p<10)$ in comparison areas.

Since baseline, we see positive results with respect to gender-equitable attitudes, with more girls agreeing that girls have a right to refuse an arranged marriage, and more agreeing that girls have a right to divorce. These indicators showed a positive trend in intervention areas while mostly staying the same in comparison areas, though these findings were not statistically significant. However, there were steep declines in agreement with the statement that there are times a 
woman deserves to be beaten ( 49.9 to $31.6 \%$ in intervention areas and 56.8 to $20.6 \%$ in comparison areas) that were significant with comparison areas having a steeper decline.

Surprisingly, we find that fewer girls in both intervention and comparison areas report being a member of a club at endline than at baseline (declines from $24.6 \%$ to $23.5 \%$ from baseline to endline in intervention areas and $26.7 \%$ to $16.3 \%$ in comparison areas), though notably, girls in intervention areas reported less of a decline in club membership $(p=.109)$. This may be due in part to the influence of Covid-19-related restrictions including school closings, and mobility and gathering restrictions that limited the ability of clubs to meet regularly in 2020. 


\section{Endline Results: Mali}

\section{Background}

With $52.6 \%$ of girls married by age 18 and $18.3 \%$ of girls married by age 15 (INSTAT CPS/SSDS-PF and ICF 2019), Mali has the fifth highest prevalence of child marriage globally (UNICEF 2018). Within Mali there is some geographic variation: child marriage is mostly concentrated in the rural south-western parts of the country, with the highest proportions of women 20-24 reporting marriage by age 18 found in Kayes (75.2\%), Tombouctou (70.0\%), and Sikasso (58.8\%) (INSTAT CPS/SS-DS-PF and ICF 2019). In Segou-the second region where the MNCP program was implemented-the proportion of women 20-24 reporting marriage by age 18 is $52.8 \%$. From 2001 to 2018 , the proportion of women ages $20-24$ who were married by age 18 has declined from $70.6 \%$ to $53.7 \%$ and the proportion married by age 15 has declined from $24.6 \%$ to $15.9 \%$. There has been virtually no change however, in the proportion of teenage girls who have begun childbearing over the past decade (35.5\% in 2006 to $36.0 \%$ in 2018). An estimated $46.2 \%$ of girls have given birth before age 18 and $13.6 \%$ by age 15 .

As qualitative research from this project (Engebretsen et al. 2020) and others (Grosz-Ngate 2000; Hertrich and Lesclingand 2013) has shown, migration is common among adolescent girls in Mali and is influenced both by preparations for marriage and to avoid unwanted early marriage. Seasonal migration for agricultural work opportunities is also common in certain regions-at midline we found that seasonal migration among adolescent girls was common, especially in Segou (Melnikas et al. 2019). High child marriage in Mali may be related to lack of investment in girls' education. In Mali, access to education for girls is limited and about half of women 20-24 (52.0\%) report no formal education (INSTAT CPS/SS-DS-PF and ICF 2019). Among children of primary school age, 68.9\% report attending primary school (INSTAT CPS/SS-DS-PF and ICF 2019), which is higher than Niger (56.4) but far lower than other neighboring countries Cote d'Ivoire (94.9\%) and Guinea (89.4) (DHS stat compiler).

\section{Sample Characteristics}

In Table 10 we look at key demographics of the survey samples. We note that marriage declined from baseline to endline across samples, as did the proportion of girls who report never attending school and pregnancy. At endline, slightly more girls reported not being enrolled in school, which may be due in part to the timing of the survey and school closures. 
Table 10. Sample Characteristics, Mali

\begin{tabular}{|c|c|c|c|c|c|c|}
\hline & \multicolumn{2}{|c|}{ Baseline } & \multicolumn{2}{|c|}{ Midline } & \multicolumn{2}{|c|}{ Endline } \\
\hline & Intervention & Comparison & Intervention & Comparison & Intervention & Comparison \\
\hline Age (mean) & 15.2 & 15.3 & 15.1 & $14.9^{++}$ & 15.2 & 15.2 \\
\hline Ever married & 11.9 & 17.1 & $6.9^{+++}$ & $8.9^{+++}$ & 7.2 & $6.9^{+++}$ \\
\hline Never attended school & 32.7 & $40.8^{* *}$ & 30.6 & $48.5^{\star \star *_{+}}$ & $21.4^{+++}$ & $33.5^{\star \star *++}$ \\
\hline Not enrolled in school & 33.1 & 38.5 & 27.3 & 25.8 & $41.0^{++}$ & $48.3^{+++^{* \star}}$ \\
\hline Cannot read or write & 44.3 & 55.4 & 41.0 & 57.4 & $30.7^{+++}$ & $39.4^{+++* *}$ \\
\hline Ever pregnant (ages 15-19) & 20.1 & 24.4 & 17.9 & 22.1 & 13.4 & 17.5 \\
\hline
\end{tabular}

\section{Program Exposure}

The proportion of girls in intervention areas that report being aware of the MNCP program increased from $21.3 \%$ at midline to $36.2 \%$ at endline reflecting that the program succeeded in increasing name recognition and reaching more girls in these communities since the midline was conducted in 2018.

Figure 11. Proportion Who Report Being Aware of the MTBA Program in Intervention Areas, Midline to Endline, Mali

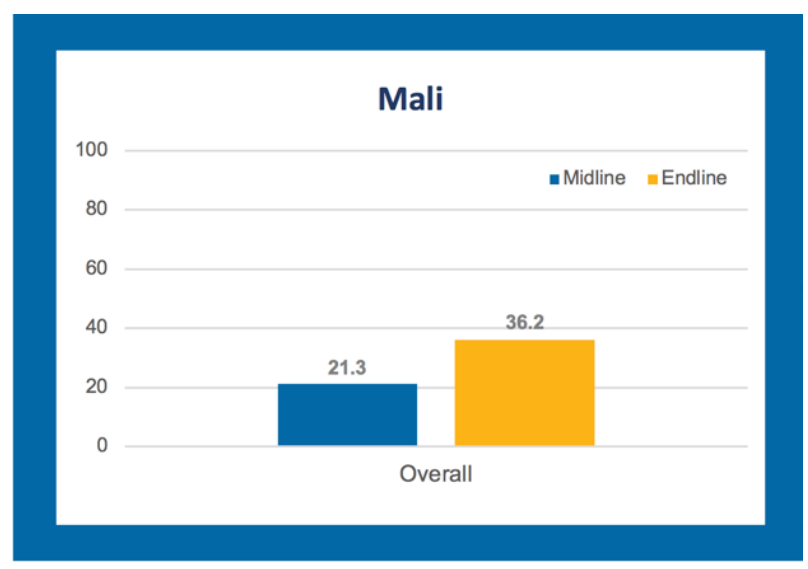




\section{Results}

Figure 12. Summary Results, Mali

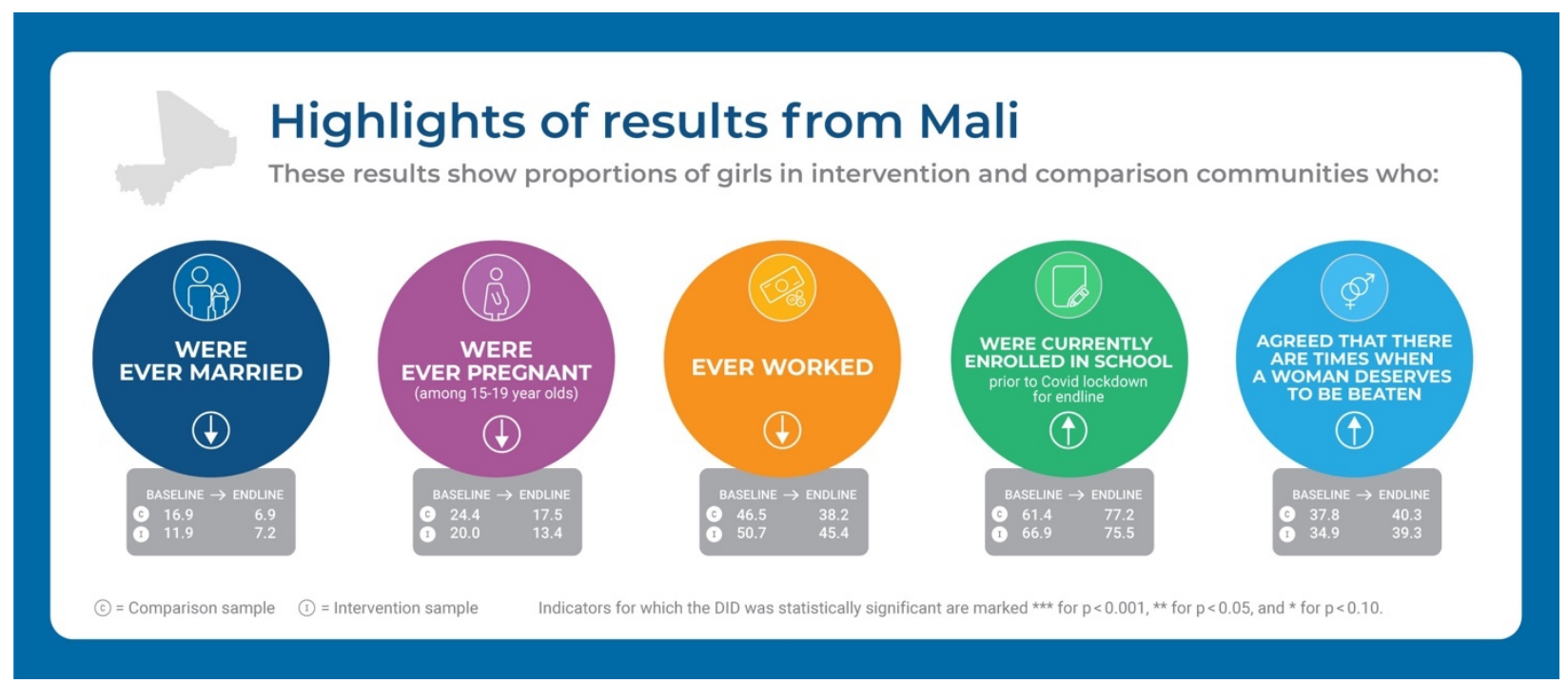

Table 11 presents impact evaluation results for Mali. The arrows next to INT and COM show the direction of change for each indicator between baseline and endline in intervention areas and comparison areas, respectively. Indicators highlighted in blue represent program impact (significant DIDs with intervention areas outperforming comparison areas). Indicators highlighted in gold represent results for which the DID was significant but comparison areas outperformed intervention areas.

Table 11. Endline Results, Mali

\begin{tabular}{|c|c|c|}
\hline Impact Area & Indicator & $\begin{array}{l}\text { Direction of change from } \\
\text { baseline to endline }\end{array}$ \\
\hline \multirow{4}{*}{ Marriage } & Ever married & INT $\downarrow \mathrm{COM} \downarrow$ \\
\hline & Can correctly identify legal age at marriage & INT - COM - \\
\hline & Can name at least three adverse effects of child marriage & INT $\uparrow \mathrm{COM} \uparrow$ \\
\hline & Mean age at marriage & INT $\uparrow$ COM - \\
\hline \multirow{5}{*}{ Health } & Ever pregnant (among girls 15-19) & $\mathrm{INT} \downarrow \mathrm{COM} \downarrow$ \\
\hline & Knows about HIV & INT - COM - \\
\hline & Knows that using a condom protects against HIV & INT $\uparrow \mathrm{COM} \uparrow$ \\
\hline & Reports that their community has a youth-friendly health center & INT $\uparrow \mathrm{COM} \uparrow$ \\
\hline & Contraceptive knowledge scale (modern methods) & INT $\uparrow \mathrm{COM} \uparrow$ \\
\hline \multirow{3}{*}{ Livelihoods } & Has ever worked for income & INT - COM $\downarrow$ \\
\hline & Is currently working for income & $\mathrm{INT} \downarrow \mathrm{COM} \downarrow$ \\
\hline & Currently enrolled in school (among ever enrolled) & INT $\downarrow$ COM $\downarrow$ \\
\hline \multirow{4}{*}{ Education } & Ever attended school & INT $\uparrow \mathrm{COM} \uparrow$ \\
\hline & Mean number of years of education completed & INT $\uparrow \mathrm{COM} \uparrow$ \\
\hline & Cannot read or write & INT $\downarrow$ COM $\downarrow$ \\
\hline & Agree that boys have the right to refuse an arranged marriage & INT $\uparrow \mathrm{COM} \uparrow$ \\
\hline
\end{tabular}




\begin{tabular}{|c|c|c|}
\hline \multirow{4}{*}{$\begin{array}{l}\text { Gender- } \\
\text { equitable } \\
\text { attitudes }\end{array}$} & Agree that girls have the right to refuse an arranged marriage & $\mathrm{INT} \uparrow \mathrm{COM} \uparrow$ \\
\hline & Agree that there are times when a woman deserves to be beaten & INT - COM - \\
\hline & Agree that a woman has a right to divorce & INT $\uparrow \mathrm{COM} \uparrow$ \\
\hline & $\begin{array}{l}\text { Agree that she can disagree with her parents (parents in law) about } \\
\text { decisions affecting her }\end{array}$ & $\mathrm{INT} \uparrow \mathrm{COM} \uparrow$ \\
\hline Social life & Report being part of a club or group & $\mathrm{INT} \downarrow \mathrm{COM} \downarrow$ \\
\hline
\end{tabular}

While the proportion of girls in the sample who reported ever being married declined from $11.9 \%$ to $7.2 \%$ in intervention communities and from $16.9 \%$ to $6.9 \%$ in comparison communities between baseline and endline, we did not see a significant difference in differences on this indicator. We observe this same trend in the proportion of girls able to identify three adverse effects of early marriage (from $13.6 \%$ to $22.1 \%$ in intervention communities and from $9.5 \%$ to $16.8 \%$ in comparison communities). On these two indicators, we conclude that the observed declines are likely the result of influences larger than the MNCP program alone. Despite a lack of impact on proportion of girls married, among girls who do marry, we see a significant impact on the age at marriage of girls in intervention areas (from 15.9 years to 16.8 years) suggesting that the program has an influence in delaying marriage to later years of adolescence for those who marry early.

Unfortunately, we do not see program impact on key health indicators in Mali. We do find decreases in the proportion of girls in the sample who report ever being pregnant in both intervention areas (from $20.0 \%$ to $13.4 \%$ ) and comparison areas (from $24.4 \%$ to $17.5 \%$ ) as well as increases in the proportion who know that using a condom protects against HIV $(44.6 \%$ to $75.1 \%$ in intervention villages and from $39.0 \%$ to $71.0 \%$ in comparison areas) and in the proportion reporting that their community has a youth-friendly health center (from $8.5 \%$ to $60.4 \%$ in intervention villages and from $8.2 \%$ to $63.4 \%$ in comparison villages). The dramatic increase in that indicator may reflect program efforts to increase awareness and availability of these resources, which may be situated to draw from multiple areas and may explain the increase in comparison areas. No significant changes were observed in the proportion of girls who knew about HIV or had correct knowledge about modern contraception methods.

In both intervention and comparison villages, we observed declines in the proportion of girls who reported currently working for income (from $50.9 \%$ to $45.3 \%$ in intervention communities and from $46.6 \%$ to $38.1 \%$ in comparison communities) and in the proportion reporting currently attending school (from $66.9 \%$ to $59.4 \%$ in intervention communities and from $61.4 \%$ to $51.7 \%$ in comparison communities). This may be impacted by Covid-19 as we know that schools were closed for part of 2020 in Mali and can assume livelihoods opportunities may have been limited as well.

Positive trends were observed with respect to education outcomes other than current enrollment, however. The proportion of girls reporting ever having attended school increased in both samples (from $67.3 \%$ to $78.6 \%$ in intervention communities and from $59.2 \%$ to $66.5 \%$ in comparison communities), as did the mean number of years of schooling completed (from 4.2 to 4.7 years in intervention communities and from 3.6 to 4.1 years in comparison communities). The proportion 
of girls who were unable to read or write additionally declined everywhere (from $44.3 \%$ to $30.7 \%$ in intervention villages and from $55.4 \%$ to $39.4 \%$ in comparison communities).

The proportion of girls who agreed that girls have the right to refuse an arranged marriage increased in both intervention and comparison villages with a significant DID, however the more significant increase was observed in comparison areas (from $22.8 \%$ to $54.46 \%$ vs. from $32.3 \%$ to $53.2 \%$ in comparison areas). We speculate some of this could be spillover from large community events focused on raising awareness of the rights of girls and harms of child marriage that may have exposed individuals in comparison areas.

Examining gender equitable attitudes, in both intervention and comparison samples, we find increases in the proportions of girls who agree that a woman should have the right to divorce (from $33.8 \%$ to $43.7 \%$ in intervention communities and from $34.1 \%$ to $45.6 \%$ in comparison communities) and who agree that a girl can disagree with her parents (or husband if she is married) about decisions affecting her life (from $24.1 \%$ to $34.0 \%$ in intervention communities and from $24.2 \%$ to $33.5 \%$ in comparison villages).

The proportion of girls reporting being part of a club or group declined similarly both in the intervention sample (from $61.6 \%$ to $14.9 \%$ ) and the comparison sample (from 58.3 to $13.4 \%$ ) from baseline to endline. School closures and other restrictions related to the Covid-19 pandemic likely played a role in this observed decline, as many MNCP girls' clubs took place at school, and increased workloads at home and worries related to the virus may have prevented girls from gathering elsewhere. 


\section{Endline Results: Niger}

\section{Background}

Unfortunately, due to concerns about data quality, the DHS Program did not release results from its 2017 surveys in Niger, meaning that the most recent available surveys are from 2012. According to the 2012 DHS, Niger has the world's highest prevalence of child marriage, with $77 \%$ of girls and women (25-49) marrying before age 18 and $28 \%$ marrying before age 15 . Prevalence data show that there has been a decline of 17 percentage points (from 83.5 to 66.3) in the proportion of women 20-24 married by age 18 over the period 1992-2012. Over this same period, the proportion married by age 15 declined by around 22 percentage points (from 50.3 to 28.0) (INS and ICF International 2013).

The practice of child marriage is deeply entrenched in Niger and has remained relatively stagnant over time compared with in neighboring countries (Fenn et al. 2015). The legal age of marriage for girls in Niger is 15 years old. Through recent MTBA research, we have found that in Niger, girls have mostly positive attitudes toward early marriage, considering marriage to be a rite of passage and a primary means of gaining the respect and admiration of one's peers and wider community. These attitudes appear to be influenced both by highly constrained educational and economic opportunities as well as by a strong socialization favoring obedience and the cultural practice of girls marrying seasonally in peer group cohorts (Saul et al. 2021). Thus, many girls in this context may feel that missing out on their perceived window of opportunity for marriage would be more detrimental to their futures than marrying early.

Other factors also influence the high proportion of child marriage in Niger. Polygamy is a common practice in Niger, with approximately $36 \%$ of currently married women in polygamous marriages. Polygamy has been found to be associated with child marriage, larger age differences between women and their husbands, which likely compounds power differentials between spouses (Wetheridge and Antonowicz 2014). Niger is also a country with considerable risk for negative climate effects including drought and consequently food insecurity. Recent insecurity and conflict also add to risks for child marriage as previous research suggests that factors such as conflict and displacement that increase financial uncertainty for families may lead to more child marriage (Alston et al. 2014; Mourtada et al. 2017). 


\section{Sample Characteristics}

In Table 12 we present sample characteristics for each of the three surveys. We note that the proportion reporting ever married has declined from baseline to endline across intervention and comparison areas and the proportion who report they never attended school had dropped. Pregnancy among girls 15-19 years of age increased in both intervention and comparison areas over the surveys $(12.7 \%$ at baseline to $19.6 \%$ at endline in comparison areas; $14.6 \%$ to $17.7 \%$ in intervention areas).

Table 12. Sample Characteristics, Niger

\begin{tabular}{|c|c|c|c|c|c|c|}
\hline & \multicolumn{2}{|c|}{ Baseline } & \multicolumn{2}{|c|}{ Midline } & \multicolumn{2}{|c|}{ Endline } \\
\hline & Intervention & Comparison & Intervention & Comparison & Intervention & Comparison \\
\hline Age (mean) & 15.2 & 15.3 & 15.1 & $14.9^{++}$ & 15.2 & 15.2 \\
\hline Ever married & 25.7 & 37.7 & $18.2^{++}$ & $26.3^{* \star *+++}$ & $16.0^{+++}$ & $15.9^{+++}$ \\
\hline Never attended school & 29.7 & $46.5^{\star \star *}$ & 25.0 & $45.1^{* \star \star}$ & 23.9 & $31.2^{+++^{\star \star}}$ \\
\hline Not enrolled in school & $27.5^{\star \star \star}$ & 49.0 & $29.0^{\star \star *}$ & 51.0 & $36.7^{+}$ & $43.0^{*}$ \\
\hline Cannot read or write & 45.0 & $64.0^{\star \star \star}$ & 44.7 & $63.5^{\star \star \star}$ & $22.9^{+++}$ & $31.9^{+++^{\star \star}}$ \\
\hline $\begin{array}{l}\text { Ever pregnant } \\
\text { (ages 15-19) }\end{array}$ & 14.6 & 12.7 & 10.7 & 19.0 & 17.7 & 19.6 \\
\hline
\end{tabular}

\section{Program Exposure}

Program exposure, measured as the proportion of girls in intervention areas who report being aware of the MNCP program increased substantially between midline (2018) and endline (2020), a nearly 40 percentage point increase $(25.3 \%$ to $63.0 \%)$ as shown in Figure 13. This suggests the program had success in improving name recognition and awareness of MNCP in intervention areas.

Figure 13. Proportion Who Report Being Aware of the MTBA Program in Intervention Areas, Midline to Endline, Niger

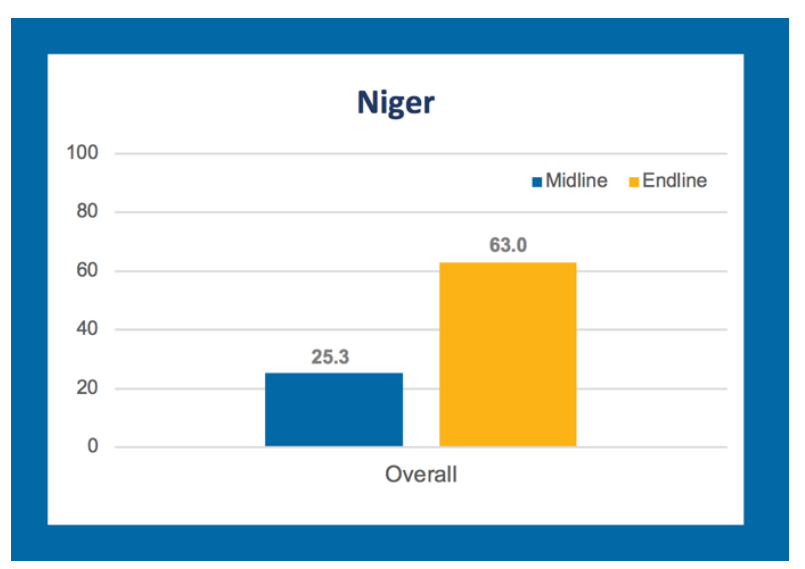




\section{Results}

Figure 14. Summary Results, Niger

\section{Highlights of results from Niger}

These results show proportions of girls in intervention and comparison communities who:
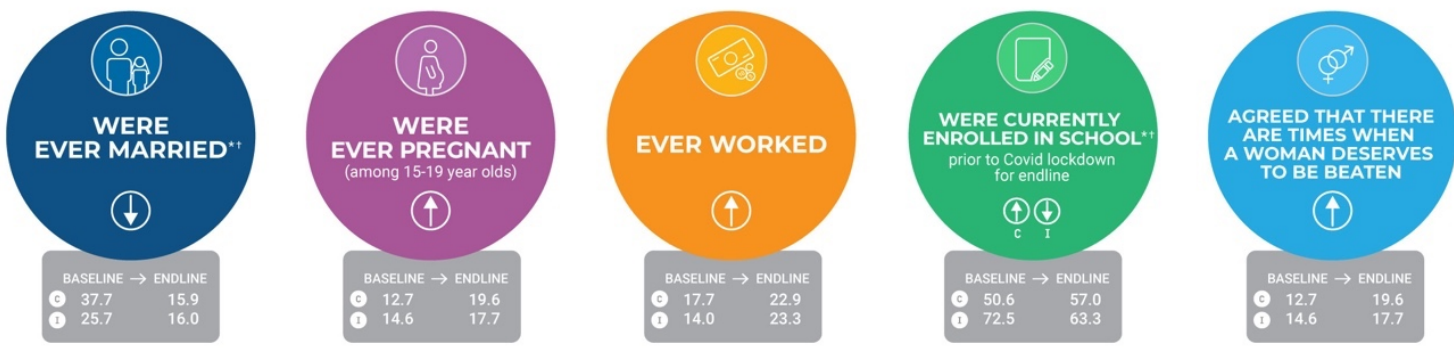

Main findings are presented in Figure 14, which shows key indicators compared from baseline to endline. Table 13 presents impact evaluation results for Niger. The arrows appearing next to INT and COM show the direction of change for each indicator between baseline and endline in intervention and comparison areas, respectively. Indicators highlighted in blue represent program impact (significant DIDs with intervention areas outperforming comparison areas). Indicators highlighted in gold represent results for which the DID was significant but comparison areas outperformed intervention areas.

Table 13. Endline Results, Niger

\begin{tabular}{lll}
\hline Impact area & Indicator & $\begin{array}{l}\text { Direction of change from } \\
\text { baseline to endline }\end{array}$ \\
\hline \multirow{4}{*}{ Marriage } & Ever married & INT $\downarrow$ COM $\downarrow$ \\
& Can correctly identify legal age at marriage & INT COM $\downarrow$ \\
& Can name at least three adverse effects of child marriage & INT $\uparrow$ COM - \\
& Mean age at marriage & INT $\uparrow$ COM - \\
\cline { 2 - 3 } Health & Ever pregnant (among girls 15-19) & INT - COM - \\
& Knows about HIV & INT $\uparrow$ COM - \\
& Knows that using a condom protects against HIV & INT $\uparrow$ COM $\uparrow$ \\
Livelihoods & Reports that their community has a youth-friendly health center & INT $\uparrow$ COM $\uparrow$ \\
& Contraceptive knowledge scale (modern methods) & INT $\uparrow$ COM $\uparrow$ \\
\cline { 2 - 3 } Education & Has ever worked for income & INT $\uparrow$ COM - \\
\cline { 2 - 3 } & Currently working for income & INT $\uparrow$ COM $\uparrow$
\end{tabular}




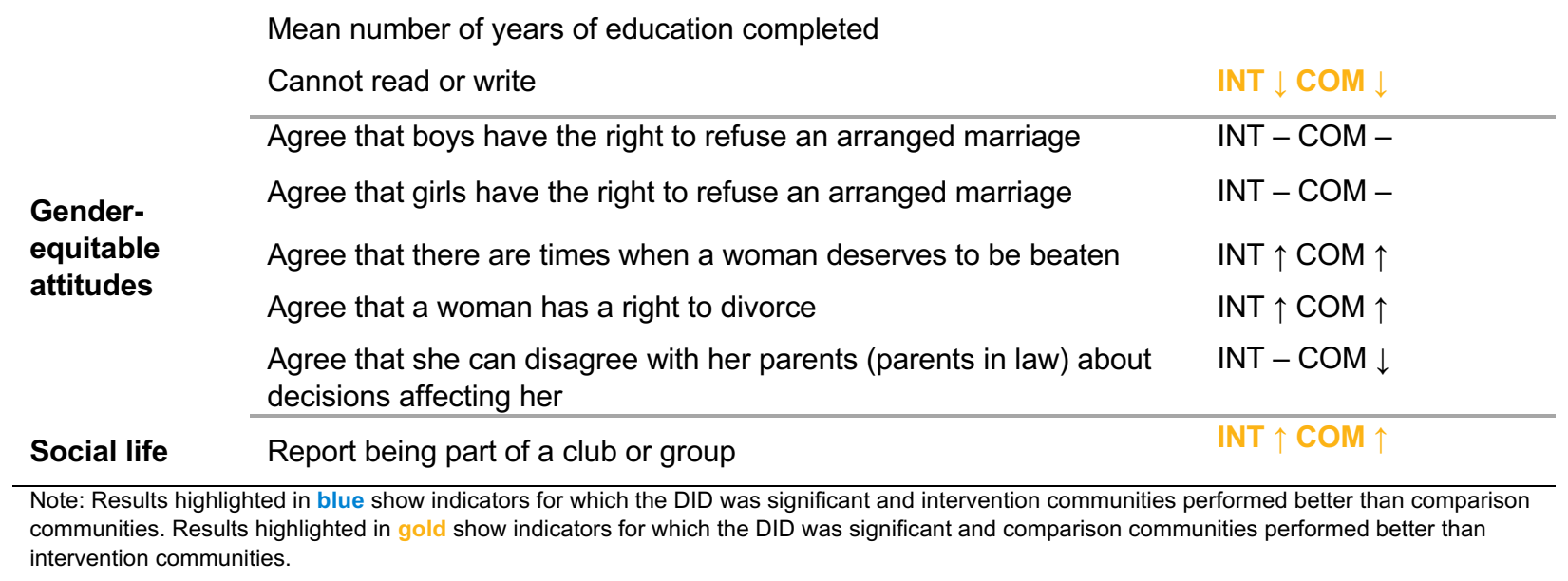

Looking at knowledge of adverse effects of child marriage in Niger, we find that girls in intervention areas performed significantly better than girls in comparison areas, with the proportion of girls able to name at least three adverse effects nearly doubling (from $15 \%$ to $29.6 \%$ ) and no significant change measured in comparison areas. We additionally note an increase in the proportion of girls able to correctly identify the legal age at marriage for girls in Niger, which increased from $18.9 \%$ to $31.9 \%$ in intervention communities with a significant DID.

We note that the proportion of girls reporting ever being married declined significantly in both intervention and comparison samples with a significant DID, however a more dramatic decrease was observed in comparison villages (from $37.7 \%$ to $15.9 \%$ ) relative to intervention villages $(25.7 \%$ to $16.0 \%)$.

An increase in mean age at marriage from 14.6 years to 16.5 years was observed in intervention areas with no change observed in comparison areas (mean age remaining at 15.1 years), however the DID was not significant.

From baseline to endline, we detected increases in knowledge of modern contraceptive methods in both intervention and comparison villages with a significant DID, suggesting that the MNCP program had an impact on these indicators. Knowledge of contraceptive methods increased from $48.3 \%$ to $64.4 \%$ in intervention villages and from $49.3 \%$ to $56.5 \%$ in comparison villages.

In both intervention and comparison areas, we observed increases in the proportion of girls who knew that using a condom protects against HIV (from $18.3 \%$ to $38.7 \%$ in intervention areas and from $18.3 \%$ to $27.9 \%$ in comparison areas) and in the proportion who reported that their community has a youth-friendly health center (from $2 \%$ to $17.9 \%$ in intervention villages and from $2 \%$ to $15.6 \%$ in comparison villages).

The proportion of girls reporting currently working for income increased significantly in both intervention and comparison communities, with a significant DID. This proportion increased more in intervention villages (from $23.8 \%$ to $67.1 \%$ ) than in comparison villages (66\% to $72.5 \%$ ), suggesting that the MNCP intervention may have played a role in successfully connecting girls to work opportunities. 
Looking at the education indicators, the proportion of girls currently enrolled in school declined in intervention areas (from $72.5 \%$ to $63.3 \%$ ) while remaining relatively stable in comparison areas (increasing from $50.6 \%$ to $57 \%$; gain not significant), representing a convergence across settings. Losses due to the Covid-19 pandemic and related school closures may have the effect of erasing any gains made in girls' school enrollment in intervention areas since midline. The proportion of girls unable to read or write declined in both samples, but less in intervention villages (from $45 \%$ to $22.9 \%$ versus from $64 \%$ to $31.9 \%$ in comparison villages).

In gender-equitable attitudes, trends are not always moving in the desired direction, perhaps reflecting deeply entrenched norms around marriage or difficulty translating this question to the Nigerien context. Although on some indicators, including the proportion who agreed that a woman should have the right to divorce, girls in intervention areas showed improvements in the desired direction (from $22.3 \%$ to $35 \%$ ). However, we do not find a significant impact when compared to the comparison areas.

At endline, significantly more girls reported being part of a club or group in both comparison and intervention areas. While comparison areas performed better (from $28 \%$ to $79 \%$ ), intervention areas also saw a large increase (from $21 \%$ to $86 \%$ ). 


\section{CHAPTER 8}

\section{Discussion}

\section{Trends in Marriage: Baseline-Midline-Endline}

Throughout this report, we have presented results from baseline to endline by country to demonstrate how the same program appears to have impacted different indicators across settings over the course of program implementation. Here, we briefly examine trends in child marriage from baseline to midline and from midline to endline. Including the midline data point allows us to see whether and how trends from baseline to midline may have continued, accelerated, or stalled in the final years of the program. Baseline-midline-endline trends for additional key indicators are included in Annex 3.

Figure 15. Trends in Girls Ever Married, Baseline-Midline-Endline

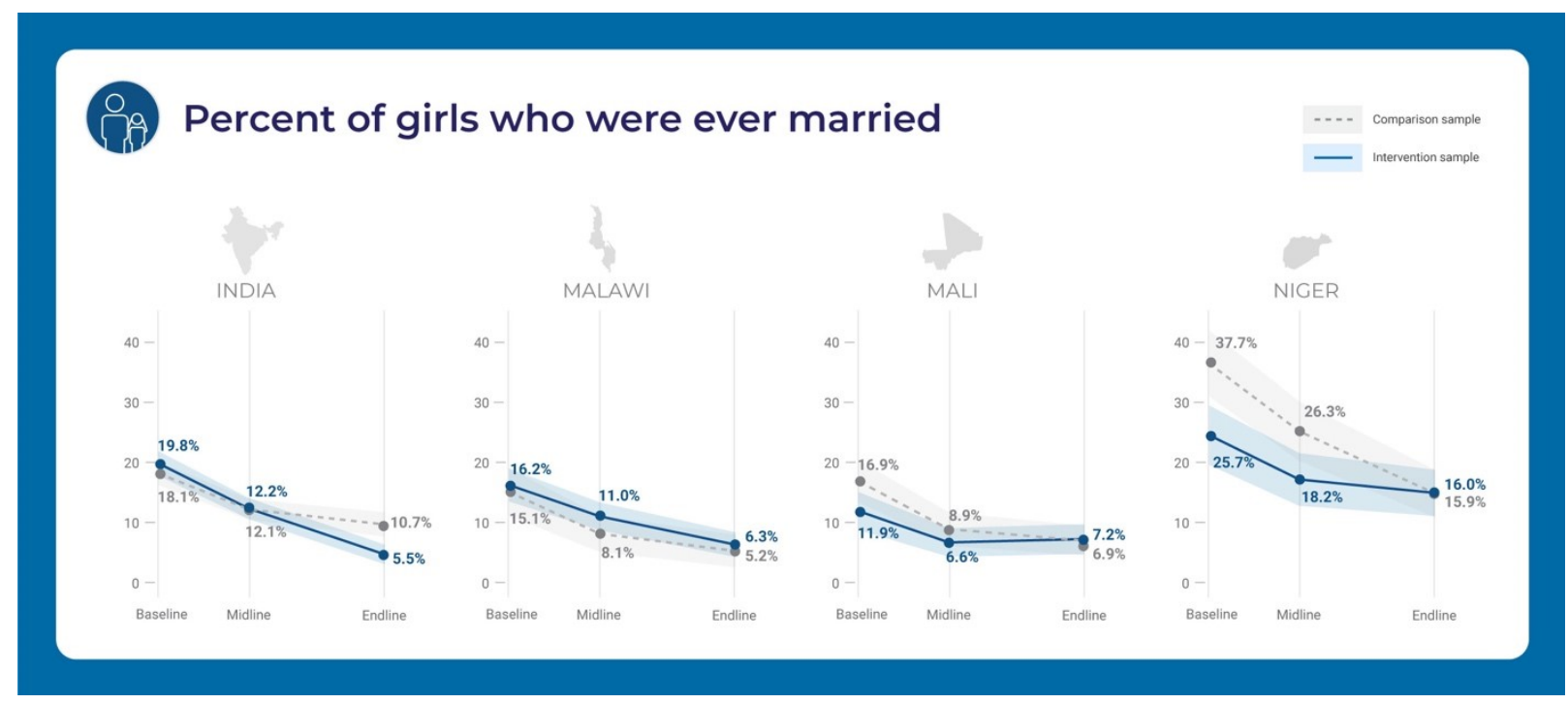

Figure 15 shows trends in prevalence of child marriage across countries, including data points in intervention and comparison samples for each survey round with corresponding $95 \%$ confidence intervals (represented as shaded areas around each trendline). In India, the baseline to midline slope remained relatively constant from midline to endline in intervention areas but declined slightly in comparison areas over the final years of the program. In Malawi, early declines continued until the end of the program across both intervention and comparison areas, while in Mali, gains made from baseline to midline appear to have stalled since midline. Interestingly, in Niger, in comparison areas we see a steep decline in child marriage prevalence over all three time points, whereas in intervention areas, we see a similar steep decline from baseline to midline but then a slower decline since midline, with both groups converging at about $16 \%$ of girls reporting ever being married at the end of the program.

The prevalence of marriage declined in all samples over the MNCP implementation period, but only in India was the change attributable to the intervention (declines observed in intervention 
areas were significantly greater than those observed in comparison areas). We note that the MNCP took place during a time of significant declines in child marriage globally. In this context, increased advocacy at both the global and national levels has likely influenced real declines in child marriage and has perhaps also reduced reporting, as awareness of the harms and/or illegality of the practice appears to have increased at the community level over this period.

\section{MNCP Intervention Impact}

Table 14 shows indicators on which the MNCP program demonstrated significant impact relative to changes observed over the intervention period in similar villages where the MNCP program was not present.

Table 14. Summary of Impact Results

\begin{tabular}{|c|c|c|c|c|}
\hline & India & Malawi & Mali & Niger \\
\hline \multicolumn{5}{|l|}{ Marriage } \\
\hline Currently married & INT $\downarrow$ COM $\downarrow$ & & & \\
\hline Mean age at marriage & & \multicolumn{3}{|c|}{ INT $\uparrow \mathrm{COM}-$} \\
\hline Can correctly identify legal age at marriage & INT $\uparrow \mathbf{C O M} \uparrow$ & INT $\uparrow \mathrm{COM}-$ & & INT $\uparrow \mathrm{COM} \downarrow$ \\
\hline $\begin{array}{l}\text { Can name at least three adverse effects of child } \\
\text { marriage }\end{array}$ & INT $\uparrow \operatorname{COM} \uparrow$ & & & INT $\uparrow \quad C O M-$ \\
\hline \multicolumn{5}{|l|}{ Health } \\
\hline Knows about HIV & INT $\uparrow \mathrm{COM} \uparrow$ & & & \\
\hline $\begin{array}{l}\text { Contraceptive knowledge scale (modern } \\
\text { methods) }\end{array}$ & & & & INT $\uparrow \mathrm{COM} \uparrow$ \\
\hline \multicolumn{5}{|l|}{ Livelihoods } \\
\hline Is currently working for income & & & & INT $\uparrow \mathrm{COM} \uparrow$ \\
\hline \multicolumn{5}{|l|}{ Education } \\
\hline Ever attended school & & INT $\uparrow \operatorname{COM} \uparrow$ & & \\
\hline \multicolumn{5}{|l|}{$\begin{array}{l}\text { Currently enrolled in school (among ever } \\
\text { enrolled) }\end{array}$} \\
\hline \multicolumn{2}{|l|}{ Mean number of years of education completed } & INT $\uparrow \mathrm{COM}-$ & & \\
\hline Cannot read or write & & INT $\downarrow$ COM $\downarrow$ & & \\
\hline \multicolumn{5}{|l|}{ Social life } \\
\hline Report being part of a club or group & INT $\uparrow \mathrm{COM}-$ & & & \\
\hline
\end{tabular}

Beyond the finding that the intervention in India demonstrated impact in reducing prevalence of child marriage (or in preventing increases in child marriage, as seen in comparison areas in some Indian states), impact was detected on a few other indicators related to marriage age, knowledge of child marriage, and SRHR knowledge. In Mali, the program demonstrated impact in increasing the mean age at marriage for girls. In India, Malawi, and Niger, the MNCP intervention appears to have played a role in increasing the proportion of girls who could correctly identify the legal age at marriage, and in India and Niger the program additionally increased awareness of the adverse effects of child marriage among girls at the community level. The 
MNCP intervention appears to have increased the proportion of girls who had knowledge about HIV in India and the proportion of girls with knowledge of modern contraceptives in Niger. Findings thus suggest that the MNCP program has had the strongest impact on influencing knowledge-related indicators. The MNCP program appears to also be able to influence key behavioral outcomes, although questions remain about why we only see impact in some settings.

Endline results detect minimal impact on indicators related to livelihoods, but more impressive results with respect to girls' education. In Malawi in particular, the MNCP intervention was able to achieve demonstrable impact on several indicators related to education, namely increasing the proportion of girls who had ever attended school, increasing the mean number of years of education completed, and decreasing prevalence of illiteracy among 12-19-year-old girls. In India, the program had an impact on increasing the proportion of girls in the community who were currently enrolled in school. In India, the MNCP program also demonstrated impact in increasing girls' engagement in groups, clubs, or associations. These improvements suggest that the MNCP program may have effectively impacted girls' and parents' commitment to girls' education, despite the challenges of remote schooling brought about by the Covid-19 pandemic.

In Niger, we find that the MNCP program demonstrated impact in increasing the proportion of girls currently working for income. The lack of program impact on most livelihood indicators may be due in part to the influence of Covid-19 and related restrictions, which caused local and national economies to contract and further limited work opportunities available to adolescent girls. Gains in school enrollment may partially explain lack of improvement in livelihood indicators, as in some areas keeping girls in school was emphasized over increasing girls' engagement in incomegenerating activities.

Despite MNCP program efforts to change social norms that perpetuate the practice of child marriage, we did not find demonstrable impact on indicators related to gender-equitable attitudes. We recognize the difficulty of changing deeply ingrained attitudes and norms about the roles of girls and women in contexts where child marriage remains entrenched at high levels. For example, it may be difficult for adolescent girls to agree that girls have a right to refuse an arranged marriage if they have never seen this occur in their communities.

\section{Challenges for Demonstrating Impact}

The endline evaluation was designed to produce comparable data across contexts, assessing program impact relative to comparison groups. The MNCP may claim impact on key indicators when the change in intervention areas is significantly greater than the change in comparison areas. We find positive trends on key outcomes_-including child marriage, education, and pregnancy-in most intervention areas. The lack of program impact detected may be due to a number of factors related to potential sources of contamination and spillover effects, program placement, and measurement challenges.

As the problem of child marriage has gained traction in the development sector in recent years, an increasing number of programs aim to educate communities about the harms of the practice and work toward its eradication, complicating efforts to measure program areas against "control" communities. Other programs addressing child marriage may have been active in comparison areas over the period of the MNCP intervention, introducing potential sources of contamination. We also know that multisectoral programs like MNCP tend to work with actors on different levels, which may cause spillover effects in comparison areas. For example, the impact of advocacy 
work with national or provincial government officials is likely not contained to specific "intervention" villages or zones.

Additionally, the placement of the MNCP program in areas where previous interventions had taken place (as was the case in Mali and Niger) rather than in areas selected through randomization (as in India and Malawi) may have inadvertently influenced findings that favored comparison areas in the impact evaluation. For example, comparison areas were relatively disadvantaged at baseline due to the challenges of matching to preselected intervention areas on factors like access to a major roadway and presence of a school within the community (see Annex 2). Therefore, improvements in comparison areas from baseline to endline may have offset gains made in intervention areas in the analysis. Note that in Figure 15 you can see clearly the effect of randomization, looking at the difference between the intervention and comparison samples at baseline in India and Malawi compared with the difference between the two samples in Mali and Niger: in countries where the selection of intervention villages was randomized, the proportion married at baseline overlapped across treatment status.

As we note, child marriage is declining globally and as the practice becomes less common (or less commonly reported) it also becomes more difficult to detect program impact. This is because as incidence declines, larger sample sizes are needed to detect significant impact. It may also become increasingly difficult to accurately measure child marriage prevalence as increasing knowledge of minimum marriage age laws and growing recognition of the harms of child marriage may encourage underreporting. Trends and patterns in migration may also distort measures of program impact at the community level, as girls who may have interacted with the program but then migrated away from their villages are not captured in intervention communities at endline. Qualitative research suggests that in Mali, for example, migration is common among adolescent girls (Hertrich and Lesclingan 2013; Engebretsen et al. 2020). In areas of Mali characterized by high rates of adolescent migration, repeat cross-sectional surveys will undercount the prevalence of girls who are attending school, are engaged in income-generating activities, or are married when girls have moved away from their villages for one of these reasons. 


\section{Study Limitations}

The MNCP endline study has a number of limitations to consider alongside results. Disruptions related to the Covid-19 pandemic upended typical ways of working across the sector and forced significant changes in our data-collection methodology. At baseline and midline, data were collected through household listings and in-depth interviews with girls 12-19 in their homes or in a private space of their choosing. In order to complete the endline evaluation in 2020, however, data-collection teams had to adapt to infection-control restrictions, including limits on travel and on face-to-face data collection that were in a place, by switching to phone-based surveys. The survey content was spread over multiple phone calls, and additional surveys with parents or other adults in girls' households were conducted to gather information normally collected during the household listing exercise. As a result, differences between the girls sampled at endline and those sampled at baseline and midline may have influenced results (see MNCP baseline and midline reports for characteristics of each sample in previous rounds of this study). We also followed an abbreviated data-collection timeline, finishing data collection and analysis in the first quarter of 2021, after many staff involved in implementing the MNCP program had moved on to other positions. This limited our ability to engage closely with program staff in interpreting the results as we had done following the midline evaluation.

We note that phone ownership and access is not ubiquitous in each of these countries but is especially limited in Malawi and Niger. Girls who were able to complete the endline phone surveys may be different from girls who would have been surveyed in face-to-face interviews. High rates of migration in some contexts, particularly in Mali, posed additional challenges to our sampling methodology. We had to over-sample in some areas because so many adolescent girls were no longer in the village and had left for marriage, schooling, work, or to stay with family members in other communities. As research adaptations made in response to the Covid-19 pandemic will likely persist in contexts of ongoing crisis or insecurity, future adolescent surveys will need to plan for these changes. Addressing unequal access to mobile phones and the movement of adolescents will be essential to maximize validity and reliability of study samples and increase the chances that evaluations will be able to detect any program impact at the community level.

\section{Implications for Future Programs}

A key contribution of the MNCP evaluation is the opportunity it presents to examine the effects of a multisectoral program to reduce child marriage across diverse contexts. The MNCP project was a community-level intervention that included proven strategies-such as girls' clubs that deliver sexual and reproductive health and rights education and connect girls to health and education services-combined with strategies aimed at strengthening an enabling environment for girls, including interventions engaging parents, the wider community, and government officials. This project was implemented in India, where child marriage prevalence has been declining over the last decade, and in Niger where the practice remains stubbornly high. The intervention was implemented in contexts where premarital sex is rare and taboo (Niger and India) and where premarital sex is more common (Mali and Malawi).

Despite a similar approach in each context, we see uneven results, with India's intervention demonstrating the most impact. The results of the MNCP evaluation challenge our conception that it is easier to demonstrate effectiveness in areas where child marriage is highest. Indeed, we see significant improvements in child marriage even in Odisha, India, where child marriage prevalence was $8.9 \%$ among girls $12-19$ in intervention areas at baseline, while we do not see 
significant improvements in Niger where prevalence at baseline was $25.7 \%$. Our results suggest that even in areas where prevalence is low or declining, child marriage programs may be able to have an impact-perhaps because these areas are already primed for change.

Our results additionally suggest the need for further adaptation of programs to account for contextspecific factors contributing to child marriage including premarital sex and pregnancy, the reality of marriage as a livelihood strategy for girls and women, and the increasing phenomenon of adolescent girls' migration. Where interventions have emphasized SRHR information and services yet premarital pregnancy continues to be a significant driver of child marriage, programs must strengthen their focus on the enabling environment to more closely address the reality that becoming pregnant and marrying early may represent a means of securing one's livelihood for many girls in these contexts. Efforts to address child marriage that do not adequately address poverty and alternative livelihoods opportunities for girls, for example, will likely fall flat. Additionally, we expect adolescent migration to increase in many contexts over the coming years. In order to maximize impact, programs operating in affected areas must adapt their strategies to work in dynamic communities with increasingly mobile populations.

By implementing multisectoral programs in widely varied settings where child marriage is high either in terms of absolute numbers or in terms of prevalence, the MNCP program makes an invaluable contribution. Overall, our data suggest that programs such as MNCP can make an important contribution to ending the practice of child marriage. Where we are able to methodologically identify the impact of programs at the community level-such as in India and to a lesser extent in Niger-we see that the specific approach adopted by MNCP of engaging communities while focusing on girls had considerable impact on girls' schooling and health indicators. In general, we see positive trends over the four years that we observed change. These are promising results and should encourage continued investments to bring about positive changes in the lives of adolescent girls in these communities. 


\section{Annex 1: Implementing Partners by Country and State/Region}

\begin{tabular}{|c|c|c|c|c|}
\hline Country & State/Region & $\begin{array}{l}\text { Alliance } \\
\text { partner(s) }\end{array}$ & Local implementing partners & $\begin{array}{l}\text { No. of } \\
\text { villages }\end{array}$ \\
\hline \multirow{6}{*}{ India } & Jharkhand & Simavi & $\begin{array}{ll}- & \text { Network for Enterprise Enhancement and } \\
& \text { Development Support (NEEDS) } \\
- & \text { Child in Need Institute (CINI) }\end{array}$ & 279 \\
\hline & & Simavi & $\begin{array}{l}\text { - Save the Children India } \\
\text { - Bihar Voluntary Health Association (BVHA)* }\end{array}$ & \\
\hline & Bihar & Save the & - Fakirana Sister Society (FSS)* & 75 \\
\hline & & Children NL & $\begin{array}{ll}- & \text { Samagra Seva Kendra (SSK) } \\
- & \text { Center for Health and Resource Management } \\
& (\text { CHARM) }\end{array}$ & \\
\hline & Odisha & $\begin{array}{l}\text { Save the } \\
\text { Children NL }\end{array}$ & $\begin{aligned}- & \text { Save the Children India } \\
- & \text { Association for Social and Health Advancement } \\
& \text { (ASHA-ODISHA) } \\
- & \text { Social Welfare Agency and Training Institute } \\
& \text { (SWATI) } \\
- & \text { Voluntary Health Association of India (VHAI) }\end{aligned}$ & 210 \\
\hline & Rajasthan & $\begin{array}{l}\text { Save the } \\
\text { Children NL }\end{array}$ & $\begin{array}{l}-\quad \text { Save the Children India } \\
-\quad \text { Shiv Shiksha Samiti Ranoli (SSSR) } \\
-\quad \text { Urmul }\end{array}$ & 45 \\
\hline \multirow[b]{2}{*}{ Pakistan** } & Punjab & Oxfam Novib & $\begin{array}{l}\text { - Oxfam Pakistan } \\
\text { - Bedari }\end{array}$ & 40 \\
\hline & Sindh & Oxfam Pakistan & $\begin{array}{l}\text { - Oxfam Pakistan } \\
-\quad \text { International Rescue Committee (IRC) } \\
- \text { Baanhn Beli }\end{array}$ & 40 \\
\hline \multirow{2}{*}{ Malawi ${ }^{* * *}$} & Mangochi & Simavi & - Youth Network and Counselling (YONECO) & 108 \\
\hline & Nkhata Bay & Simavi & - Girls Empowerment Network (GENET) & 45 \\
\hline \multirow{2}{*}{ Mali } & Segou & $\begin{array}{l}\text { Save the } \\
\text { Children NL }\end{array}$ & $\begin{array}{l}\text { - Save the Children Mali } \\
\text { - } \quad \text { AGIR pour l'environnement et la qualité de vie }\end{array}$ & 30 \\
\hline & Sikasso & Oxfam Novib & $\begin{array}{l}\text { - Oxfam Mali } \\
\text { - WALE } \\
\text { - FAWE } \\
\text { - } \text { A Soro }\end{array}$ & 12 \\
\hline \multirow[t]{2}{*}{ Niger } & Maradi & $\begin{array}{l}\text { Save the } \\
\text { Children NL }\end{array}$ & $\begin{array}{l}- \text { Save the Children Niger } \\
- \text { Association pour le Bien-Etre Familiale (ANBEF) } \\
- \text { SongES } \\
- \text { ASEC Mungane } \\
- \text { ADD Fassali }\end{array}$ & 10 \\
\hline & Tillabéri & Oxfam Novib & $\begin{array}{ll}- & \text { Oxfam Niger } \\
- & \text { SOS Femmes et Enfants Victimes de Violence } \\
& \text { Familiale (SOS FEVVF) } \\
- & \text { Association pour le Bien-Etre Familiale (ANBEF) }\end{array}$ & 32 \\
\hline
\end{tabular}

*Population Council's MNCP evaluation did not involve communities working in BVHA or FSS areas in Bihar.

${ }^{* *}$ Population Council's MNCP evaluation did not cover the intervention in Pakistan.

${ }^{* * *} \mathrm{MNCP}$ was also implemented in Mchinji but that part of the program was removed from the research due to the presence of a preexisting largescale livelihoods initiative. 


\section{Annex 2: Study Design Differences}

\section{Cluster Randomized Cross-Sectional Design in India and Malawi}

In India and Malawi, the MNCP program was not designed to build from an existing intervention (as was the case in Mali and Niger) and thus the research team was able to randomize implementation of the MNCP intervention. A cluster randomized cross-sectional design was used because treatment occurs at the community level and includes multiple focus areas; this design allows for a comparison of the full MNCP program in intervention areas with the absence of the intervention in comparison areas. In mid-2016, clusters (gram panchayats in India; group head villages in Malawi) were randomly assigned to either intervention or comparison groups, with an equal number of clusters designated in each group. The research unit is the EA: we matched group head villages with EAs based on GPS points provided by the program.

In Malawi, the number of clusters was influenced by implementing partners' geographical presence and the existence of a similar livelihoods program in one of the planned study areas. In Mchinji, the existence of a large livelihoods program was deemed too big a threat to our ability to assess impact and was therefore dropped from the impact evaluation sample, though Mchinji remains an MNCP intervention area. Unfortunately, contamination issues in Malawi resulted in some clusters that had been assigned as comparison areas at baseline receiving the intervention, and one cluster that was planned as intervention had not received any activities by mid-2018. As a result of these issues and because the scale of the contamination was larger than we could absorb within our sample, we present as-implemented results in Malawi as the only adjustment in the DID analysis.

In India, we have a larger sample compared to the other countries and are thus able to provide state-level comparisons. In India, we randomly assigned gram panchayats (GP) as either intervention or comparison areas and used corresponding PSUs as the research unit. Although some activities occur at the district or block level and may influence GPs designated as comparison, any activities occurring at lower geographic levels were implemented only in designated intervention GPs.

\section{Quasi-Experimental Matched Design in Mali and Niger}

In Mali and Niger, MNCP site selection was shaped by implementers' decision to build on a previous program - the My Rights My Voice program - which was implemented in approximately 20 communities in Mali and 15 communities in Niger and focused on building community support to delay marriage. Because of the existence of My Rights My Voice and experience selecting and working with local partners in Mali and Niger, MNCP partners decided to build upon those programs and to implement in those same communities. As a result, a quasi-experimental matched design was implemented for this cross-sectional study. Comparison communities were selected based on their similarities to communities that had implemented My Rights My Voice. Where possible, we tried to match comparison communities to intervention communities on the following criteria: 
1. May have been selected as an intervention community for My Rights My Voice based on village's accessibility;

2. Had a similar number of schools;

3. Had a similar number of health centers; and

4. Was similar in population size.

As Mali and Niger built on existing programs already being implemented in select communities, MTBA implementation was limited to those select areas, including 50 villages in Mali and 42 villages in Niger. Consequently, sample size was limited; we were unable to randomly assign the intervention and thus needed to find suitable matches to the selected intervention villages. Our sample sizes were limited to 40 clusters in Mali (20 intervention and 20 matched comparisons) and to 30 clusters in Niger (15 intervention and 15 comparison). Sample size calculations may be found in baseline reports available at https://morethanbrides.org. 


\section{Annex 3: Trends in Key Indicators: Baseline-Midline-Endline}

The following figures present trends in key indicators across the three rounds of the MNCP evaluation in India, Malawi, Mali, and Niger. Proportions are presented for both intervention samples and comparison samples, with 95\% confidence intervals represented as the shaded bands around each trendline. We summarize key trends for each indicator below.

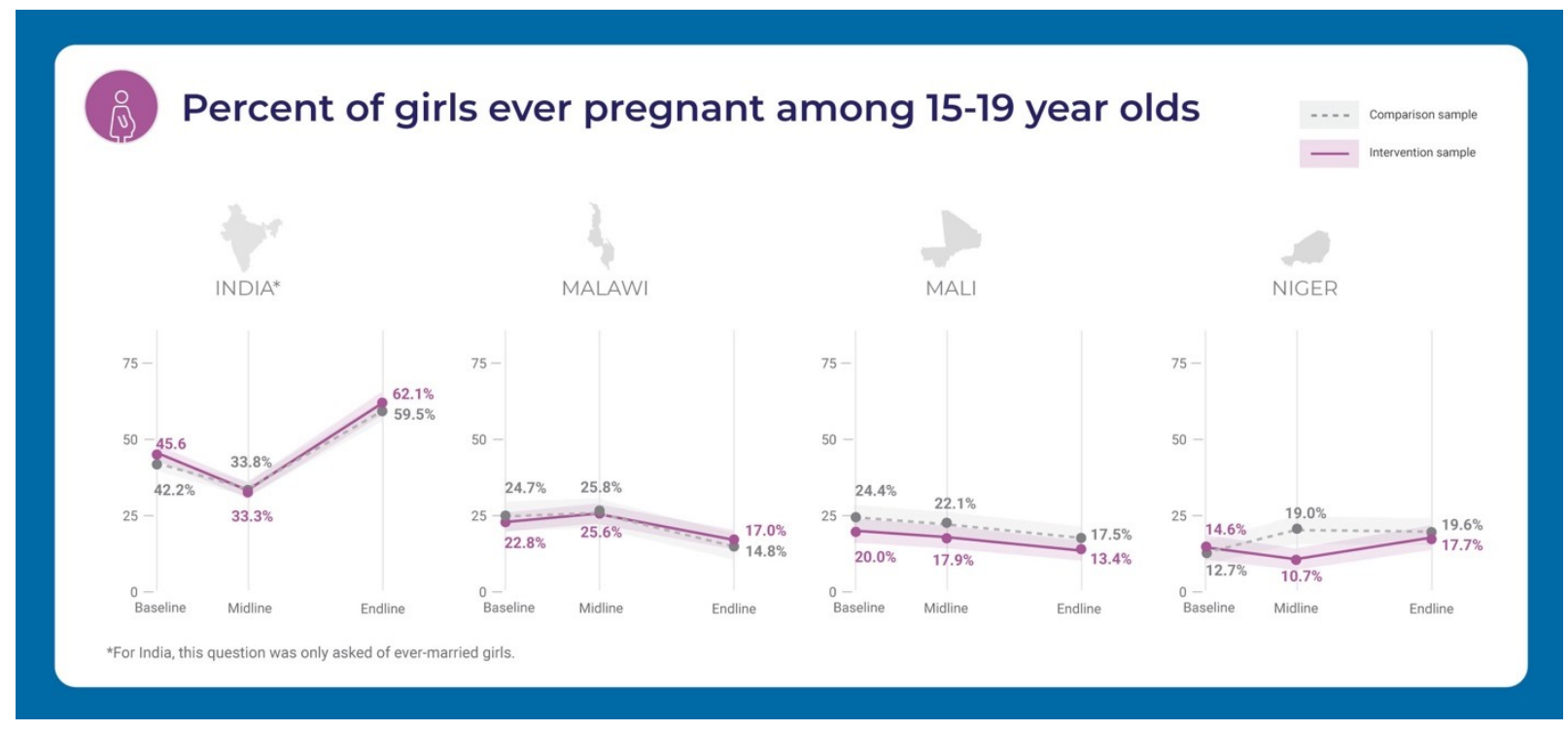

Looking at prevalence of pregnancy among adolescent girls in the samples, trends in India stand out. Since in India questions related to pregnancy were asked only of married girls ages 15-19, the data presented on this indicator for India reflect only pregnancy among married girls and are not comparable with data presented for the other three countries. In the other three countries, we note that the proportion of girls reporting ever being pregnant remained relatively stable over the program period. In Niger-where rates of child marriage are highest and data suggest sexual initiation occurs almost exclusively within marriage-most reported pregnancies are likely among married girls. In Malawi and Mali, on the other hand, the proportion of girls reporting ever being pregnant is higher than the proportion of girls reporting ever being married at each round of the study, suggesting that premarital pregnancies are occurring among adolescents in these settings. 


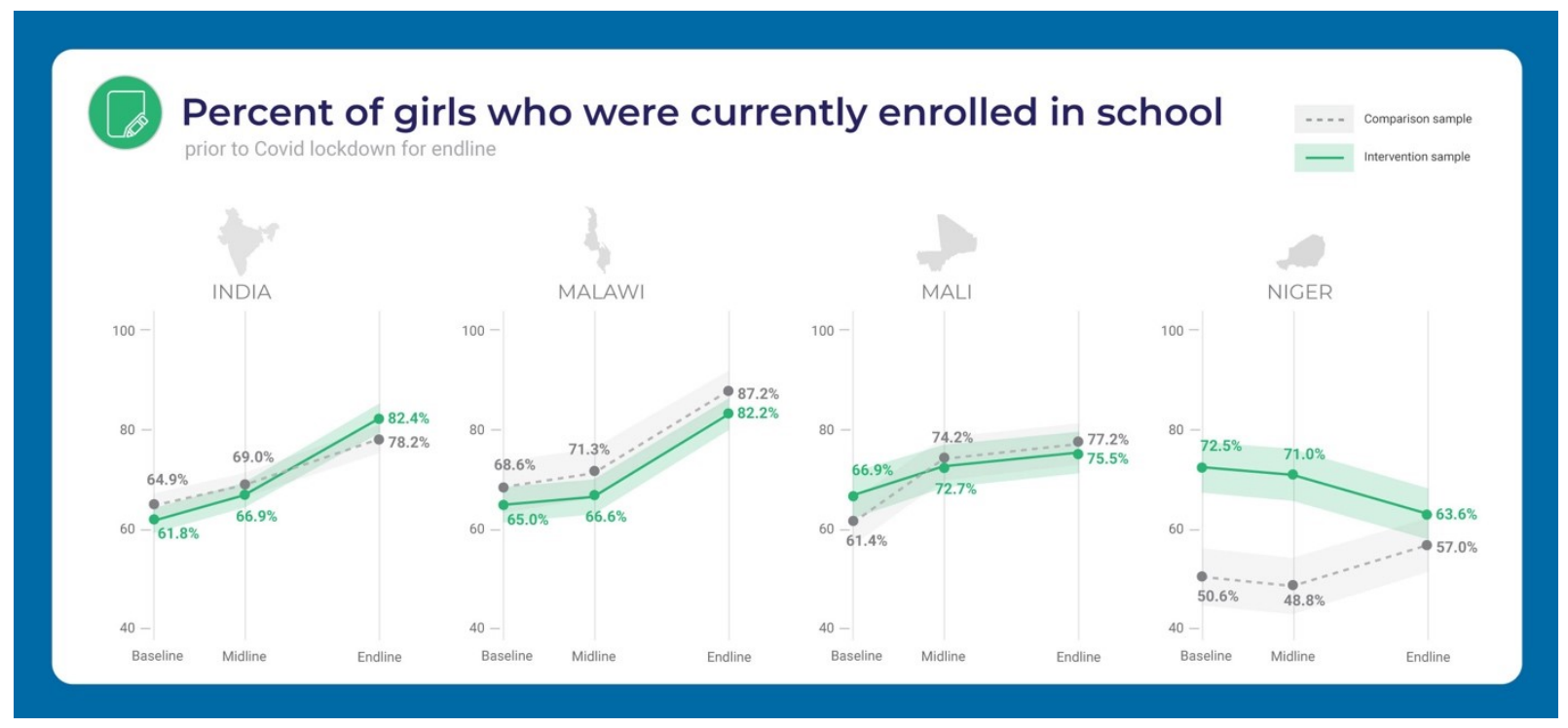

With respect to girls' school enrollment, we see significant increases in intervention and comparison areas in all countries except Niger (note that the endline question asked about enrollment in school just prior to Covid-19-related school closures). In intervention areas in Niger, girls' school enrollment remained relatively stagnant between baseline and midline before declining substantially between midline and endline, while the opposite trend was apparent in comparison communities. This may be due in part to large differences in intervention and comparison areas at baseline and challenges of matching to preferred intervention communities.

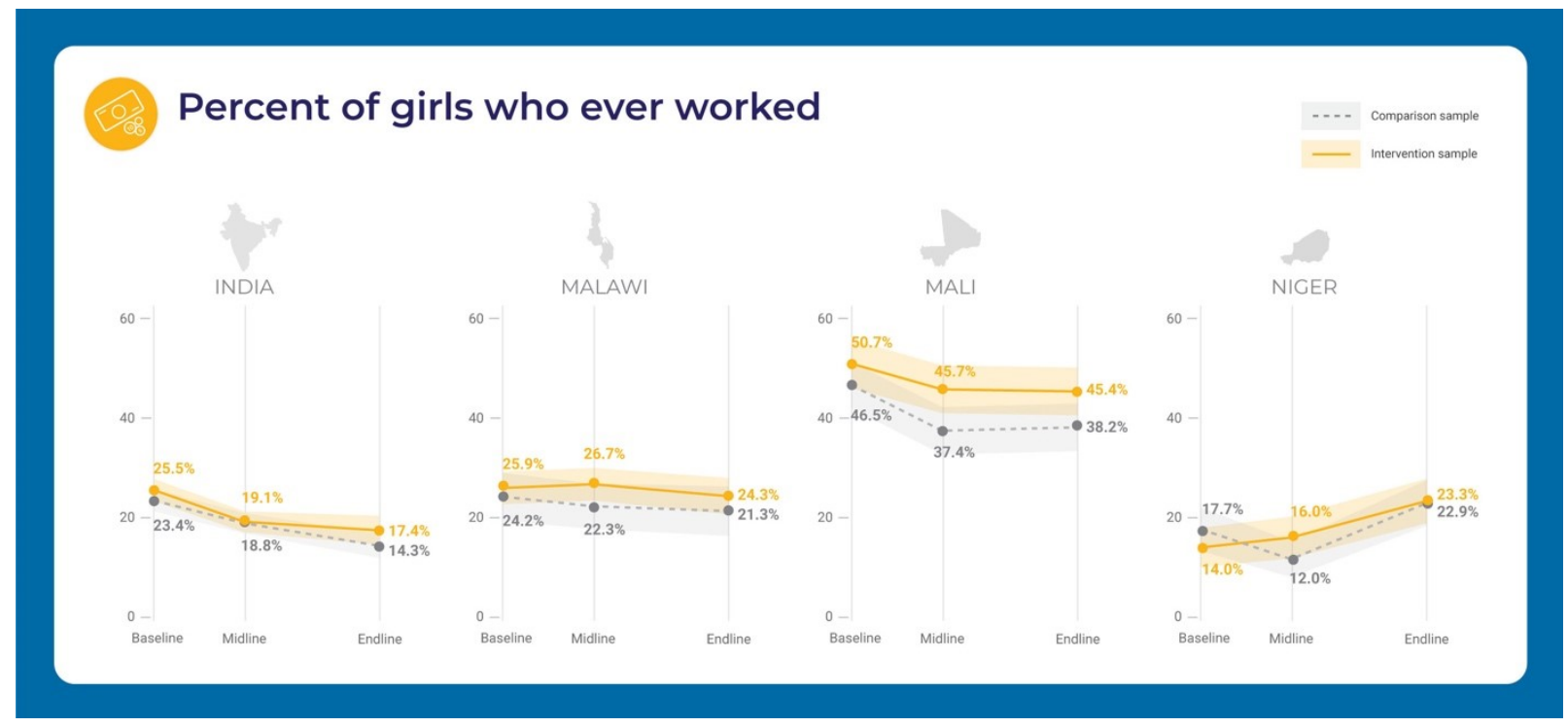

Looking at the proportion of girls who reported ever having worked for money, we observed moderate declines in most countries over the intervention period, with the exception of in Niger, where this proportion steadily increased in intervention communities. However, despite increases observed in Niger, the proportion of girls with work experience remains highest in Mali (where our data additionally likely reflect an underestimation of the true proportion on this indicator, due to high rates of work-related migration among adolescent girls). 


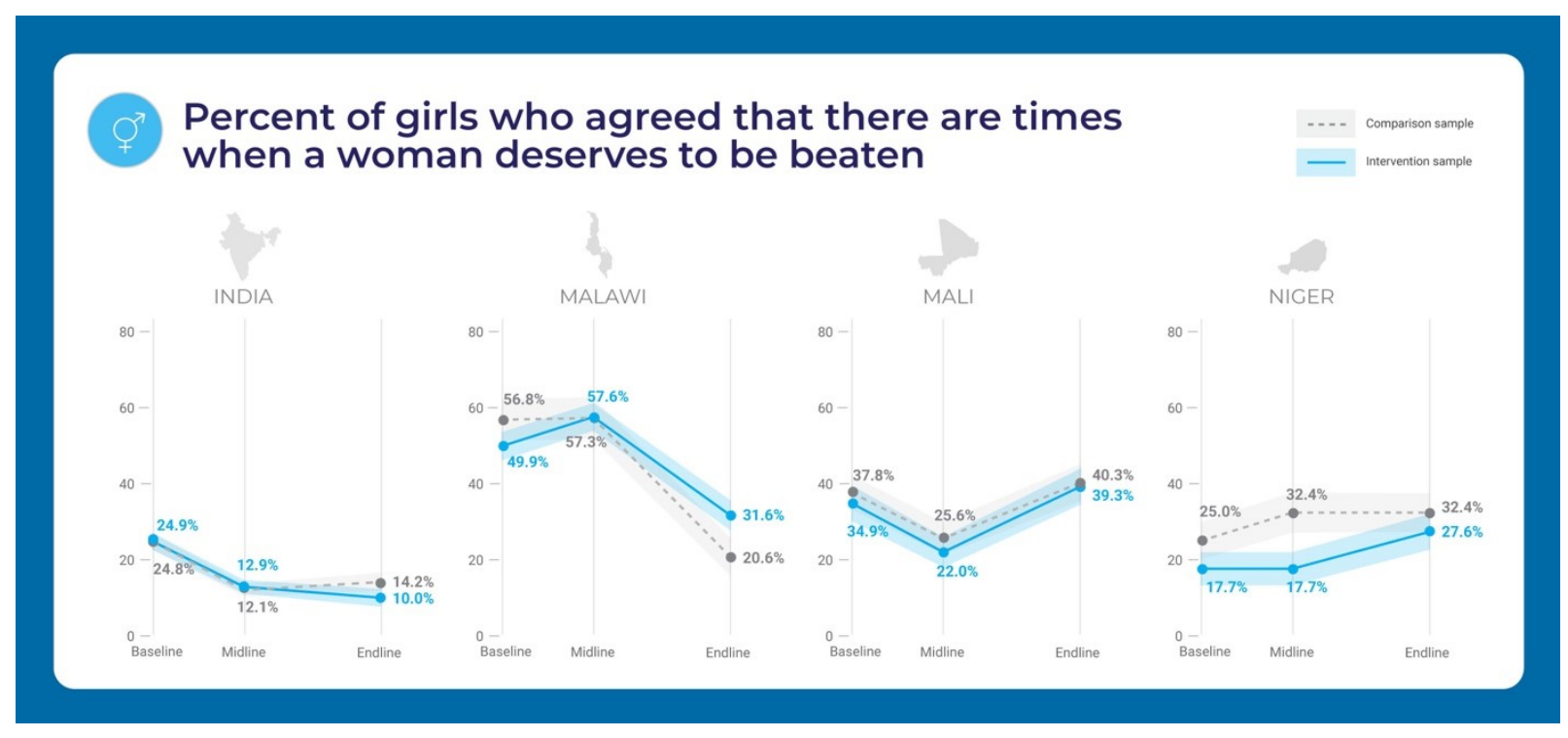

We see clear gains in India and Malawi with respect to acceptance of violence, with the proportion of girls agreeing that there are times a woman deserves to be beaten declining substantially from baseline to endline, across both intervention and comparison samples. In Mali, intervention communities were making clear gains at midline that then reversed course, perhaps reflecting some of the distress and tension we see in data related to the impact of the Covid-19 pandemic (girls in Mali reported higher depression and higher burden of chores) or to changes in the sample due to migration and mobile-data collection. In Niger, almost no change was observed in intervention communities from baseline to midline, but increases were observed from midline to endline. 


\section{Annex 4: Detailed Results from DID Analyses}

How to read table results

Significant positive results in expected direction (intervention performed better than comparison)

Significant unexpected results (results in wrong direction or comparison area performed better)

\section{India}

\begin{tabular}{|c|c|c|c|c|c|c|c|}
\hline & & $\begin{array}{r}\text { Intervention } \\
\text { - Baseline }\end{array}$ & $\begin{array}{r}\text { Intervention } \\
\text { - Endline }\end{array}$ & $\begin{array}{l}\text { Control - } \\
\text { Baseline }\end{array}$ & $\begin{array}{r}\text { Control } \\
\text { Endline }\end{array}$ & $\begin{array}{r}\text { Difference } \\
\text { in } \\
\text { difference }\end{array}$ & Significance \\
\hline & & $\%$ & $\%$ & $\%$ & $\%$ & & $p$-value \\
\hline \multicolumn{8}{|l|}{ Marriage } \\
\hline \multirow{6}{*}{$\begin{array}{c}\text { Can correctly } \\
\text { identify legal age } \\
\text { at marriage }\end{array}$} & & & & & & & \\
\hline & All states & 61.9 & 88.6 & 66.1 & 83.6 & $9 \%$ & $0.017^{* *}$ \\
\hline & Bihar & 58.6 & 86.8 & 66.6 & 85.8 & $9 \%$ & 0.13 \\
\hline & Jharkhand & & & & & & 0.276 \\
\hline & Odisha & 53.8 & 80.1 & 55.6 & 64.8 & $17 \%$ & $0.063^{*}$ \\
\hline & Rajasthan & 77.9 & 95.9 & 80.7 & 95 & $4 \%$ & 0.434 \\
\hline \multirow{5}{*}{$\begin{array}{r}\text { Currently married } \\
\text { (all) }\end{array}$} & All states & 14.8 & 4.5 & 12.4 & 9.6 & $-8 \%$ & $0.001^{* * *}$ \\
\hline & Bihar & 16.0 & 7.6 & 11.0 & 10.3 & $-7 \%$ & 0.108 \\
\hline & Jharkhand & 26.9 & 9.3 & 25.9 & 19.3 & $-11 \%$ & $0.035^{\star *}$ \\
\hline & Odisha & 8.9 & 0 & 6 & 2.17 & $-5 \%$ & $0.062^{*}$ \\
\hline & Rajasthan & 8.4 & 2.1 & 6.5 & 9 & $-9 \%$ & $0.006^{\star \star \star}$ \\
\hline \multirow[t]{5}{*}{$\begin{array}{r}\text { Currently married } \\
(15-19)\end{array}$} & All states & 26.4 & 7.9 & 22.4 & 16.4 & $-13 \%$ & $0.001^{* \star \star}$ \\
\hline & Bihar & 32.0 & 13.5 & 21.7 & 15.6 & $-12 \%$ & 0.115 \\
\hline & Jharkhand & 50 & 18.3 & 47.4 & 32.7 & $-17 \%$ & $0.051^{*}$ \\
\hline & Odisha & 15 & 0 & 10 & 4.7 & $-10 \%$ & $0.030^{\star *}$ \\
\hline & Rajasthan & 14 & 3.2 & 11.6 & 14.1 & $-13 \%$ & $0.007^{* \star *}$ \\
\hline $\begin{array}{r}\text { Can name at least } \\
\text { three adverse } \\
\text { effects of child } \\
\text { marriage }\end{array}$ & All states & 28 & 45.8 & 26.4 & 34.8 & $9 \%$ & $0.092^{*}$ \\
\hline
\end{tabular}




\begin{tabular}{|c|c|c|c|c|c|c|c|}
\hline & Bihar & 17.4 & 36.3 & 20.2 & 36.3 & 2 & 0.792 \\
\hline & Jharkhand & 15.7 & 38.7 & 17.6 & 20.5 & $20 \%$ & $0.028^{* *}$ \\
\hline & Odisha & 55.9 & 63.3 & 48.7 & 42.6 & 13.5 & 0.278 \\
\hline & Rajasthan & 22.6 & 40.0 & 20.9 & 36.2 & 2 & 0.83 \\
\hline \multicolumn{8}{|l|}{ Health } \\
\hline \multirow{5}{*}{$\begin{array}{r}\text { Ever pregnant } \\
\text { (among ever } \\
\text { married and aged } \\
15+\text { ) }\end{array}$} & All states & 45.6 & 62.1 & 42.2 & 59.5 & $-1 \%$ & 0.931 \\
\hline & Bihar & 58.8 & 66.7 & 47.2 & 66.7 & $-12 \%$ & 0.401 \\
\hline & Jharkhand & 57.7 & 64.3 & 56.1 & 72.7 & $-10 \%$ & 0.476 \\
\hline & Odisha & 52.9 & 15.8 & 57.1 & 20.0 & 0 & .. \\
\hline & Rajasthan & 14.7 & 33.3 & 15.3 & 40.0 & $-6 \%$ & 0.838 \\
\hline \multirow[t]{5}{*}{ Knows about HIV } & All states & 22.4 & 50.2 & 20.2 & 39 & $9 \%$ & $0.082^{*}$ \\
\hline & Bihar & 10.2 & 27.4 & 12.5 & 35.8 & -6 & 0.335 \\
\hline & Jharkhand & 6.2 & 37.3 & 9.6 & 14.2 & $27 \%$ & $0.001^{* * *}$ \\
\hline & Odisha & 56.2 & 73.5 & 45.0 & 58.3 & 4 & 0.677 \\
\hline & Rajasthan & 16.3 & 56.6 & 15.9 & 41.6 & $15 \%$ & 0.157 \\
\hline \multirow{5}{*}{$\begin{array}{r}\text { Reports that their } \\
\text { community has a } \\
\text { youth-friendly } \\
\text { health center }\end{array}$} & All states & 5.9 & 33.5 & 7.4 & 18.4 & $17 \%$ & $0.000^{* \star *}$ \\
\hline & Bihar & 5.2 & 20.1 & 8.4 & 11.9 & 11 & 0.107 \\
\hline & Jharkhand & 3.4 & 37.7 & 8.8 & 8.8 & $34 \%$ & $0.000^{* * *}$ \\
\hline & Odisha & 7.8 & 36.3 & 4.6 & 27.6 & 5 & 0.582 \\
\hline & Rajasthan & 7.2 & 40 & 7.4 & 22.2 & $18 \%$ & $0.031^{* *}$ \\
\hline \multicolumn{8}{|l|}{ Livelihoods } \\
\hline \multirow{5}{*}{$\begin{array}{c}\text { Has ever worked } \\
\text { for income }\end{array}$} & All states & 25.5 & 17.4 & 23.4 & 14.3 & 1 & 0.773 \\
\hline & Bihar & 16.9 & 17.2 & 14.8 & 18.6 & -3 & 0.556 \\
\hline & Jharkhand & 27.7 & 16.0 & 22.5 & 8.0 & 3 & 0.701 \\
\hline & Odisha & 34.7 & 23.5 & 39.0 & 18.7 & 9 & 0.269 \\
\hline & Rajasthan & 22.9 & 11.0 & 19.1 & 10.9 & -4 & 0.44 \\
\hline \multirow{5}{*}{$\begin{array}{c}\text { Is currently } \\
\text { working for } \\
\text { income }\end{array}$} & All states & 43.0 & 54.0 & 47.6 & 64.7 & -6 & 0.466 \\
\hline & Bihar & 39.3 & 55.6 & 41.4 & 65.8 & -8 & 0.566 \\
\hline & Jharkhand & 48.5 & 33.3 & 50 & 78.6 & $-44 \%$ & $0.058^{*}$ \\
\hline & Odisha & 46.5 & 54.3 & 56.6 & 58.1 & 6 & 0.56 \\
\hline & Rajasthan & 34.4 & 81.2 & 32.9 & 66.7 & 13 & 0.417 \\
\hline
\end{tabular}




\begin{tabular}{|c|c|c|c|c|c|c|c|}
\hline Education & & & & & & & \\
\hline $\begin{array}{c}\text { Currently enrolled } \\
\text { in school }\end{array}$ & All states & 61.8 & 82.4 & 64.9 & 78.2 & $7 \%$ & $0.035^{* *}$ \\
\hline \multirow[t]{4}{*}{$\begin{array}{c}\text { (among ever } \\
\text { enrolled) }\end{array}$} & Bihar & 64.3 & 80 & 75.6 & 79.8 & $12 \%$ & $0.068^{*}$ \\
\hline & Jharkhand & 54.8 & 80.7 & 59.1 & 75.3 & 10 & 0.197 \\
\hline & Odisha & 63.7 & 85.0 & 57.7 & 73.3 & 6 & 0.423 \\
\hline & Rajasthan & 64.3 & 83.2 & 66.7 & 84.3 & 1 & 0.828 \\
\hline \multirow{5}{*}{$\begin{array}{r}\begin{array}{r}\text { Ever attended } \\
\text { school }\end{array} \\
\end{array}$} & All states & 93.3 & 98.9 & 94.6 & 97.8 & $2 \%$ & $0.098^{*}$ \\
\hline & Bihar & 89.0 & 98.7 & 91.1 & 97.1 & 4 & 0.255 \\
\hline & Jharkhand & 93.6 & 100 & 99.5 & 98.6 & $7 \%$ & $0.005^{* * *}$ \\
\hline & Odisha & 95.4 & 98.5 & 94.8 & 97.8 & - & 0.982 \\
\hline & Rajasthan & 94.9 & 98.6 & 93.2 & 97.7 & - & 0.77 \\
\hline $\begin{array}{c}\text { Highest grade level } \\
\text { completed }\end{array}$ & All states & 7.5 & 8.4 & 7.7 & 8.4 & 13 & 0.549 \\
\hline \multirow[t]{4}{*}{ (in years) } & Bihar & 6.5 & 7.9 & 7.3 & 7.9 & 0.8 & $0.086^{*}$ \\
\hline & Jharkhand & 7.2 & 7.9 & 7.4 & 8.1 & -1 & 0.968 \\
\hline & Odisha & 8.5 & 8.6 & 7.8 & 8.4 & -46 & 0.188 \\
\hline & Rajasthan & 7.8 & 9.2 & 8.1 & 9.1 & 41 & 0.387 \\
\hline \multirow{5}{*}{$\begin{array}{r}\text { Literacy (can read } \\
\text { at least one } \\
\text { sentence) } \\
\end{array}$} & All states & 87.9 & 97.1 & 88.9 & 94.8 & 3 & 0.108 \\
\hline & Bihar & 82.0 & 94.9 & 85.7 & 92.2 & 6 & 0.186 \\
\hline & Jharkhand & 87.7 & 99.3 & 92 & 94.9 & $9 \%$ & $0.028^{* *}$ \\
\hline & Odisha & 94.6 & 99.5 & 88.5 & 97.4 & -4 & 0.117 \\
\hline & Rajasthan & 87.0 & 93.8 & 89.6 & 94.6 & 2 & 0.72 \\
\hline \multicolumn{8}{|l|}{$\begin{array}{l}\text { Gender-equitable } \\
\text { attitudes }\end{array}$} \\
\hline \multirow{5}{*}{$\begin{array}{r}\text { Agree that boys } \\
\text { have the right to } \\
\text { refuse an arranged } \\
\text { marriage }\end{array}$} & All states & 68.9 & 86.0 & 63.2 & 82.6 & -2 & 0.579 \\
\hline & Bihar & 674 & 930 & 689 & 873 & 7 & 033 \\
\hline & Jharkhand & 67.5 & 92.0 & 65.8 & 84.1 & 6 & 0.439 \\
\hline & Odisha & 68.5 & 78.1 & 57.9 & 79.6 & -12 & 0.223 \\
\hline & Rajasthan & 72.0 & 82.8 & 59.8 & 80.1 & -10 & 0.154 \\
\hline \multirow{4}{*}{$\begin{array}{r}\text { Agree that girls } \\
\text { have the right to } \\
\text { refuse an arranged } \\
\text { marriage }\end{array}$} & All states & & & & & & 0.215 \\
\hline & Bihar & 35.9 & 39.5 & 37.8 & 67.2 & $-26 \%$ & $.055^{*}$ \\
\hline & Jharkhand & 29.4 & 59.3 & 25.4 & 52.3 & 3 & 0.308 \\
\hline & Odisha & 46.2 & 74.5 & 42.1 & 78.3 & -8 & 0.246 \\
\hline
\end{tabular}




\begin{tabular}{|c|c|c|c|c|c|c|c|}
\hline & Rajasthan & 52.7 & 73.8 & 47.5 & 64.3 & 4 & 0.536 \\
\hline \multirow{5}{*}{$\begin{array}{l}\text { Agree that there } \\
\text { are times when a } \\
\text { woman deserves } \\
\text { to be beaten }\end{array}$} & All states & 24.9 & 10.0 & 24.8 & 14.2 & -4 & 0.214 \\
\hline & Bihar & 33.7 & 9.6 & 38.3 & 15.2 & -1 & 0.853 \\
\hline & Jharkhand & 35.9 & 9.3 & 29.9 & 10.2 & -7 & 0.322 \\
\hline & Odisha & 16.1 & 10.7 & 19.5 & 18.7 & -5 & 0.311 \\
\hline & Rajasthan & 15.3 & 10.3 & 11.0 & 11.8 & -6 & 0.218 \\
\hline \multirow{5}{*}{$\begin{array}{r}\text { Agree that a } \\
\text { woman has a right } \\
\text { to divorce }\end{array}$} & All states & 52.1 & 62.7 & 51.1 & 60.0 & 1 & 0.669 \\
\hline & Bihar & 49.2 & 60.5 & 49.2 & 54.4 & 6 & 0.454 \\
\hline & Jharkhand & 45.1 & 64.0 & 46.0 & 59.1 & 6 & 0.404 \\
\hline & Odisha & 61.6 & 62.2 & 57.6 & 66.5 & -8 & 0.225 \\
\hline & Rajasthan & 52.2 & 64.1 & 52.2 & 59.3 & 5 & 0.574 \\
\hline \multirow{5}{*}{$\begin{array}{r}\text { Agree that she can } \\
\text { disagree with her } \\
\text { parents (parents in } \\
\text { law) about } \\
\text { decisions affecting } \\
\text { her }\end{array}$} & All states & 54.2 & 76.1 & 56.1 & 76.9 & 1 & 0.813 \\
\hline & Bihar & 64.6 & 86 & 70.7 & 77 & $15 \%$ & $0.066^{*}$ \\
\hline & Jharkhand & 42.6 & 76.0 & 46.8 & 81.8 & -1 & 0.856 \\
\hline & Odisha & 50.5 & 63.8 & 51.9 & 77.4 & -12 & 0.201 \\
\hline & Rajasthan & 58.8 & 82.1 & 54.3 & 72.4 & 5 & 0.535 \\
\hline Social life & All states & 2.7 & 49.8 & 4.5 & 11.1 & $41 \%$ & $0.000^{\star \star *}$ \\
\hline \multirow{4}{*}{$\begin{array}{l}\text { Report being part } \\
\text { of a club or group }\end{array}$} & Bihar & 5.8 & 28 & 6.6 & 6.4 & $23 \%$ & $0.036^{* *}$ \\
\hline & Jharkhand & 0.8 & 67.3 & 5.9 & 29 & $43 \%$ & $0.000^{\star \star \star}$ \\
\hline & Odisha & 3.2 & 44.4 & 2.9 & 7.8 & $36 \%$ & $0.025^{\star \star}$ \\
\hline & Rajasthan & 1 & 62.8 & 2.3 & 4.5 & $60 \%$ & $0.000^{\star \star \star}$ \\
\hline & & & & & & & \\
\hline
\end{tabular}

${ }^{* * *} p<.01$ difference between comparison and intervention; ${ }^{* *} p<.05$ difference between comparison and intervention; ${ }^{*} p<.10$ difference between comparison and intervention. 


\begin{tabular}{|c|c|c|c|c|c|c|c|}
\hline & & $\begin{array}{l}\text { Intervention } \\
\text { - Baseline }\end{array}$ & $\begin{array}{l}\text { Intervention } \\
\text { - Endline }\end{array}$ & $\begin{array}{l}\text { Control - } \\
\text { Baseline }\end{array}$ & $\begin{array}{l}\text { Control } \\
\text { Endline }\end{array}$ & $\begin{array}{l}\text { Difference } \\
\text { in } \\
\text { difference }\end{array}$ & Significance \\
\hline & & $\%$ & $\%$ & $\%$ & $\%$ & & p-value \\
\hline \multicolumn{8}{|l|}{ Marriage } \\
\hline & Ever married & 16.2 & 6.3 & 15.1 & 5.2 & -0.001 & 0.975 \\
\hline & $\begin{array}{l}\text { Ever married or } \\
\text { in union } \\
\text { (includes } \\
\text { engaged) }\end{array}$ & 16.2 & 7.5 & 15.1 & 6.6 & -0.002 & 0.942 \\
\hline & \multirow{2}{*}{$\begin{array}{l}\text { Can name three } \\
\text { adverse effects } \\
\text { of early } \\
\text { marriage }\end{array}$} & & & & & & \\
\hline & & 9 & 29.8 & 5.7 & 31.5 & -0.05 & 0.43 \\
\hline & $\begin{array}{l}\text { Can correctly } \\
\text { identify legal age } \\
\text { at marriage }\end{array}$ & 44.5 & 59.5 & 45.6 & 51.1 & 0.095 & $0.051^{*}$ \\
\hline & $\begin{array}{l}\text { Mean age } \\
\text { difference with } \\
\text { partner }\end{array}$ & 4 & 3.6 & 4.6 & 3.8 & 0.406 & 0.682 \\
\hline & $\begin{array}{l}\text { Ideal age at first } \\
\text { marriage }\end{array}$ & 19.4 & 20.3 & 19.3 & 20 & 0.251 & 0.37 \\
\hline & $\begin{array}{l}\text { Mean age at first } \\
\text { marriage }\end{array}$ & 16.4 & 17.3 & 16.2 & 16.9 & 0.251 & 0.709 \\
\hline \multicolumn{8}{|l|}{ Health } \\
\hline & $\begin{array}{l}\text { Ever } \\
\text { pregnant (among } \\
\text { aged 15+) }\end{array}$ & 22.8 & 17 & 24.7 & 14.8 & 0.04 & 0.433 \\
\hline & $\begin{array}{l}\text { Knows about } \\
\text { HIV }\end{array}$ & 80.7 & 94.1 & 85.5 & 96.1 & 0.028 & 0.449 \\
\hline & $\begin{array}{l}\text { Knows that using } \\
\text { a condom } \\
\text { protects against } \\
\text { HIV }\end{array}$ & 63.9 & 83.8 & 67.9 & 89.9 & -0.021 & 0.668 \\
\hline & $\begin{array}{l}\text { Reports that } \\
\text { their community } \\
\text { has a youth- } \\
\text { friendly health } \\
\text { center }\end{array}$ & 4.3 & 59.3 & 3.8 & 52.7 & 0.061 & 0.387 \\
\hline & $\begin{array}{l}\text { Contraceptive } \\
\text { knowledge scale } \\
\text { (modern } \\
\text { methods) }\end{array}$ & 75.1 & 87 & 79.9 & 91.4 & 0.006 & 0.876 \\
\hline \multicolumn{8}{|l|}{ Livelihoods } \\
\hline & $\begin{array}{l}\text { Has ever worked } \\
\text { for income }\end{array}$ & 26 & 24.3 & 24.2 & 21.3 & 0.012 & 0.84 \\
\hline & $\begin{array}{l}\text { Is currently } \\
\text { working for } \\
\text { income }\end{array}$ & 13.1 & 39 & 15.6 & 47.3 & -0.058 & 0.673 \\
\hline
\end{tabular}




\begin{tabular}{|c|c|c|c|c|c|c|c|}
\hline \multicolumn{8}{|l|}{ Education } \\
\hline & $\begin{array}{l}\text { Currently } \\
\text { enrolled in } \\
\text { school }\end{array}$ & 65 & 83.2 & 68.6 & 87.9 & -0.011 & 0.81 \\
\hline & $\begin{array}{l}\text { Ever attended } \\
\text { school }\end{array}$ & 95.9 & 97.8 & 99 & 98 & 0.03 & $0.094^{*}$ \\
\hline & $\begin{array}{l}\text { Mean number of } \\
\text { years of } \\
\text { education } \\
\text { completed }\end{array}$ & 3.9 & 4.5 & 4.7 & 4.6 & 0.683 & $0.059^{*}$ \\
\hline & $\begin{array}{l}\text { Cannot read or } \\
\text { write }\end{array}$ & 32.3 & 14.4 & 21.4 & 13.2 & -0.097 & $0.098^{*}$ \\
\hline \multicolumn{8}{|l|}{$\begin{array}{l}\text { Gender- } \\
\text { equitable } \\
\text { attitudes }\end{array}$} \\
\hline & $\begin{array}{l}\text { Agree that boys } \\
\text { have the right to } \\
\text { refuse an } \\
\text { arranged } \\
\text { marriage }\end{array}$ & 61.3 & 73.1 & 68.3 & 72.9 & 0.072 & 0.248 \\
\hline & $\begin{array}{l}\text { Agree that girls } \\
\text { have the right to } \\
\text { refuse an } \\
\text { arranged } \\
\text { marriage }\end{array}$ & 65.9 & 72.5 & 66 & 65.1 & 0.074 & 0.337 \\
\hline & $\begin{array}{l}\text { Agree that there } \\
\text { are times when a } \\
\text { woman deserves } \\
\text { to be beaten }\end{array}$ & 49.9 & 31.6 & 56.8 & 20.6 & 0.179 & $0.039^{* *}$ \\
\hline & $\begin{array}{l}\text { Agree that } \\
\text { women have a } \\
\text { right to divorce }\end{array}$ & 56 & 66.4 & 55 & 56 & 0.094 & 0.179 \\
\hline & $\begin{array}{l}\text { Agree that she } \\
\text { can disagree } \\
\text { with her parents } \\
\text { (or husband if } \\
\text { married) about } \\
\text { decisions } \\
\text { affecting her }\end{array}$ & 36.2 & 45.3 & 33.3 & 51.4 & -0.101 & 0.142 \\
\hline \multicolumn{8}{|l|}{ Social life } \\
\hline & $\begin{array}{l}\text { Report being } \\
\text { part of a club or } \\
\text { group }\end{array}$ & 24.6 & 23.5 & 26.7 & 16.3 & 0.093 & 0.109 \\
\hline
\end{tabular}

${ }^{* * *} \mathrm{p}<.01$ difference between comparison and intervention; ${ }^{* *} \mathrm{p}<.05$ difference between comparison and intervention; ${ }^{*} p<.10$ difference between comparison and intervention. 
Mali

\begin{tabular}{|c|c|c|c|c|c|c|c|}
\hline & & $\begin{array}{l}\text { Intervention } \\
\text { - Baseline }\end{array}$ & $\begin{array}{l}\text { Intervention } \\
\text { - Endline }\end{array}$ & $\begin{array}{l}\text { Control - } \\
\text { Baseline }\end{array}$ & $\begin{array}{l}\text { Control - } \\
\text { Endline }\end{array}$ & $\begin{array}{l}\text { Difference } \\
\text { in } \\
\text { difference }\end{array}$ & Significance \\
\hline & & $\%$ & $\%$ & $\%$ & $\%$ & & p-value \\
\hline \multicolumn{8}{|l|}{ Marriage } \\
\hline & Ever married & 11.9 & 7.2 & 16.9 & 6.9 & 0.045 & 0.188 \\
\hline & $\begin{array}{l}\text { Can name three } \\
\text { adverse effects of } \\
\text { early marriage }\end{array}$ & 13.6 & 22.1 & 9.5 & 16.8 & 0.006 & 0.883 \\
\hline & $\begin{array}{l}\text { Can correctly } \\
\text { identify legal age at } \\
\text { marriage }\end{array}$ & 4.4 & 3.4 & 5.3 & 5 & -0.008 & 0.721 \\
\hline & $\begin{array}{l}\text { Mean age } \\
\text { difference with } \\
\text { partner }\end{array}$ & 11.4 & 7.5 & 9.7 & 8.6 & -2.827 & 0.111 \\
\hline & $\begin{array}{l}\text { Mean age at } \\
\text { marriage }\end{array}$ & 15.9 & 16.8 & 16.2 & 16.3 & 0.855 & $0.074^{*}$ \\
\hline & $\begin{array}{l}\text { Ideal age at } \\
\text { marriage }\end{array}$ & 18 & 18.3 & 17.4 & 18.1 & 0.141 & 0.467 \\
\hline \multicolumn{8}{|l|}{ Health } \\
\hline & $\begin{array}{l}\text { Ever } \\
\text { pregnant (aged } \\
15+)\end{array}$ & 20 & 13.4 & 24.42 & 17.52 & -0.015 & 0.739 \\
\hline & Knows about HIV & 82.34 & 84.41 & 77.28 & 77.48 & 0.014 & 0.741 \\
\hline & $\begin{array}{l}\text { Knows that using a } \\
\text { condom protects } \\
\text { against HIV }\end{array}$ & 44.55 & 75.1 & 38.8 & 70.94 & -0.015 & 0.799 \\
\hline & $\begin{array}{l}\text { Reports that their } \\
\text { community has a } \\
\text { youth-friendly } \\
\text { health center }\end{array}$ & 8.51 & 60.39 & 8.2 & 63.43 & -0.026 & 0.776 \\
\hline & $\begin{array}{l}\text { Contraceptive } \\
\text { knowledge scale } \\
\text { (modern methods) }^{1}\end{array}$ & 50.74 & 57.5 & 47.67 & 54.7 & -0.02 & 0.606 \\
\hline \multicolumn{8}{|l|}{ Livelihoods } \\
\hline & $\begin{array}{l}\text { Has ever worked } \\
\text { for income }\end{array}$ & 50.87 & 45.32 & 46.55 & 38.12 & 0.014 & 0.829 \\
\hline & $\begin{array}{l}\text { Is currently working } \\
\text { for income }\end{array}$ & 44.66 & 25.9 & 39.81 & 21.04 & 0.005 & 0.948 \\
\hline & $\begin{array}{l}\text { Reports saving } \\
\text { money for the } \\
\text { future }\end{array}$ & & & & & & \\
\hline
\end{tabular}




\begin{tabular}{|c|c|c|c|c|c|c|c|}
\hline \multicolumn{8}{|l|}{ Education } \\
\hline & $\begin{array}{l}\text { Currently enrolled } \\
\text { in school }\end{array}$ & 66.91 & 75.5 & 61.42 & 77.2 & -0.018 & 0.72 \\
\hline & $\begin{array}{l}\text { (among ever } \\
\text { enrolled) }\end{array}$ & & & & & & \\
\hline & $\begin{array}{l}\text { Ever attended } \\
\text { school }\end{array}$ & 67.25 & 78.61 & 59.2 & 66.5 & 0.038 & 0.209 \\
\hline & $\begin{array}{l}\text { Mean number of } \\
\text { years of education } \\
\text { completed }\end{array}$ & 4.2 & 4.7 & 3.6 & 4.1 & 0.184 & 0.543 \\
\hline & $\begin{array}{l}\text { Cannot read or } \\
\text { write }\end{array}$ & 44.31 & 30.7 & 55.43 & 39.36 & 0.018 & 0.566 \\
\hline \multicolumn{8}{|l|}{$\begin{array}{l}\text { Gender- } \\
\text { equitable } \\
\text { attitudes }\end{array}$} \\
\hline & $\begin{array}{l}\text { Agree that boys do } \\
\text { not have the right } \\
\text { to refuse an } \\
\text { arranged marriage }\end{array}$ & 33.5 & 55.16 & 23.3 & 53.96 & -0.089 & 0.101 \\
\hline & $\begin{array}{l}\text { Agree that girls do } \\
\text { not have the right } \\
\text { to refuse an } \\
\text { arranged marriage }\end{array}$ & 32.26 & 53.24 & 22.8 & 54.46 & -0.105 & $0.045^{* *}$ \\
\hline & $\begin{array}{l}\text { Agree that there } \\
\text { are times when a } \\
\text { woman deserves to } \\
\text { be beaten }\end{array}$ & 34.9 & 39.33 & 37.78 & 40.35 & 0.014 & 0.826 \\
\hline & $\begin{array}{l}\text { Agree or strongly } \\
\text { agree that a } \\
\text { woman has a right } \\
\text { to divorce }\end{array}$ & 33.83 & 43.65 & 34.08 & 45.54 & -0.017 & 0.805 \\
\hline & $\begin{array}{l}\text { Agree that she can } \\
\text { disagree with her } \\
\text { parents (or } \\
\text { husband if married) } \\
\text { about decisions } \\
\text { affecting her }\end{array}$ & 26.3 & 52.43 & 27.07 & 55.11 & -0.025 & 0.642 \\
\hline \multicolumn{8}{|l|}{ Social life } \\
\hline & $\begin{array}{l}\text { Report being part } \\
\text { of a club or group }\end{array}$ & 61.63 & 14.9 & 58.31 & 13.4 & -0.018 & 0.746 \\
\hline & & & & & & & \\
\hline
\end{tabular}

${ }^{1}$ The endline questionnaire includes an additional modern method (female condom).

${ }^{* * *} p<.01$ difference between comparison and intervention; ${ }^{* *} p<.05$ difference between comparison and intervention; ${ }^{*} p<.10$ difference between comparison and intervention. 
Niger

\begin{tabular}{|c|c|c|c|c|c|c|c|}
\hline & & \multicolumn{2}{|c|}{ Intervention } & \multicolumn{2}{|c|}{ Control } & \multicolumn{2}{|c|}{ Adjusted $^{1}$} \\
\hline & & Baseline & Endline & Baseline & Endline & $\begin{array}{l}\text { Difference in } \\
\text { difference }\end{array}$ & Significance \\
\hline \multicolumn{8}{|l|}{ Marriage } \\
\hline & Ever married & 25.67 & 15.95 & 37.67 & 15.92 & 0.134 & $0.098^{*}$ \\
\hline & $\begin{array}{l}\text { Can name three } \\
\text { adverse effects of } \\
\text { early marriage }\end{array}$ & 15 & 29.63 & 19.33 & 19.82 & 0.153 & $0.029^{* *}$ \\
\hline & $\begin{array}{l}\text { Can correctly identify } \\
\text { legal age at marriage }\end{array}$ & 18.87 & 31.89 & 40.65 & 17.94 & 0.291 & $0.013^{* *}$ \\
\hline & $\begin{array}{l}\text { Mean age difference } \\
\text { with partner }\end{array}$ & 8.9 & 8.9 & 8.8 & 7.2 & 0.006 & 0.997 \\
\hline & $\begin{array}{l}\text { Mean age at } \\
\text { marriage }\end{array}$ & 14.6 & 16.5 & 15.1 & 15.1 & 1.512 & 0.123 \\
\hline & $\begin{array}{l}\text { Ideal age at } \\
\text { marriage }\end{array}$ & 17.7 & 17.6 & 16.8 & 17.5 & -0.691 & 0.111 \\
\hline \multicolumn{8}{|l|}{ Health } \\
\hline & $\begin{array}{l}\text { Ever pregnant (aged } \\
15+)\end{array}$ & 14.62 & 17.71 & 12.73 & 19.62 & -0.041 & 0.637 \\
\hline & Knows about HIV & 65.67 & 75 & 57.5 & 58.5 & 0.103 & 0.468 \\
\hline & $\begin{array}{l}\text { Knows that using a } \\
\text { condom protects } \\
\text { against HIV }\end{array}$ & 18.3 & 45.2 & 18.3 & 30.9 & 0.182 & 0.12 \\
\hline & $\begin{array}{l}\text { Reports that their } \\
\text { community has a } \\
\text { youth-friendly health } \\
\text { center }\end{array}$ & 2 & 17.9 & 2 & 15.6 & 0.007 & 0.933 \\
\hline & $\begin{array}{l}\text { Contraceptive } \\
\text { knowledge scale } \\
\text { (modern methods) }\end{array}$ & 48.3 & 64.4 & 49.3 & 56.5 & 0.178 & $0.069^{*}$ \\
\hline \multicolumn{8}{|l|}{ Livelihoods } \\
\hline & $\begin{array}{l}\text { Has ever worked for } \\
\text { income }\end{array}$ & 14 & 23.3 & 17.7 & 22.9 & 0.065 & 0.506 \\
\hline & $\begin{array}{l}\text { Is currently working } \\
\text { for income }\end{array}$ & 23.8 & 67.1 & 66 & 72.5 & 0.405 & $0.099^{*}$ \\
\hline & $\begin{array}{l}\text { Reports saving } \\
\text { money for the future }\end{array}$ & & & & & & \\
\hline \multicolumn{8}{|l|}{ Education } \\
\hline & $\begin{array}{l}\text { Currently enrolled in } \\
\text { school }\end{array}$ & 72.5 & 63.3 & 50.6 & 57 & -0.175 & $0.084^{*}$ \\
\hline & $\begin{array}{l}\text { (among ever } \\
\text { enrolled) }\end{array}$ & & & & & & \\
\hline & Ever attended school & 70.3 & 76.1 & 53.3 & 68.8 & 0.231 & 0.542 \\
\hline & $\begin{array}{l}\text { Mean number of } \\
\text { years of education } \\
\text { completed }\end{array}$ & 5.3 & 6.3 & 4.4 & 5.3 & -0.064 & 0.894 \\
\hline & Cannot read or write & 45 & 22.9 & 64 & 31.9 & 0.151 & $0.062^{*}$ \\
\hline
\end{tabular}

${ }^{1}$ Adjusted for age, education, village-level wealth, and village-level ethnicity. 


\begin{tabular}{|c|c|c|c|c|c|c|c|}
\hline \multicolumn{8}{|l|}{$\begin{array}{l}\text { Gender- } \\
\text { equitable } \\
\text { attitudes }\end{array}$} \\
\hline & $\begin{array}{l}\text { Agree that boys have } \\
\text { the right to refuse an } \\
\text { arranged marriage }\end{array}$ & 52.7 & 50.1 & 51.3 & 51.7 & -0.014 & 0.872 \\
\hline & $\begin{array}{l}\text { Agree that girls have } \\
\text { the right to refuse an } \\
\text { arranged marriage }\end{array}$ & 55.7 & 57.8 & 54.3 & 54.7 & 0.004 & 0.962 \\
\hline & $\begin{array}{l}\text { Agree or strongly } \\
\text { agree that there are } \\
\text { times when a woman } \\
\text { deserves to be } \\
\text { beaten }\end{array}$ & 17.6 & 27.6 & 25 & 32.4 & -0.071 & 0.381 \\
\hline & $\begin{array}{l}\text { Agree or strongly } \\
\text { agree that a woman } \\
\text { has a right to divorce }\end{array}$ & 22.3 & 35 & 22.3 & 32.7 & 0.048 & 0.539 \\
\hline & $\begin{array}{l}\text { Agree that she can } \\
\text { disagree with her } \\
\text { parents (or husband } \\
\text { if married) about } \\
\text { decisions affecting } \\
\text { her }\end{array}$ & 15.8 & 13.6 & 13.6 & 8.7 & 0.045 & 0.352 \\
\hline \multicolumn{8}{|l|}{ Social life } \\
\hline & $\begin{array}{l}\text { Report being part of a } \\
\text { club or group }\end{array}$ & 28 & 79 & 21 & 86 & -0.136 & $0.059^{*}$ \\
\hline
\end{tabular}

${ }^{* * *} \mathrm{p}<.01$ difference between comparison and intervention; ${ }^{* *} \mathrm{p}<.05$ difference between
comparison and intervention; ${ }^{*} \mathrm{p}<.10$ difference between comparison and intervention. 


\section{Annex 5. Power Calculations}

India

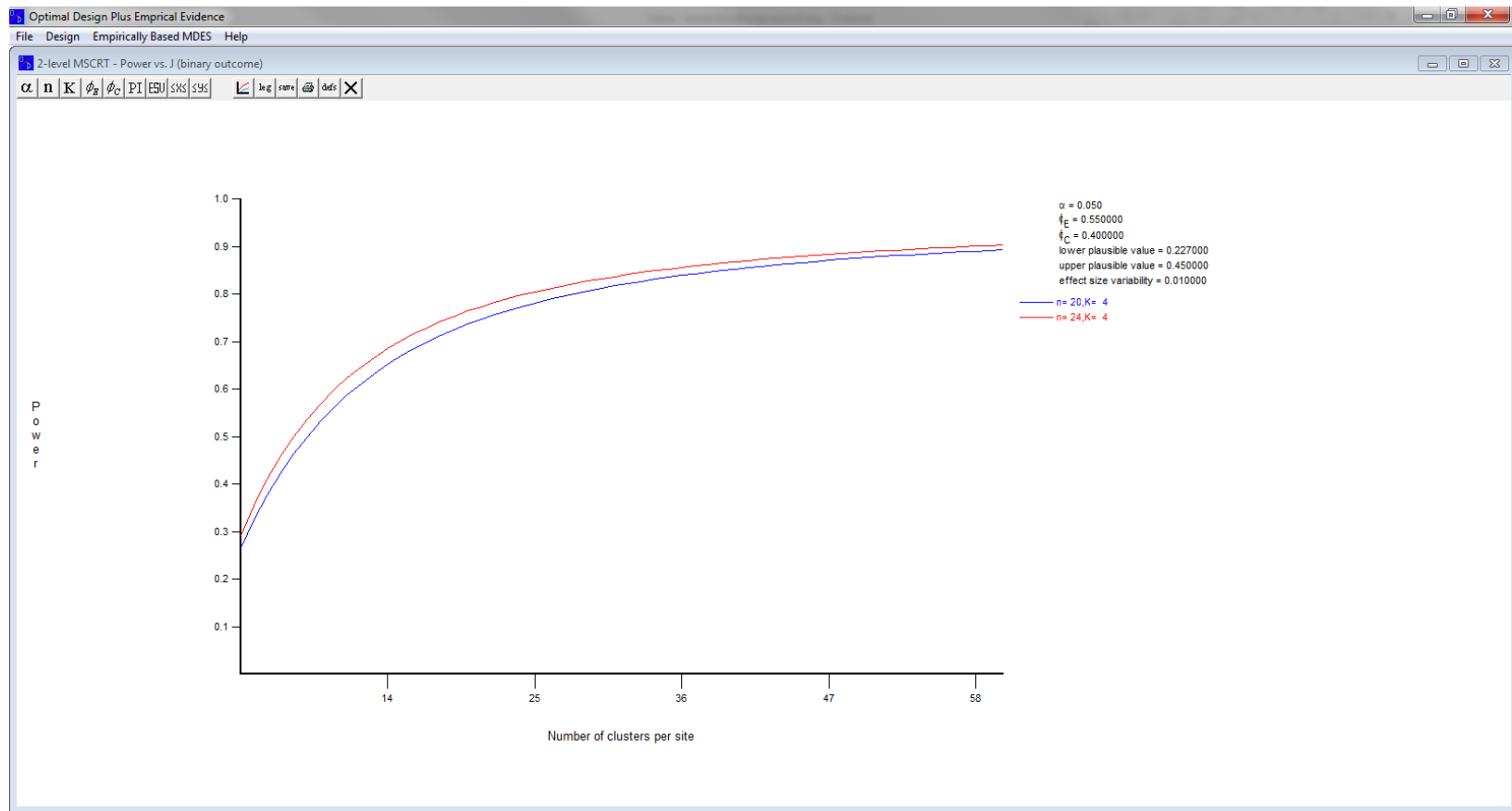

Malawi

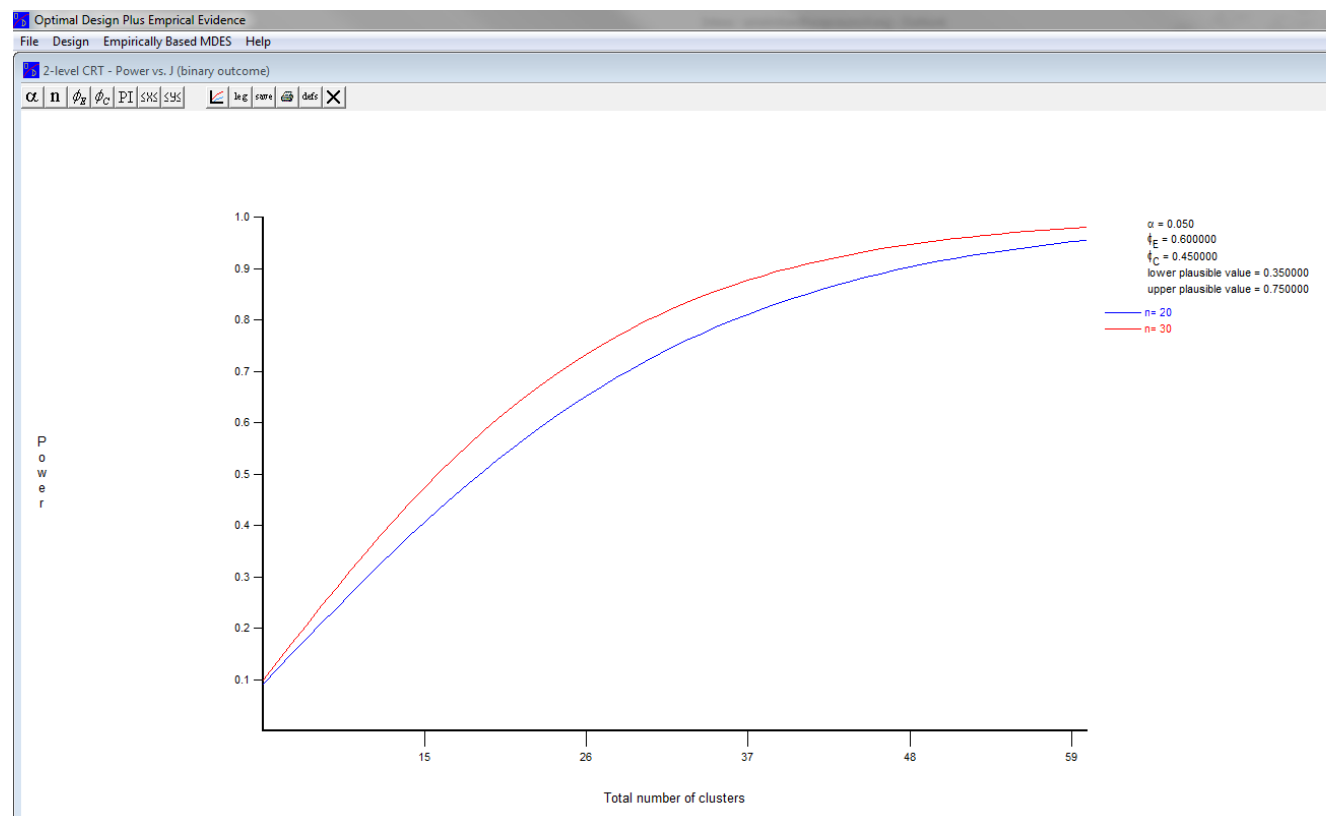


Mali

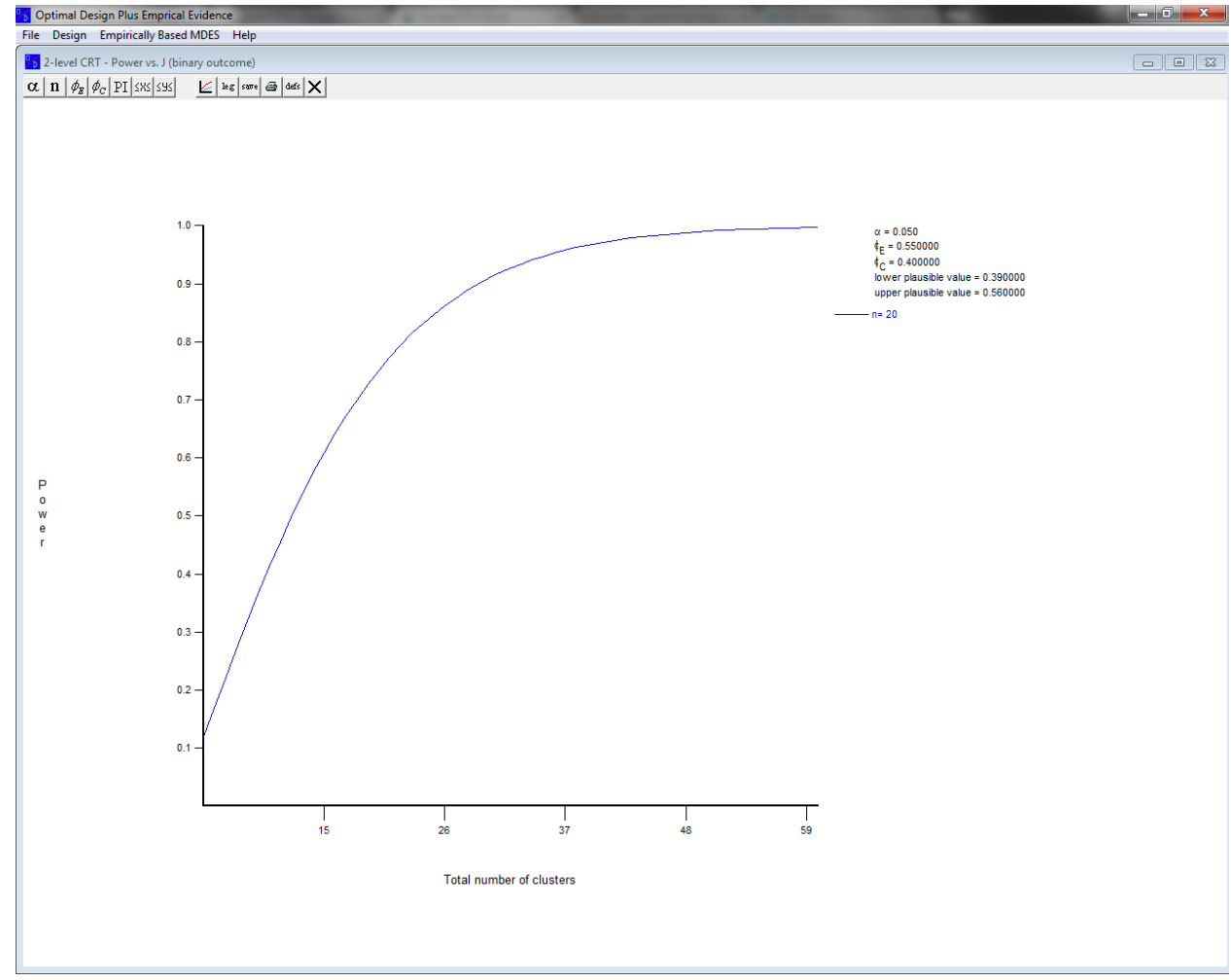

Niger

Optimal Design Plus Emprical Evidence $\quad x \quad-\quad x$

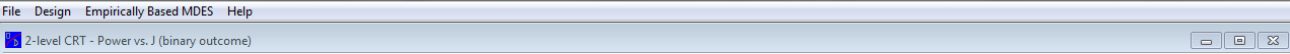

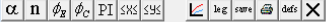

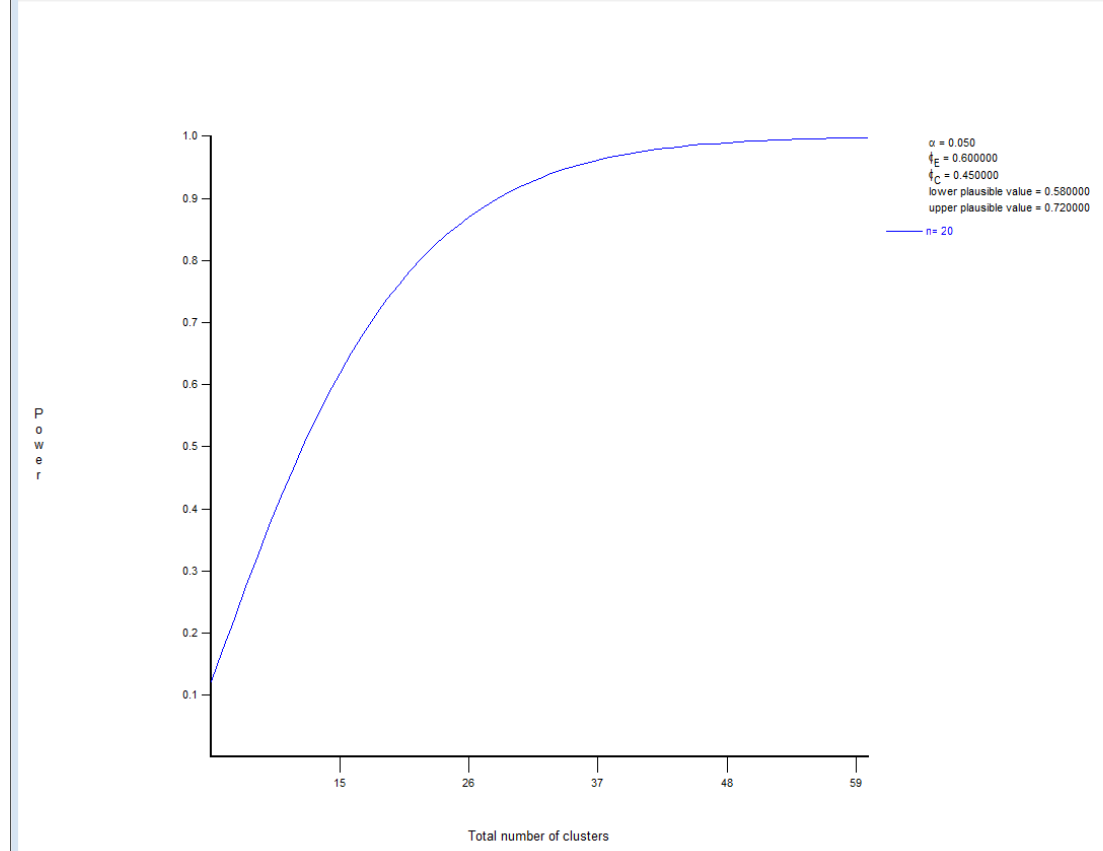




\section{References}

Alston, M., K. Whittenbury, A. Haynes, N. Godden. 2014. "Are climate challenges reinforcing child and forced marriage and dowry as adaptation strategies in the context of Bangladesh?" Women Studies International Forum 47(A): 137-144.

Amin, S., J.S. Saha, and J.A. Ahmed. 2018. "Skills-building programs to reduce child marriage in Bangladesh: A randomized controlled trial," Journal of Adolescent Health 63(3): 293300.

Andriano, L. and J. Behrman. 2020. "The effects of growing-season drought on young women's life course transitions in a sub-Saharan context," Population Studies 74(3): 331-350.

Ansell, N., F. Hadju, L. van Blerk, and E. Robson. 2018. "'My happiest time' or 'my saddest time'? The spatial and generational construction of marriage among youth in rural Malawi and Lesotho," Transactions of the Institute of British Geographers 43(2): 184199.

Baird, S., C. Mclntosh, and B. Ozler. 2016. "When the Money Runs Out Do Cash Transfers Have Sustained Effects on Human Capital Accumulation?" World Bank Group Policy Research Working Paper 7901.

Bandiera, O., N. Buehren, M. Goldstein, I. Rasul, and A. Smurra. 2018. "The Economic Lives of Young Women in the Time of Ebola: Lessons from an Empowerment Program," Washington, DC: World Bank.

Biddlecom, A., R. Gregory, and C.B. Lloyd. 2008. "Associations between Premarital Sex and Leaving School in Four Sub-Saharan African Countries," Studies in Family Planning 39(4): 337-350.

Chae, S. and T. Ngo. 2017. "The global state of evidence on interventions to prevent child marriage," GIRL Center Research Brief No.1. New York: Population Council.

Daniel, E.E. and R. Nanda. 2012. "The effect of reproductive health communication interventions on age at marriage and first birth in rural Bihar, India: A retrospective study." Watertown: Pathfinder International. Mastipur, Bodh Gaya, Bihar, India: Pathfinder International.

Demographic and Health Surveys. StatCompiler. Available at: https://www.statcompiler.com/en/. Accessed March 9, 2021.

Engebretsen, S., M. Gueye, A.J. Melnikas, S. Fofana, B. Fané, and S. Amin. 2020. "Adolescent girls' migration and its impact on early marriage: Qualitative findings in Mali," PLOS ONE 15(3): 1-18.

Felton-Biermann, C. 2006. "Gender and natural disaster: Sexualized violence and the tsunami," Development 49(3): 82-86. 
Fenn, N.S., J. Edmeades, H. Lantos, and O. Onovo. 2015. "Child Marriage, Adolescent Pregnancy, and Family Formation in West and Central Africa." Washington, DC, and New York: ICRW and UNICEF.

Gage A. 2013. "Association of child marriage with suicidal thoughts and attempts among adolescent girls in Ethiopia," Journal of Adolescent Health 52(5): 654-656.

Girls Not Brides (GNB). 2021. Girls Not Brides: About Child Marriage. Available at: https://www.girlsnotbrides.org/about-child-marriage/\#sources. Accessed March 10, 2021.

Glynn, J.R., B.S. Sunny, B. DeStavola, A. Dube, M. Chihana, A.J. Price, and A.C. Crampin. 2018. "Early school failure predicts teenage pregnancy and marriage: A large population-based cohort study in northern Malawi," PLoS ONE 13(5): e0196041.

Greene, M., S. Perlson, and J. Hart. 2018. "The Centrality of Sexuality for Understanding Child, Early and Forced Marriage." Washington, DC, and New York: American Jewish World Service.

Grosz-Ngate, M. 2000. "Labor migration, gender, and social transformation in rural Mali," in Democracy and Development in Mali (Bingen, R., D. Robinson, and J. Staatz (eds). East Lansing: Michigan State University Press, 87-101.

Hertrich, V. and M. Lesclingand. 2013. "Adolescent migration in rural Africa as a challenge to gender and intergenerational relationships: Evidence from Mali," The Annals of the American Academy of Political and Social Science 648(1): 175-188.

Hindin, M.J., S. Kishor, and D.L. Ansara. 2008. "Intimate partner violence among couples in 10 DHS countries: Predictors and health outcomes," DHS Analytical Studies No. 18. Calverton, MD, USA: Macro International.

Hoogeveen, J., B. van de Klaauw, and G. von Lomwell. 2011. "On the timing of marriage, cattle, and shocks," Economic Development and Cultural Change 60(1): 121-154.

Institut National de la Statistique (INS) et ICF International. 2013. "Enquête Démographique et de Santé et à Indicateurs Multiples du Niger 2012." Calverton, MD, USA: INS et ICF International.

Institut National de la Statistique (INSTAT), Cellule de Planification et de Statistique Secteur Santé-Développement Social et Promotion de la Famille (CPS/SS-DS-PF), et ICF. 2019. Enquête Démographique et de Santé au Mali 2018. Bamako, Mali, et Rockville, MD, USA: INSTAT, CPS/SS-DS-PF, et ICF.

International Institute for Population Sciences (IIPS) and ICF. 2017. "India National Family Health Survey (NFHS-4) 2015-16." Deonar, Mumbai, India: IIPS.

Jensen R. 2012. "Do labor market opportunities affect young women's work and family decisions? Experimental evidence from India," The Quarterly Journal of Economics 127: 753-792. 
Kalamar, A.M., S. Lee-Rife, and M.J. Hindin. 2016. "Interventions to prevent child marriage among young people in low- and middle-income countries: A systematic review of the published and gray literature," Journal of Adolescent Health 59 (3 Suppl):16-21.

Kelly, C.A., A.J. Melnikas, S. Amin, J. Mkandawire, and H. Daud. 2017. "More Than Brides Alliance: Baseline Report, Malawi." New York: Population Council.

Kim, S. 2020. "Gender earnings gap among the youth in Malawi," African Development Review 32(2): 176-187.

Lee-Rife, S., A. Malhotra, A. Warner, and A.M. Glinski. 2012. "What works to prevent child marriage: A review of the evidence," Studies in Family Planning 43(4): 287-303.

Malhotra, A. and S. Elnakib. 2021. "20 years of the evidence base on what works to prevent child marriage: A systematic review," Journal of Adolescent Health: 1-16.

Melnikas, A., S. Ainul, I. Ehsan, E. Haque, and S. Amin. 2020. "Child marriage practices among the Rohingya in Bangladesh," Conflict and Health 14(28).

Melnikas, A.J., G. Saul, S. Singh, J. Mkandawire, M. Gueye, A. Diarra, and S. Amin. 2019. "More Than Brides Alliance: Midline Evaluation Report." New York: Population Council.

Mensch, B., J. Bruce, and M. Green. 1998. "The Uncharted Passage: Girls' Adolescence in the Developing World.” New York: Population Council.

More Than Brides Alliance. 2016-2021: More Than Brides Alliance. Available at: http://morethanbrides.org.

Mourtada, R., J. Schlect, and J. DeLong. 2017. "A qualitative study exploring child marriage practices among Syrian conflict-affected populations in Lebanon," Conflict and Health 11(1): 27.

National Statistical Office (NSO) [Malawi] and ICF. 2017. "Malawi Demographic and Health Survey 2015-16." Zomba, Malawi, and Rockville, MD, USA: NSO and ICF.

Nour N. 2009. Child marriage: a silent health and human rights issue. Reviews in Obstetrics \& Gynecology. 2(1): 51-56.

Pande, R., K. Kurz, S. Walia, K. MacQuarrie, and S. Jain. 2006. "Improving the reproductive health of married and unmarried youth in India." New Delhi, India: ICRW.

Population Council. 2016-2020. Testing Effective Approaches to Ending Child Marriage. Available at: https://www.popcouncil.org/research/testing-effective-approaches-to-endchild-marriage.

Population Council. 2019. "More Than Brides Alliance: Qualitative Findings from Malawi." New York: Population Council.

Saul, G., A. Diarra, A.J. Melnikas, and S. Amin. 2021. "Voice without choice? Investigating adolescent girls' agency in marital decision-making in Niger," Progress in Development Studies 20(4): 270-281. 
Steinhaus, M., L. Hinson, and A.T. Rizzo. 2019. "Measuring social norms related to child marriage among adult decision-makers of young girls in Phalombe and Thyolo, Malawi," Journal of Adolescent Health 64(4 Suppl): S37-S44.

Sunny, B.S., M. Elze, M. Chihana, L. Gondwe, A.C. Crampin, M. Munkhondya, S. Kondowe, and R. Glynn. 2017. "Failing to progress or progressing to fail? Age-for-grade heterogeneity and grade repetition in primary schools in Karonga district, northern Malawi," International Journal of Educational Development 52: 68-80.

United Nations Children's Fund (UNICEF). 2018. "Child Marriage: Latest trends and future prospects." New York: UNICEF.

United Nations Population Fund (UNFPA). 2020. "Millions more cases of violence, child marriage, female genital mutilation, unintended pregnancy expected due to the COVID19 pandemic." April 28, 2020. Accessed March 9, 2021:

https://www.unfpa.org/news/millions-more-cases-violence-child-marriage-female-genitalmutilation-unintended-pregnancies.

Wetheridge, L. and L. Antonowicz. 2014. "Child Marriage in West Africa and Cameroon: A Desk Review." Plan WARO.

Wodon, Q., C. Male, A. Nayihouba, A. Onagoruwa, A. Savadogo, A. Yedan, J. Edmeades, A. Kes, N. John, L. Murithi, M. Steinhaus, and S. Petroni. 2017. "Economic Impacts of Child Marriage: Global Synthesis Report." Washington, DC: The World Bank and International Center for Research on Women. 